\title{
IMPACTS OF BOTTLE STORAGE ON WINE FLAVOR AND UNDERLYING CHEMISTRY
}

A Thesis
presented to
the Faculty of the Graduate School
at the University of Missouri-Columbia
In Partial Fulfillment
of the Requirements for the Degree
Master of Science
bTEPHANIE GRAU
Dr. Misha T. Kwasniewski, Thesis Supervisor

May 2017 
The undersigned, appointed by the dean of the Graduate School, have examined the thesis entitled

\title{
IMPACTS OF BOTTLE STORAGE ON WINE FLAVOR AND UNDERLYING CHEMISTRY
}

presented by Stephanie Grau, a candidate for the degree of master of science, and hereby certify that, in their opinion, it is worthy of acceptance.

Professor Misha T. Kwasniewski

\author{
Professor Michael Harmata
}

Professor Azlin Mustapha 


\section{ACKNOWLEDGEMENTS}

First and foremost, I would like to thank my advisor, Dr. Misha Kwasniewski, for the opportunity to work as a graduate student in his research group. Each time I learned something new from him about flavor and analytical chemistry, I would again realize how little I actually knew in the grand scheme of the field. This feeling was both invigorating and somewhat overwhelming, but overall a good thing of course! Thank you for sharing so much valuable knowledge and advice.

I would also like to thank my other committee members, Dr. Azlin Mustafa and Dr. Michael Harmata. I truly appreciate your time, perspectives, and feedback. This research would not have been possible without the expertise and support of Connie Liu. Thank you for making sure I was always well fed with dumplings, for your willingness and patience when teaching me new techniques, and for helping to keep the lab both fun and productive.

Thank you to my lab mates Paula, Courtney, Brian, and Megan. It takes a village (to complete your master's degree, that is) and each one of you helped me out in some way or another, whether talking through a research problem or going for a stress relieving run on the MKT together. Last but not least, I'd like to thank my parents and boyfriend, Kameron. Thank you for your constant support and encouragement. 


\section{TABLE OF CONTENTS}

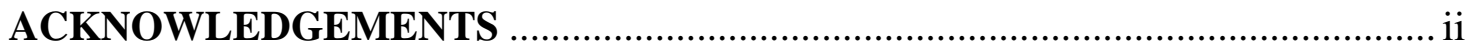

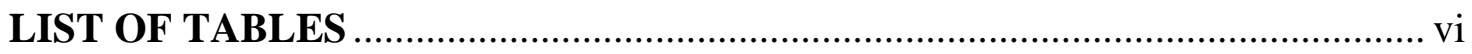

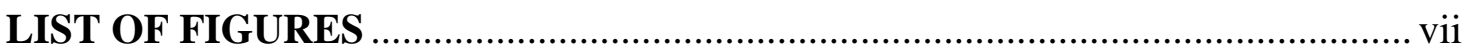

Chapter 1 - INTRODUCTION TO THE IMPACTS OF OXYGEN ON WINE CHEMISTRY AND THE OCCURANCE OF MALODOROUS VOLATILE

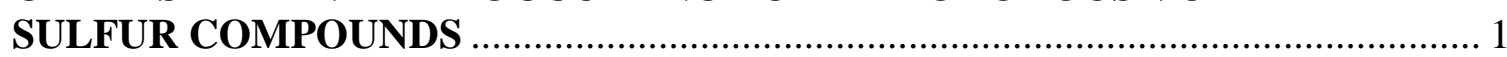

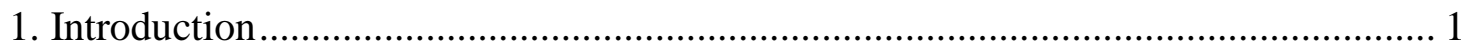

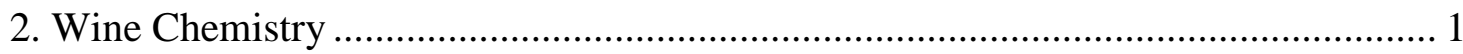

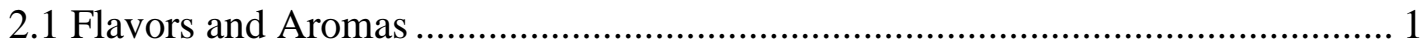

2.2 Color and Astringency …………............................................................ 4

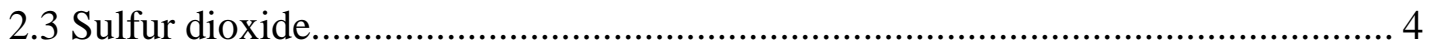

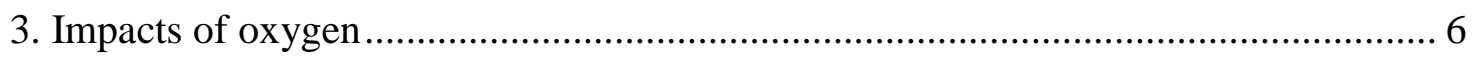

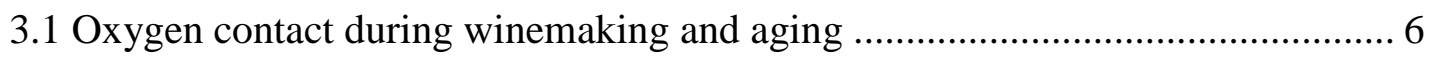

3.2 Positive and negative impacts of oxygen on quality.......................................... 7

3.3 Chemical mechanisms of oxygen reactions ........................................................ 11

3.4 Oxygen measurement methods ...................................................................... 11

4. Occurrence of undesirable volatile sulfur compounds in wine................................. 13

4.1 $\mathrm{H}_{2} \mathrm{~S}$ formation during fermentation and remediation strategies ........................ 13

4.2 Post-bottling emergence of $\mathrm{H}_{2} \mathrm{~S}$ and MeSH.................................................. 15

4.3 Other malodorous volatile sulfur compounds in wine ....................................... 16

4.4 Measurement methods ................................................................................ 17

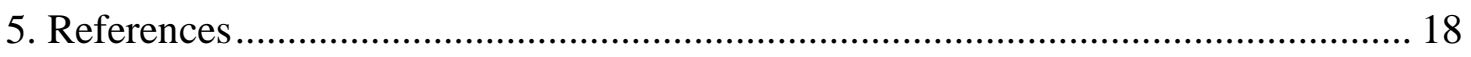

\section{Chapter 2 - IMPACT OF DIFFERENT RESEALING METHODS ON} PRESERVING WINE QUALITY AFTER OPENING ……………...................... 29

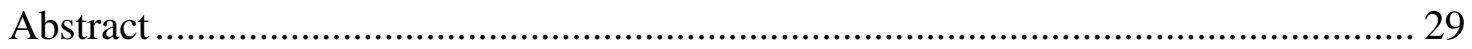

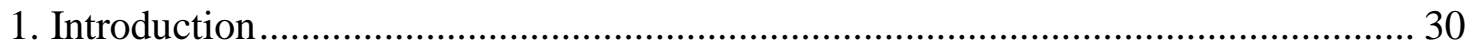

2. Materials and Methods.............................................................................. 38

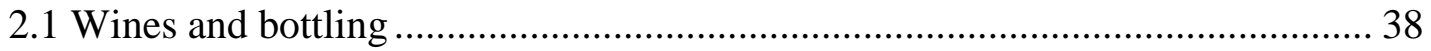

2.2 Resealing and air exposure treatments............................................................ 39

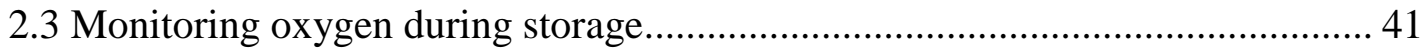

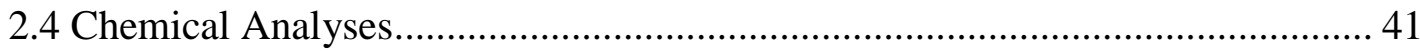

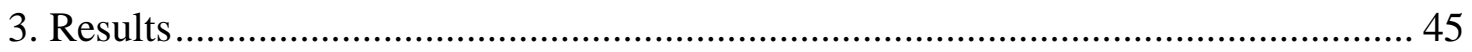

3.1 Headspace oxygen (HS) and dissolved oxygen (DO) ..................................... 45

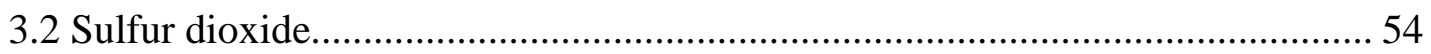


3.3 Acetaldehyde levels in white wine 56

3.4 Anthocyanin, tannin, phenolics, small and large polymeric pigments levels in red wine. 57

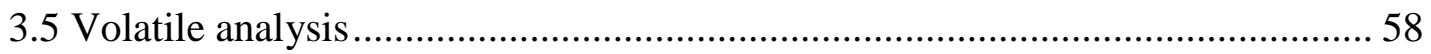

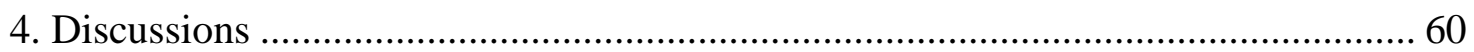

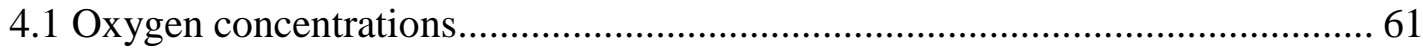

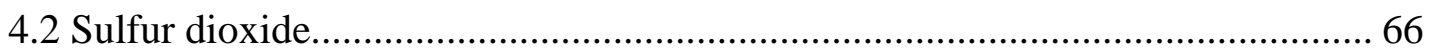

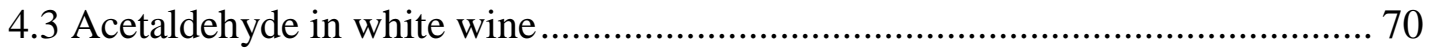

4.4 Anthocyanin, tannin, phenolics, small and large polymeric pigments levels in red

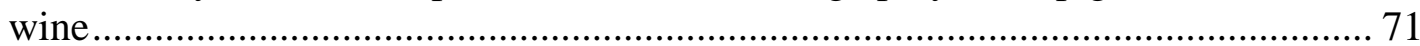

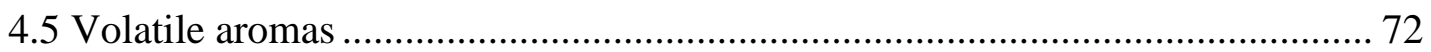

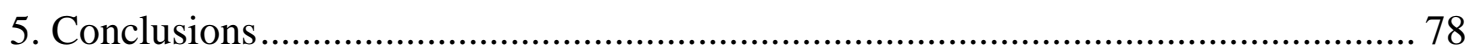

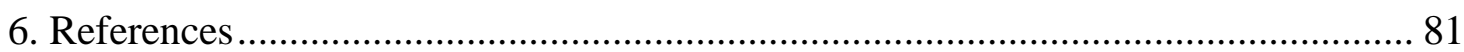

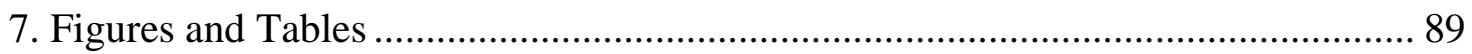

\section{Chapter 3 - EMERGENCE OF H2S FROM PRECURSORS IN WINE AFTER}

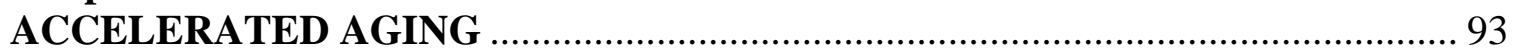

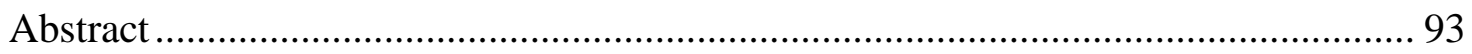

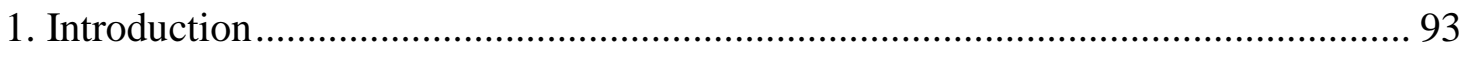

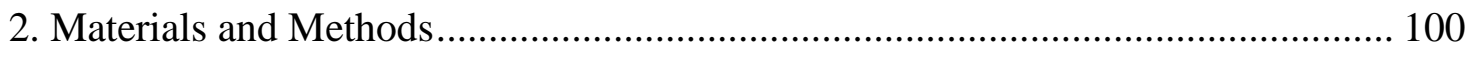

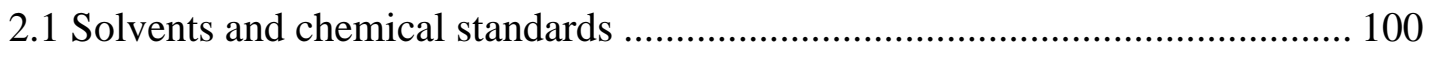

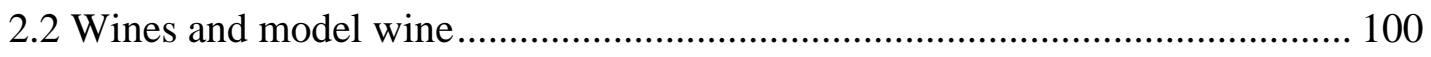

2.3 Synthesis of $\mathrm{H}_{2} \mathrm{~S}-4$-methylcatechol adduct mixture ................................... 101

2.4 Measurement of $\mathrm{H}_{2} \mathrm{~S}$ with colorimetric gas detection tubes .......................... 103

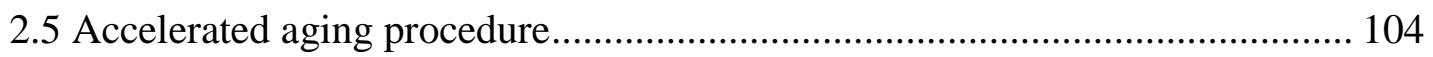

2.6 Emergence of $\mathrm{H}_{2} \mathrm{~S}$ after accelerated aging of model wine and wine spiked with potential $\mathrm{H}_{2} \mathrm{~S}$ precursors ....................................................................... 104

2.7 Statistical Analysis and Data Treatment ...................................................... 105

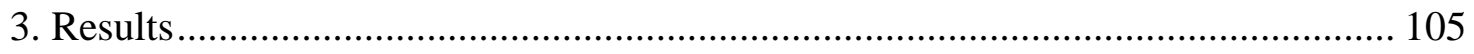

3.1 Emergence of $\mathrm{H}_{2} \mathrm{~S}$ in wines after accelerated aging .................................. 105

$3.2 \mathrm{H}_{2} \mathrm{~S}-4 \mathrm{MeC}$ adducts reaction mixture analysis ............................................. 107

3.3 Emergence of $\mathrm{H}_{2} \mathrm{~S}$ after accelerated aging in model wine and wines spiked with hypothesized precursors ................................................................................ 107

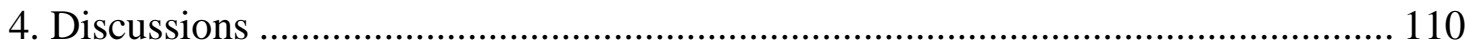

4.1 Trends in emergence of $\mathrm{H}_{2} \mathrm{~S}$ in two red wines during accelerated aging ......... 111

4.2 Emergence of $\mathrm{H}_{2} \mathrm{~S}$ after accelerated aging in wines spiked with hypothesized

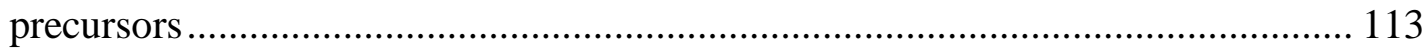




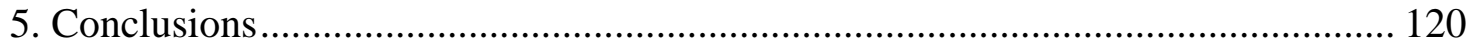

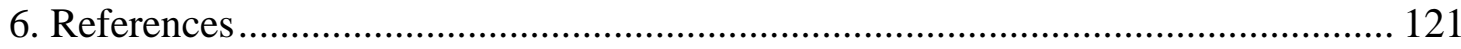

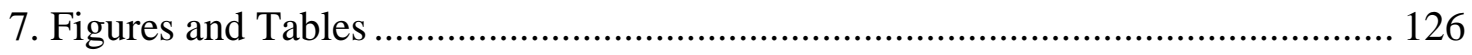




\section{LIST OF TABLES}

Table 2.1 Final headspace and dissolved oxygen $(\mathrm{mg} / \mathrm{L})$ after three days of storage for each of the four experiments with white and red wine.

Table 2.2 Free, bound, and total $\mathrm{SO}_{2}(\mathrm{mg} / \mathrm{L})$ measured post-storage for each of the four experiments with white and red wine.

Table 2.3 Relative peak area or concentration of volatile aroma compounds after three days of storage in white wine resealed with different closure treatments (Exp 1) and in red wine with different air exposure time and closure treatments (Exp 4).

Table 3.1 Preliminary results for emergence of $\mathrm{H}_{2} \mathrm{~S}(\mu \mathrm{g} / \mathrm{L})$ after accelerated aging treatment at $80{ }^{\circ} \mathrm{C}$ for 1 hour in three wines spiked with hypothesized precursors. Values are averages and standard deviations for $n=3$ in Syrah Control, Syrah Cysteine, and Chambourcin Control; $n=2$ in all other measurements.

Table 3.2 Emergence of $\mathrm{H}_{2} \mathrm{~S}(\mu \mathrm{g} / \mathrm{L})$ after accelerated aging at 50, 80, and $100{ }^{\circ} \mathrm{C}$ for 1 hour or after addition of reducing agent (TCEP) in model wine spiked with hypothesized precursors. Values are averages and standard deviations for $\mathrm{n}=2$ for all measurements excluding $\mathrm{H}_{2} \mathrm{~S}-4 \mathrm{MeC}$ treatment with TCEP, where $\mathrm{n}=1$.

Table 3.3 Emergence of $\mathrm{H}_{2} \mathrm{~S}(\mu \mathrm{g} / \mathrm{L})$ at room temperature (free $\mathrm{H}_{2} \mathrm{~S}$ ), after accelerated aging treatment at $80^{\circ} \mathrm{C}$ for 1 hour, or after addition of reducing agent (TCEP) in 2014 Syrah spiked with hypothesized precursors $(n=3)$.

Table 3.4 Emergence of $\mathrm{H}_{2} \mathrm{~S}(\mu \mathrm{g} / \mathrm{L})$ after accelerated aging treatment at $50{ }^{\circ} \mathrm{C}$ for 1 week in Pinot Grigio and at $50{ }^{\circ} \mathrm{C}$ for 1 week, $80^{\circ} \mathrm{C}$ for 1 hour, and after addition of reducing agent (TCEP) in Cabernet Sauvignon spiked with hypothesized precursors. Values are averages and standard deviations for $n=3$ in all treatments except where noted. 128 


\section{LIST OF FIGURES}

Figure 2.1 Headspace and dissolved oxygen $(\mathrm{mg} / \mathrm{L})$ for all experiments over three days of storage (hours). a) $\operatorname{Exp} 1$, b) $\operatorname{Exp} 2$, c) $\operatorname{Exp} 3$, d) Exp 4 Stelvin Reseal treatments, and e) Exp 4 Strong Vacuum treatments. Error bars represent the standard deviation of three replicates (with the exception of Stopper-Type Average in Exp 1, 2, and 3 where $n=12$, 9, and 9 respectively and 73 hours unsealed in Exp 4, where $n=6$ ).

Figure 3.1 Emergence of $\mathrm{H}_{2} \mathrm{~S}(\mu \mathrm{g} / \mathrm{L})$ in 2014 Syrah after accelerated aging treatment at $50,65,80$, and $100^{\circ} \mathrm{C}$ compared to aging at cellar temperature $\left(15.5^{\circ} \mathrm{C}\right)$ over 4 hours in $\mathrm{A}$ and over 2 weeks in B. Dashed line in B represents $\mathrm{H}_{2} \mathrm{~S}$ concentration at $100{ }^{\circ} \mathrm{C}$ for 4 hours, not actual values and is shown for comparative purposes. Error bars represent standard deviation for $n=2$ in $15.5,65,80$ and $100{ }^{\circ} \mathrm{C}$ and $n=3$ in $50{ }^{\circ} \mathrm{C}$.

Figure 3.2 Emergence of $\mathrm{H}_{2} \mathrm{~S}(\mu \mathrm{g} / \mathrm{L})$ in 2015 Chambourcin after accelerated aging treatment at 50 and $100{ }^{\circ} \mathrm{C}$ over 4 hours. Error bars represent standard deviation for $n=4$ in $100^{\circ} \mathrm{C}$. Error bars are too small to be seen behind the data points in $50^{\circ} \mathrm{C}$, each point is the average value for $n=2$

Figure 3.3 Emergence of $\mathrm{H}_{2} \mathrm{~S}\left(\mu \mathrm{g} / \mathrm{L}\right.$ ) at room temperature (free $\mathrm{H}_{2} \mathrm{~S}$ ), after accelerated aging treatment at $50^{\circ} \mathrm{C}$ for 1 week and $80{ }^{\circ} \mathrm{C}$ for 1 hour, or after addition of reducing agent (TCEP) in 2014 Syrah spiked with hypothesized precursors. Error bars represent standard deviation for $n=3$. 


\section{CHAPTER 1 - INTRODUCTION TO THE IMPACTS OF OXYGEN ON WINE CHEMISTRY AND THE OCCURANCE OF MALODOROUS VOLATILE SULFUR COMPOUNDS}

\section{Introduction}

Grape variety, climate, terroir, and viticultural practices impact the quality of grapes delivered to the winery, and decisions made by the winemaker during vinification ultimately shape the wine sensory profile and quality. Excess, moderate, or insufficient oxygen contact during bottle storage further modulates development of desirable and undesirable flavor attributes. During storage either oxidative or unpleasant sulfurous odors may emerge. Both unfortunate, fairly common faults lead to consumer complaints and lower perception of value. Even when wine reaches the consumer in optimal condition, if consumers do not drink the entire bottle after first opening it or reseal it properly, the quality of subsequent glasses days later diminishes rapidly. Considering the range of positive and negative outcomes influenced by oxygen, understanding the short term and long term impacts of various oxygen dosages on wine quality is vital to optimizing the product received by consumers and storage methods for extending shelf life of unfinished wines.

\section{Wine Chemistry}

\subsection{Flavors and Aromas}

Wines often exhibit remarkably complex and diverse aromatic profiles due to differences in odor-active compounds derived from the grape itself, as well as winemaking and aging techniques. In addition to the unique flavors that can be attributed to different viticultural and enological interventions, the majority of wines also have a wide range of aroma compounds in common. Varietal aromas are derived from the grape itself and are 
generally attributed to $\mathrm{C}_{13}$-norisoprenoids, methoxypyrazines, polyfunctional thiols, and monoterpenes. Typically, varietal aromas remain recognizable in young wines of the same grape variety even when treated with different vinification and maturation techniques (Ferreira and others 2000). For example, polyfunctional thiols such as 3-mercaptohexanol and its acetate, contribute passionfruit, grapefruit, and citrus notes in Sauvignon blanc (Tominaga and others 1998). The unique minerality of Riesling is attributed to the $\mathrm{C}_{13^{-}}$ norisoprenoid, 1,1,6-trimethyl-1,2-dihydronapthalene (TDN) (Simpson 1978). Vegetal, herbaceous, and green pepper aromas of Cabernet Sauvignon and Sauvignon blanc are related to concentrations of 3-isobutyl-2-methoxypyrazine and 3-isopropyl-2methoxypyrazine (Ferreira and others 2000; Benkwitz and others 2012). Monoterpenes such as linalool, terpineol, and geraniol contribute floral aromas which are characteristic to the highly aromatic Muscat wines (Ribéreau-Gayon 1975). The overall fruity and fresh notes that also characterize the aroma of young wines in general are attributed to esters formed during fermentation by yeast metabolic activity (Ferreira and others 2000; BalboaLagunero and others 2011; Ugliano and others 2015) such as isoamyl acetate, which is formed by conversion of isoamyl alcohol by acetyl coenzyme A (Slingsby and others 1980) and frequently found above its odor threshold in red wines (Ferreira and others 2000). Fermentation-derived flavors such as fruity, pineapple, and wine-like, are associated with phenylethyl acetate, ethyl hexanoate, and diethyl succinate, respectively. The $\mathrm{C}_{13^{-}}$ norisoprenoid, $\beta$-damascenone, is also ubiquitous in wines, and contributes descriptors such as fruit, floral, baked apple, honey, and dark berries (Guth 1997; Ferreira and others 2000; Juan and others 2012). When present below its detection threshold (2 -7 $\mu \mathrm{g} / \mathrm{L}$ in red wine (Pineau and others 2007)), it is thought to have an indirect positive impact on wine 
aroma by lowering the aroma threshold of other compounds responsible for fruity notes, thus enhancing perception of fruity character (Escudero and others 2007; Pineau and others 2007). Aging in oak barrels or with oak chips is carried out on red wines and some whites to add woody, spicy, coconut, and vanilla nuances. Depending on the oak toast level, compounds formed by thermolysis of cellulose and hemicellulose and by Maillard browning reactions add deep caramel, smoky, and tobacco character (Chatonnet and others 1999). Sensorially important compounds extracted from oak such as whiskylactones, eugenol, furfural alcohol, vanillin, and guaiacol contribute the notes associated with oak aging (Juan and others 2012), while small quantities of oxygen entering through the barrel staves also contributes to wine development, adding further layers of complexity to a wine (Oberholster and others 2015). Other changes in the aromatic profile over aging which are not oxygen or oak related may be due to release of glycosidically bound norisporenoids and acid hydrolysis of esters (Winterhalter and others 1990; Balboa-Lagunero and others 2011; Patrianakou and Roussis 2013).

The molecules in wine that dictate its flavor and aroma profile are commonly studied and quantified using gas chromatography (GC) with mass spectroscopy (MS) or flame ionization detection (FID). Prior to analysis, aromas must be isolated and concentrated due to their trace concentrations in wine. Two preconcentration techniques widely used in wine aroma analysis, solid phase extraction (SPE) and solid phase microextraction (SPME), utilize the selective retention of analytes based on polarity of the solid phase resin. The desired analytes are eluted by organic solvents in SPE and a small sample of the liquid extract (usually $1 \mu \mathrm{L}$ ) is injected into the GC, while desorption with SPME is achieved by placing the fiber directly into the GC injection port. 


\subsection{Color and Astringency}

Initial concentration of various phenolic species in wine is largely dependent upon grape variety, growing conditions, oxygen management during fermentation (McRae and others 2015), maceration (skin contact) time (Darias-Martín and others 2000; Gómez-Plaza and others 2001), and pressure gradient applied at pressing (Boselli and others 2010). Red wine color, astringent mouthfeel, and greater oxygen capacity are due to significantly higher concentrations of phenolic compounds than white wine. Anthocyanin monomers extracted from skins during fermentation give young red wines a purple color that shifts to red-orange hues as anthocyanins cross-link with flavon-3-ols and undergo reactions with acetaldehyde, pyruvic acid, vinylphenols, and vinylflavanols to progressively form new, more stable pigments (Fulcrand and others 2004). Red grape-derived tannins are responsible for the sensation of astringency, including flavon-3-ol monomers (catechin and epicatechin) and chains of flavon-3-ol monomers known as condensed tannins. The majority of phenolic extraction from white grape skins occurs during pressing and is a function of the pressure gradient applied (Boselli and others 2010). Alternatively, prefermentation maceration may also be used to increase phenolic levels in white wine (Darias-Martín and others 2000). Hydroxycinnamic acids and their derivatives, catechin, and epicatechin are phenolic compounds typical of white wine, contributing slight astringency and participating in browning reactions in must and wine (Singleton and Trousdale 1983).

\subsection{Sulfur dioxide}

The most widely used antioxidant and antimicrobial additive in winemaking is sulfur dioxide $\left(\mathrm{SO}_{2}\right)$. At wine $\mathrm{pH}(3-4)$, free $\mathrm{SO}_{2}$ is present in the form of bisulfite $(>95 \%$, 
$\left.\mathrm{HSO}_{3}{ }^{-}\right)$, molecular $\mathrm{SO}_{2}$, and as sulfite $\left(\mathrm{SO}_{3}{ }^{2-}\right)$ at trace levels. Free forms carry out antioxidant and antimicrobial function, with the limit of protection at concentrations around $10 \mathrm{mg} / \mathrm{L}$ (Godden and others 2001; Lopes and others 2009) and $0.8-1.5 \mathrm{mg} / \mathrm{L}$ molecular $\mathrm{SO}_{2}$ generally considered the desired range for optimal protection (Jackson 2014). $\mathrm{SO}_{2}$ is also present in forms where bisulfite is covalently bound with carbonyl groups of wine compounds, such as acetaldehyde, pyruvate, and $\alpha$-ketoglutaric acid or bound with anthocyanins (Bueno and others 2016). Acetaldehyde accounts for approximately $80 \%$ or more of bound $\mathrm{SO}_{2}$ in white wines (Jackowetz and Mira de Orduña 2013a). Free and bound forms are interconnected by different equilibrium reactions, with acid-base equilibria between free forms occurring at a faster rate than free-bound equilibria (Ferreira and others 2015b). While maintaining adequate free $\mathrm{SO}_{2}$ concentrations is key for guarding against oxygen and microbial damage, winemakers measure total $\mathrm{SO}_{2}$ for legal and sensory reasons. The limit for total $\mathrm{SO}_{2}$ in the United States for all wine types is $350 \mathrm{mg} / \mathrm{L}$ (27 Code of Federal Regulations 4.22(b)(1)). At excessive concentrations, $\mathrm{SO}_{2}$ is responsible for a pungent sensation in the nose and struck match odor. A push from consumers for reducing the use of $\mathrm{SO}_{2}$ has resulted in research exploring the efficacy of alternative antioxidant additives such as glutathione, which is naturally found in grapes and formed by yeast (Ugliano and others 2011b), and ascorbic acid (Chinnici and others 2013).

Desirable yeast that perform alcoholic fermentation are $\mathrm{SO}_{2}$-resistant, however the majority of spoilage microbes found in must and wine are highly sensitive to $\mathrm{SO}_{2}$ (Jackson 2014). Diffusion of bisulfite and molecular $\mathrm{SO}_{2}$ into unwanted wild bacterial and yeast cells inhibits cellular enzyme function through cleavage of disulfide bonds, which ultimately obstructs ATP production causing cell death (Jackson 2014). To protect against 
oxidative browning and aroma deterioration, $\mathrm{SO}_{2}$ sacrificially reacts with the primary products of oxidation in wine: quinones and $\mathrm{H}_{2} \mathrm{O}_{2}$. Bisulfite essentially removes the quinone by forming a sulfonic addition product, thereby recycling the highly reactive electrophile back to a more stable phenol species. Similarly, $\mathrm{SO}_{2}$ reduces the oxidizing potential of $\mathrm{H}_{2} \mathrm{O}_{2}$ by reacting with it before it can push additional oxidation reactions forward (Oliveira and others 2011; Nikolantonaki and Waterhouse 2012; Nikolantonaki and others 2014; Danilewicz 2016). Overall, these reactions result in oxygen consumption without damage to wine quality.

\section{Impacts of oxygen}

\subsection{Oxygen contact during winemaking and aging}

Damage to the berry sustained during mechanical harvest or at crushing of handpicked fruit is the first contact of oxygen with berry contents, enabling enzymatic and chemical oxidation to influence chemistry of the subsequent wine. Winemakers then choose to purposefully introduce or exclude oxygen based on concerns regarding wine stability and style. Early introduction of oxygen during fermentation of red wines through pump-overs ensures optimal yeast activity, facilitates extraction of phenolic compounds, and helps avoid growth of unwanted microorganisms on the cap (Moenne and others 2014). In contrast, air contact is minimized during white wine fermentation to allow for yeast activity without risk of browning or spoilage and is excluded as much as possible for the rest of vinification to avoid deterioration of fruity aromas.

Traditionally, pre-bottle maturation of red wines is carried out in oak barrels where the slow transfer of oxygen into the wine promotes phenolic evolution and flavor development. Due to expense and inconvenient size, barrels are not always practical for 
high volume commercial wineries. Alternatively, micro-oxygenation (MOX) protocols applied to wine stored in tanks with oak chips or staves can also achieve similar sensory attributes as barrel-aged wine at significantly lower cost (Oberholster and others 2015). Further attempts to control long term oxygen exposure, and subsequently, the progress of wine maturation, can be achieved through the selection of packaging, closure, and dose of inert gas at bottling (Silva and others 2011; Moreira and others 2016). Sources of oxygen over bottle maturation include total package (headspace and dissolved) oxygen at bottling, air trapped within pores of natural and synthetic corks, and air permeating through the closure. Oxygen barrier properties of the closure material and the closure-bottle interface dictate the oxygen transmission rate (OTR) of each closure type. For example, wine sealed by natural cork may be exposed to between $0.0001-0.12 \mathrm{~mL} \mathrm{O}_{2} / \mathrm{day}$, while wine sealed by screw cap would experience levels between $0.0002-0.0008 \mathrm{~mL} \mathrm{O}_{2} /$ day (Ugliano 2013). Initial oxygen ingress over the first month of storage observed in bottles sealed with natural cork vary widely depending on pore size and cork grade. Ingress through three corks (including oxygen contributed from within cork pores) of similar grade from different lots was found to range between $2.3-3.8 \mathrm{mg} \mathrm{O}_{2} / \mathrm{L} /$ month during the first month (Lopes and others 2005). Variability in ingress between natural cork from different producers illustrates one of the challenges associated with selecting an optimal closure for achieving the desired final wine.

\subsection{Positive and negative impacts of oxygen on quality}

Defining precise oxygen levels that would ensure optimal evolution of wine aroma is difficult due to the variations in oxygen sensitivity of important aroma compounds and the wide range of other wine constituents that influence the oxygen capacity of a given 
wine. Although the outcomes of too little or too much oxygen exposure during vinification and bottle maturation are well characterized (Ugliano 2013), the impact of intermediate levels on aroma and sensory characteristics are less well defined.

Several studies have found that the greatest impacts on tannin structure and anthocyanin content occur during alcoholic fermentation where larger oxygen dosages can be introduced (McRae and others 2013; McRae and others 2015). Positive changes in phenolic composition under the relatively limited oxygen exposure of barrel aging (estimated rate of oxygen diffusion into new French barrels is $1.66-2.5 \mathrm{~mL} / \mathrm{L} / \mathrm{month}$ (Nevares and del Alamo 2008)) and bottle maturation are slow, but still significant after extended periods and essential for reaching optimal quality in many red wines (Ugliano and others 2012; Han and others 2015). After 10 months bottle maturation, red wines sealed by closures with higher OTR were found to have higher color intensity due to lower $\mathrm{SO}_{2}$, higher levels of stable anthocyanin pigments due to oxidative conversion from monomeric anthocyanin, and lower levels of flavon-3-ol monomers (Wirth and others 2010). No impacts of oxygen on mouthfeel were perceivable after 6 - 10 months of storage in several studies (Caillé and others 2010; Oberholster and others 2015), but decreases in tannin concentration occurred after 2 years bottle aging in bottles sealed with higher OTR closures in another study, thereby softening astringency (McRae and others 2013). In regards to phenolic compounds associated with color and astringency, anthocyanins appear to be the primary targets of oxidation and are progressively converted to more stable pigments as a result (Wirth and others 2010). Oxygen also plays an indirect role in promoting the stability of color compounds through the formation of oxidation products, such as acetaldehyde from ethanol oxidation, which then participate in subsequent acetaldehyde-mediated 
reactions of both tannins and anthocyanins (Timberlake and Bridle 1976). Ensuring that moderately oxidative conditions are maintained in the bottle via selection closures which allows an oxygen dose of between $2-5 \mathrm{mg} / \mathrm{L}$ over one year is also an effective method for preventing the development of unwanted volatile sulfur compounds, while avoiding negative impacts of overly oxidative conditions (Ugliano 2013). Time dependent increases in pleasant aromas over aging are typically associated with chemical shifts unrelated to oxygen, primarily hydrolysis of glycosidically bound norisporenoid precursors and acid hydrolysis of esters (Winterhalter and others 1990; Balboa-Lagunero and others 2011; Patrianakou and Roussis 2013).

Excessive levels of oxygen in bottles can drastically increase the risk of wine being faulted by oxidative spoilage (Ugliano 2013), with greater oxygen ingress significantly decreasing free and total $\mathrm{SO}_{2}$ levels by 6 months of bottle storage and also resulting in increased oxidized aromas (Godden and others 2001). Wines sealed with screw cap closures allowing significantly less oxygen ingress tend to have higher fruit intensity, minimal oxidized aromas, but more frequent incidence of reductive odors due to volatile sulfur compounds (Godden and others 2001). Extensive qualitative and quantitative research has been conducted to profile the sensory attributes in wines oxidized under moderate to extreme conditions (Ferreira and others 1997; Escudero and others 2002; Balboa-Lagunero and others 2011; Ugliano 2013). In general, for red wines, decreases in fruity, floral, fresh, and herbal aromas and increases in sherry and cooked fruit notes are observed. Similarly, the general changes observed in white wines include decreases in varietal, fruity, fresh, and herbal aromas and increases in cooked vegetable, honey, and hay notes (Balboa-Langueno 2011). These descriptors are directly linked to the diminishing 
concentrations of varietal thiols which react rapidly with products of polyphenol oxidation (Blanchard and others 2004; Lopes and others 2009; Ugliano and others 2011b; Nikolantonaki and Waterhouse 2012) and emergence of aldehydes which can have an overwhelming masking effect on fruit expression (Cullere and others 2007). Aldehydes are responsible for the majority of key aroma markers of oxidative spoilage, particularly acetaldehyde, methional, phenylacetaldehyde, 2-methylpropanal, 3-methylbutanal, (E)-2hexenal (Ferreira and others 2015a). These compounds contribute overripe fruit, cooked vegetable, raisin, molasses, sherry, and varnish notes to oxidized wines (Escudero and others 2000; Balboa-Lagunero and others 2011; Grant-Preece and others 2013). Strecker degradation from amino acids methionine and phenylalanine (Grant-Preece and others 2013) and release from $\mathrm{SO}_{2}$ complexes (Bueno and others 2016) result in increased concentrations of methional and phenylacetaldehyde. In non-oxidized red and white wines, an estimated $99 \%$ of acetaldehyde is present in bound forms in wines with sufficient concentrations of $\mathrm{SO}_{2}$ (Bueno and others 2016). Consumption of free $\mathrm{SO}_{2}$ causes a shift in equilibrium from bound forms to replenish free $\mathrm{SO}_{2}$, resulting in dissociation of acetaldehyde from the bisulfite complexes (Wildenradt and Singleton 1974; Jackowetz and Mira de Orduña 2013a) which may then have significant consequences on sensory quality. Acetaldehyde from ethanol oxidation may also increase bruised apple odor in oxidized wines (Wildenradt and Singleton 1974). Anthocyanin oxidation to form new pigments is responsible for the changing wine hue from purple-red to brick-red and eventually brown (Fulcrand and others 2004). Browning becomes an issue after prolonged exposure to excessive oxygen levels has already resulted in depletion of free $\mathrm{SO}_{2}$ and aroma degradation (Singleton and others 1979; Skouroumounis and others 2005). 


\subsection{Chemical mechanisms of oxygen reactions}

Determination of the mechanisms behind the previously described sensory changes offer important insights into controlling and preventing oxidative deterioration of wine quality. A complex series of oxidation reactions is catalyzed upon interaction of dissolved oxygen with iron present at trace levels in wine, forming quinones and $\mathrm{H}_{2} \mathrm{O}_{2}$. Donation of an electron by $\mathrm{Fe}^{2+}$ to oxygen produces radical species that oxidize wine polyphenols with the $o$-dihydroxyphenol functional group (e.g. catechin, epicatechin, gallic acid, and caffeic acid) to form o-quinones (Singleton 1987; Waterhouse and Laurie 2006). As highly unstable molecules, quinones then participate in an array of reactions with aroma compounds containing the thiol moiety, other polyphenols, and amino acids (Nikolantonaki and others 2010; Ugliano 2013). Additionally, $\mathrm{H}_{2} \mathrm{O}_{2}$ undergoes further reaction with iron to form the hydroxyl radical, a strong oxidizing species that then reacts with wine components in proportion to their concentration. By this pathway, oxidation of ethanol, the most abundant nonwater wine component, produces acetaldehyde. Other abundant wine components such as organic acids, glycerol, and sugars are also oxidized by the hydroxyl radical (Singleton 1987; Danilewicz and Wallbridge 2010; Oliveira and others 2011). The undesirable chemical changes induced by the primary oxidation products, quinones and $\mathrm{H}_{2} \mathrm{O}_{2}$, can be mitigated through the action of antioxidants such as $\mathrm{SO}_{2}$ (Danilewicz and others 2008), as previously discussed.

\subsection{Oxygen measurement methods}

Careful introduction or exclusion of oxygen is a powerful tool winemakers use to achieve specific wine styles, from a delicate, fruit-forward white to a robust, tannic red. Advancements in oxygen measurement technology have enabled researchers and 
winemakers to better understand the impacts of oxygen and how it can be controlled during each stage of winemaking (Moenne and others 2014; Day and others 2015; del AlamoSanza and others 2015). Levels of oxygen dissolved in wine are commonly measured by polarographic oxygen sensors, of which Clark electrodes are most often used (Blanchard and others 2004; Laurie and others 2008; Chinnici and others 2013), and optical sensors (Day and others 2015). Clark electrodes consist of a sensing platinum electrode and silver references electrode inside an oxygen permeable membrane. Oxygen is reduced to hydroxide ions by a polarizing voltage in a current that is proportional to the concentration of dissolved oxygen. Electrode measurement of oxygen is somewhat inconvenient considering that the sample must be stirred to continuously replenish oxygen depleted by reduction to hydroxide, but handled and stirred carefully to avoid introduction of air (Ramamoorthy and others 2003). Optical probes contain a light source (LED or laser) that causes excitation of luminescent dye within sensors in contact with the sample, afterwards the excited state is quenched by energy transfer upon collision with oxygen molecules and the degree of quenching proportional to the oxygen concentration (Ramamoorthy and others 2003). Oxygen measurement with optical probes offers several key advantages over the traditional Clark electrode. First, is the ability to nondestructively measure both headspace and dissolved oxygen of wine in sealed containers, enabling users to conveniently and non-invasively measure oxygen evolution in the same sample over time. Additionally, optical sensors have rapid signal response, require less frequent calibration, have a longer lifetime, and are highly convenient for winery use due to their portability and durability. 


\section{Occurrence of undesirable volatile sulfur compounds in wine}

Sulfur-containing volatiles are linked to both pleasant and highly off-putting aroma descriptors in wine. For example, notes of roasted coffee in barrel aged wines are imparted by to 2-furanmethanethiol (Tominaga and others 2000) and 3-mercaptohexanol, 3mercaptohexyl acetate, and 4-mercapto-4-methylpentanone contribute grapefruit, passion fruit, and box tree aromas to Sauvignon blanc (Tominaga and others 1998), a wine that is sought after due to its unique sensory characteristics. On the other hand, the presence of low molecular weight sulfur volatiles, such as hydrogen sulfide and methanethiol, leads to particularly unappetizing wines with odors of sewage and cooked cabbage. While both groups of sulfur-containing volatile compounds have important implications for wine aroma, the occurrence and quantification of malodorous volatile sulfur compounds (VSCs) in wine will be the focus here.

\section{1 $\mathrm{H}_{2} \mathrm{~S}$ formation during fermentation and remediation strategies}

Under normal wine fermentation conditions, $\mathrm{H}_{2} \mathrm{~S}$ is produced by yeast at levels sufficient for its function as an intermediate metabolite in the biosynthesis of sulfurcontaining amino acids and small peptides (such as cysteine, methionine, and glutathione), compounds which are important for cell metabolism and growth (Eschenbruch 1974). Naturally occurring sulfite $\quad\left(\mathrm{SO}_{3}{ }^{2-}\right)$ or from $\mathrm{SO}_{2}$ added as an antioxidant and antimicrobial agent and sulfate $\left(\mathrm{SO}_{4}{ }^{2-}\right)$ are inorganic sulfur species that fuel the sulfur assimilation pathway in Saccharomyces cerevisiae (Schutz and Kunkee 1977; Jiranek and others 1995). When yeast are pressured by nitrogen starvation due to inadequate supplementation with diammonium phosphate, this pathway is disrupted and $\mathrm{H}_{2} \mathrm{~S}$ production outpaces metabolic demand, resulting in diffusion of excess $\mathrm{H}_{2} \mathrm{~S}$ from the cell 
into the wine (Jiranek and others 1995). Other factors besides nutrient availability also impact $\mathrm{H}_{2} \mathrm{~S}$ formed during fermentation, including yeast strain differences in sulfite reductase activity (Jiranek and others 1995; Ugliano and others 2009; Ugliano and others 2011a), presence of metal ions (Eschenbruch 1974), fermentation temperature (Schutz and Kunkee 1977), and elemental sulfur $\left(\mathrm{S}^{0}\right)$ residue concentrations greater than $1 \mu \mathrm{g} / \mathrm{g}$ from fungicide sprayed on grapes during the growing season (Schutz and Kunkee 1977; Thomas and others 1993; Kwasniewski and others 2014). $\mathrm{H}_{2} \mathrm{~S}$ concentrations in finished wine are not found to be related to excessive production of total $\mathrm{H}_{2} \mathrm{~S}$ during fermentation, but more specifically to fermentations with a large amount of $\mathrm{H}_{2} \mathrm{~S}$ liberated towards the end of fermentation when production of $\mathrm{CO}_{2}$ is not as vigorously displacing $\mathrm{H}_{2} \mathrm{~S}$ (Ugliano and others 2009).

To avoid excess $\mathrm{H}_{2} \mathrm{~S}$ formation in musts that may have $\mathrm{S}^{0}$ residue, pre-fermentation clarification procedures that allow sediment to settle and then racking the juice off the sediment layer was found to reduce $\mathrm{S}^{0}$ by more than $95 \%$ in juice (Kwasniewski and others 2014). However, in red wine fermentations with skin contact, $S^{0}$ residue would likely still result in increased $\mathrm{H}_{2} \mathrm{~S}$ production during fermentation. Excess $\mathrm{H}_{2} \mathrm{~S}$ present after fermentation can be managed by sparing with inert gas to physically displace $\mathrm{H}_{2} \mathrm{~S}$, aeration through splash racking to promote formation of disulfides or other oxidation products within the wine such as quinones, which readily bind with $\mathrm{H}_{2} \mathrm{~S}$ to form nonvolatile adducts (Nikolantonaki and Waterhouse 2012), or addition of lees which allows contact with dead yeast cell walls that seem to bind $\mathrm{H}_{2} \mathrm{~S}$ (Vasserot and others 2003). Copper fining with copper sulfate or copper citrate, a procedure described in winemaking texts (Jackson 2014), is another standard technique for treating wines with rotten egg odors. The addition of 
copper traps $\mathrm{H}_{2} \mathrm{~S}$ by forming insoluble $\mathrm{CuS}$, which is thought to be removed from solution by racking or filtration. Although widely used by winemakers, copper fining suffers from several disadvantages, particularly the removal of desirable varietal thiols and the inability to trap malodorous VSCs without a free thiol group (thioacetates, disulfides, cyclic sulfur compounds) (Kreitman and others 2016a). Furthermore, its actual efficacy at removing $\mathrm{H}_{2} \mathrm{~S}$ and MeSH to avoid issues during bottle storage has recently been called into question (Viviers and others 2013; Clark and others 2015; Bekker and others 2016b). It was recently found that oxygenated handling of wine during fermentation was more effective at reducing the emergence of $\mathrm{H}_{2} \mathrm{~S}$ and $\mathrm{MeSH}$ over bottling aging than copper fining before fermentation (Bekker and others 2016b).

\subsection{Post-bottling emergence of $\mathrm{H}_{2} \mathrm{~S}$ and MeSH}

It appears that any wine may be susceptible to the emergence of $\mathrm{H}_{2} \mathrm{~S}$ and MeSH if stored under low oxygen conditions where ingress through the closure over bottle storage is approximately $<1.5 \mathrm{mg} / \mathrm{L} /$ year (Ugliano 2013). Screw cap closures are selected by winemakers to seal bottles due to their convenience for consumers, consistency over aging (Godden and others 2001; Ugliano 2013), and preservation of fresh and fruity aromas (Godden and others 2001; Lopes and others 2009); however, given the minimal oxygen ingress through these closures, the occurrence of reductive odors may become an issue after months to years of storage (Godden and others 2001; Lopes and others 2009; Dimkou and others 2011; Ugliano and others 2011b; Ugliano 2013). Post-bottle occurrence of $\mathrm{H}_{2} \mathrm{~S}$ in wines that were defect-free at the time of bottling do not appear to be directly related to $\mathrm{H}_{2} \mathrm{~S}$ production during fermentation (Ugliano and others 2011a). Several recent studies have traced back the emergence of $\mathrm{H}_{2} \mathrm{~S}$ and $\mathrm{MeSH}$ during low-oxygen bottle maturation to 
pools of reversibly bound nonvolatile thiol-copper complexes and other metal ions such as manganese, iron, and zinc (Franco-Luesma and Ferreira 2016a; Kreitman and others 2016b; Bekker and others 2016c). Trace concentrations of metal ions are naturally present in grapes, and levels may increase from contact with winery equipment, use of pesticides or herbicides that contain metal, or copper fining treatment. A number of compounds have been proposed to account for the remaining sources of $\mathrm{H}_{2} \mathrm{~S}$ and MeSH not attributed to metal complexes. Thiol-quinone adducts (Nikolantonaki and Waterhouse 2012; Smith and others 2015a), thioacetates (Bracher and others 2011), cysteine (Pripis-Nicolau and others 2000), glutathione (Bekker and others 2016c), methionine (Pripis-Nicolau and others 2000), sulfur dioxide (Danilewicz 2007; Lopes and others 2009), elemental sulfur (Jastrzembski and Sacks 2015), disulfides (Bobet and others 1990), and polysulfides (Chen and others 2016) have been briefly mentioned by other authors as hypothetical precursors based on known enzymatic and chemical reactions (Smith and others 2015a), though, studies have yet to specifically examine the majority of these compounds in the context of their potential as sources of $\mathrm{H}_{2} \mathrm{~S}$ or MeSH during wine bottle storage. The conversion rate from potential precursors to $\mathrm{H}_{2} \mathrm{~S}$ or MeSH is likely dependent on complex interactions with wine components (such as metal ions, quinones, tannins), length of bottle storage, oxygen concentrations, and $\mathrm{pH}$. Furthermore, the actual concentrations of $\mathrm{H}_{2} \mathrm{~S}$ and $\mathrm{MeSH}$ at a given time are related to reactivity with other wine components as well (Franco-Luesma and Ferreira 2014).

\subsection{Other malodorous volatile sulfur compounds in wine}

In wine tasting, unpleasant sulfurous odors such as rotten egg, sewage, cooked cabbage, and burnt rubber are termed "reductive" odors. The odors are attributed to the 
volatile sulfur compounds (VSCs) hydrogen sulfide $\left(\mathrm{H}_{2} \mathrm{~S}\right)$, methanethiol $(\mathrm{MeSH})$, ethanethiol (EtSH), dimethyl sulfide (DMS), dimethyl disulfide (DMDS), and methyl thioacetate (MTA). Odor detection threshold concentrations for VSCs range between $\mu \mathrm{g} / \mathrm{L}$ and ng/L levels (Goniak and Noble 1987; Siebert and others 2009; Solomon and others 2010), consequently these compounds are powerful impact odorants with the potential to lessen consumer acceptance of a wine. Despite negative implications at above threshold levels, at sub-detection threshold concentrations, $\mathrm{H}_{2} \mathrm{~S}$ and DMS can contribute fruity notes (Escudero and others 2007; Siebert and others 2009). $\mathrm{H}_{2} \mathrm{~S}, \mathrm{MeSH}$, and DMS are most often found above their odor threshold values in "reduced" wines (Siebert and others 2010) and are therefore considered the primary contributors to wines faulted by sulfurous off-odors.

\subsection{Measurement methods}

Quantification of VSCs is challenging due to their low concentrations in wine, sensitivity to oxygen, volatility, and reactivity (López and others 2007). Common instrumental methods for VSC analysis pair static headspace (HS) or solid-phase microextraction (SPME) sampling with gas chromatographic separation and sulfur selective detectors, sulfur chemoluminescence detection (SCD) (Siebert and others 2010; Ugliano and others 2012) or pulsed flame photometric detection (PFPD) (Fang and Qian 2005; López and others 2007). Although analyte enrichment by SPME frequently suffers from artifact formation and competition for active cites which favors extraction of certain analytes over others, it is relatively convenient to perform. Static HS sampling in combination with cool-on-column injection addresses the disadvantages of SPME, but requires a specialized injection port and cryogenic cooling equipment which are not commonly available in most research labs. An alternative option for accurate, convenient 
$\mathrm{H}_{2} \mathrm{~S}$ measurement utilizes gas detection tubes filled with a metal salt (lead acetate or mercury chloride) and inert packing material which undergoes a colorimetric reaction with $\mathrm{H}_{2} \mathrm{~S}$ as it moves into the tube. The length of color change along the tube is proportional to the quantity of $\mathrm{H}_{2} \mathrm{~S}$ present. This method has been used to monitor evolution of $\mathrm{H}_{2} \mathrm{~S}$ during fermentation (Park 2008; Ugliano and Henschke 2010), to quantify $\mathrm{H}_{2} \mathrm{~S}$ generated by elemental sulfur residue in grape must (Kwasniewski and others 2011), and to quantify $\mathrm{H}_{2} \mathrm{~S}$ released from copper complexes in wine (Chen and others 2016). The difficulty in developing accurate, reproducible, and reliable sampling and quantification techniques for VSCs in wine has slowed the progress of research aimed at understanding their formation pathways during vinification and bottle aging.

\section{References}

Avizcuri J, Echávarri J, Ferreira V, Fernández-Zurbano P. 2016. Evaluation of the impact of initial red wine composition on changes in color and anthocyanin content during bottle storage: Color \& anthocyanic composition changes in wines during bottle storage. Food Chem 213:123-134. doi: 10.1016/j.foodchem.2016.06.050.

Balboa-Lagunero T, Arroyo T, Cabellos JM, Aznar M. 2011. Sensory and olfactometric profiles of red wines after natural and forced oxidation processes. Am J Enol Vitic 62:527-5365. doi: 10.5344/ajev.2011.10080.

Bekker M, Smith M, Smith P, Wilkes E. 2016a. Formation of Hydrogen Sulfide in Wine: Interactions between Copper and Sulfur Dioxide. Molecules 21:1214. doi: 10.3390/molecules21091214.

Bekker MZ, Day MP, Holt H, and others. 2016b. Effect of oxygen exposure during fermentation on volatile sulfur compounds in Shiraz wine and a comparison of strategies for remediation of reductive character. Aust J Grape Wine Res 22:24-35. doi: 10.1111/ajgw.12172.

Bekker MZ, Mierczynska-Vasilev A, Smith PA, Wilkes EN. 2016c. The effects of pH and copper on the formation of volatile sulfur compounds in Chardonnay and Shiraz wines post-bottling. Food Chem 207:148-156. doi: 10.1016/j.foodchem.2016.03.060.

Benkwitz F, Nicolau L, Lund C, and others. 2012. Evaluation of key odorants in Sauvignon blanc wines using three different methodologies. J Agric Food Chem 60:6293-6302. doi: 10.1021/jf300914n.

Bergmeyer HU. 1974. Methods of Enzymatic Analysis, 2nd edn. Verlag Chemie and Academic Press, New York, NY.

Bertrand GL. 1976. Free Sulfur Dioxide in Red Wine : A Comparison of Analytical 
Methods in Relation to Thermodynamic Actitivy. Am J Enol Vitic 27:106-110.

Blanchard L, Darriet P, Dubourdieu D. 2004. Reactivity of 3-Mercaptohexanol in Red Wine: Impact of Oxygen, Phenolic Fractions, and Sulfur Dioxide. Am J Enol Vitic 55:115-120.

Bobet RA, Noble AC, Boulton RB. 1990. Kinetics of the ethanethiol and diethyl disulfide interconversion in wine-like solutions. J Agric Food Chem 38:449-452. doi: 10.1021/jf00092a025.

Bordiga M, Rinaldi M, Locatelli M, and others. 2013. Characterization of Muscat wines aroma evolution using comprehensive gas chromatography followed by a postanalytic approach to 2D contour plots comparison. Food Chem 140:57-67. doi: 10.1016/j.foodchem.2013.02.051.

Boselli E, Di Lecce G, Alberti F, Frega NG. 2010. Nitrogen gas affects the quality and the phenolic profile of must obtained from vacuum-pressed white grapes. LWT Food Sci Technol 43:1494-1500. doi: 10.1016/j.lwt.2010.03.006.

Bracher PJ, Snyder PW, Bohall BR, Whitesides GM. 2011. The Relative Rates of ThiolThioester Exchange and Hydrolysis for Alkyl and Aryl Thioalkanoates in Water. Orig Life Evol Biosph 41:399-412. doi: 10.1007/s11084-011-9243-4.

Bueno M, Carrascon V, Ferreira V. 2016. Release and Formation of Oxidation-Related Aldehydes during Wine Oxidation. J Agric Food Chem 64:608-617. doi: 10.1021/acs.jafc.5b04634.

Burns JA, Butler JC, Moran J, Whitesides GM. 1991. Selective reduction of disulfides by tris(2-carboxyethyl)phosphine. J Org Chem 56:2648-2650. doi: $10.1021 /$ jo00008a014.

Caillé S, Samson A, Wirth J, and others. 2010. Sensory characteristics changes of red Grenache wines submitted to different oxygen exposures pre- and post-bottling. Anal Chim Acta 660:35-42. doi: 10.1016/j.aca.2009.11.049.

Caleb OJ, Mahajan P V., Al-Said FAJ, Opara UL. 2013. Modified Atmosphere Packaging Technology of Fresh and Fresh-cut Produce and the Microbial Consequences-A Review. Food Bioprocess Technol 6:303-329. doi: 10.1007/s11947-012-0932-4.

Carrascon V, Ferreira V, Fernandez-Zurbano P, Bueno M. 2015. Oxygen Consumption by Red Wines. Part II: Differential Effects on Color and Chemical Composition Caused by Oxygen Taken in Different Sulfur Dioxide-Related Oxidation Contexts. J Agric Food Chem 63:10938-10947. doi: 10.1021/acs.jafc.5b02989.

Castro R, Natera R, Durán E, García-Barroso C. 2008. Application of solid phase extraction techniques to analyse volatile compounds in wines and other enological products. Eur Food Res Technol 228:1-18. doi: 10.1007/s00217-008-0900-4.

Cesano J. 2009. Friends Don't Let Friends Vacu-Vin. In: John Wine - a wine blog. https://johnonwine.com/2009/12/17/friends-dont-let-friends-vacu-vin/. .

Chatonnet P, Cutzach I, Pons M, Dubourdieu D. 1999. Monitoring Toasting Intensity of Barrels by Chromatographic Analysis of Volatile Compounds from Toasted Oak Wood. J Agric Food Chem 47:4310-4318.

Chen Y, Jastrzembski JA, Sacks GL. 2016. Copper-Complexed Hydrogen Sulfide in Wine: Measurement by Gas Detection Tubes and Comparison of Release Approaches. Am J Enol Vitic. doi: 10.5344/ajev.2016.16024.

Chinnici F, Sonni F, Natali N, Riponi C. 2013. Oxidative evolution of (+)-catechin in 
model white wine solutions containing sulfur dioxide, ascorbic acid or gallotannins. Food Res Int 51:59-65. doi: 10.1016/j.foodres.2012.11.013.

Clark AC, Grant-Preece P, Cleghorn N, Scollary GR. 2015. Copper(II) addition to white wines containing hydrogen sulfide: Residual copper concentration and activity. Aust J Grape Wine Res 21:30-39. doi: 10.1111/ajgw.12114.

Coelho JM, Howe PA, Sacks GL. 2015. A Headspace Gas Detection Tube Method to Measure SO2 in Wine without Disrupting SO2 Equilibria. Am J Enol Vitic 66:257265. doi: 10.5344/ajev.2015.14125.

Cullere L, Cacho J, Ferreira V. 2007. An Assessment of the Role Played by Some Oxidation-Related Aldehydes in Wine Aroma. J Agric Food Chem 55:876-881.

Daniel MA, Elsey GM, Capone DL, and others. 2004. Fate of damascenone in wine: the role of SO2. J Agric Food Chem 52:8127-8131. doi: 10.1021/jf048582h.

Danilewicz JC. 2011. Review of Oxidative Processes in Wine and Value of Reduction Potentials in Enology. Am J Enol Vitic 63:1-10. doi: 10.5344/ajev.2011.11046.

Danilewicz JC. 2016. Reaction of oxygen and sulfite in wine. Am J Enol Vitic 67:13-17. doi: 10.5344/ajev.2015.15069.

Danilewicz JC. 2007. Interaction of sulfur dioxide, polyphenols, and oxygen in a winemodel system: Central role of iron and copper. Am J Enol Vitic 58:53-60.

Danilewicz JC, Seccombe JT, Whelan J. 2008. Mechanism of Interaction of Polyphenols, Oxygen, and Sulfur Dioxide in Model Wine and Wine. Am J Enol Vitic 59:128136.

Danilewicz JC, Wallbridge PJ. 2010. Further Studies on the Mechanism of Interaction of Polyphenols, Oxygen, and Sulfite in Wine. Am J Enol Vitic 61:166-175.

Darias-Martín JJ, Rodríguez O, Díaz E, Lamuela-Raventós RM. 2000. Effect of skin contact on the antioxidant phenolics in white wine. Food Chem 71:483-487. doi: 10.1016/S0308-8146(00)00177-1.

Day MP, Schmidt SA, Smith PA, Wilkes EN. 2015. Use and impact of oxygen during winemaking. Aust J Grape Wine Res 21:693-704. doi: 10.1111/ajgw.12199.

de Fátima Alpendurada M. 2000. Solid-phase microextraction: A promising technique for sample preparation in environmental analysis. J Chromatogr A 889:3-14. doi: 10.1016/S0021-9673(00)00453-2.

del Alamo-Sanza M, Laurie VF, Nevares I. 2015. Wine evolution and spatial distribution of oxygen during storage in high-density polyethylene tanks. J Sci Food Agric 95:1313-1320. doi: 10.1002/jsfa.6824.

Dimkou E, Ugliano M, Dieval JB, and others. 2011. Impact of Headspace Oxygen and Closure on Sulfur Dioxide, Color, and Hydrogen Sulfide Levels in a Riesling Wine. Am J Enol Vitic 62:261-269. doi: 10.5344/ajev.2011.11006.

Drysdale GS, Fleet GH. 1989. The Growth and Survival of Acetic Acid Bacteria at Different Concentrations of Oxygen. Am J Enol Vitic 40:99-105.

Durner D, Ganss S, Fischer U. 2010. Monitoring oxygen uptake and consumption during microoxygenation treatments before and after malolactic fermentation. Am J Enol Vitic 61:465-473. doi: 10.5344/ajev.2010.10055.

Eggers NJ, Bohna K, Dooley B. 2006. Determination of vitispirane in wines by stable isotope dilution assay. Am J Enol Vitic 57:226-232.

Elias RJ, Waterhouse AL. 2010. Controlling the fenton reaction in wine. J Agric Food Chem 58:1699-1707. doi: 10.1021/jf903127r. 
Eschenbruch R. 1974. Sulfite and Sulfide formation during winemaking - A Review. Am J Enol Vitic 25:23-27.

Escudero A, Asensio E, Cacho J, Ferreira V. 2002. Sensory and chemical changes of young white wines stored under oxygen. An assessment of the role played by aldehydes and some other important odorants. Food Chem 77:325-331. doi: 10.1016/S0308-8146(01)00355-7.

Escudero A, Campo E, Farina L, and others. 2007. Analytical characterization of the aroma of five premium red wines. Insights into the role of odor families and the concept of fruitiness of wines. J Agric Food Chem 55:4501-4510. doi: 10.1021/jf0636418.

Escudero A, Hernández-Orte P, Cacho J, Ferreira V. 2000. Clues about the Role of Methional As Character Impact Odorant of Some Oxidized Wines. J Agric Food Chem 48:4268-4272. doi: 10.1021/jf991177j.

Fang Y, Qian MC. 2005. Sensitive quantification of sulfur compounds in wine by headspace solid-phase microextraction technique. J Chromatogr A 1080:177-185. doi: 10.1016/j.chroma.2005.05.024.

Ferreira V. 2014. Key Changes in Wine Aroma Active Compounds during Bottle Storage of Spanish Red Wines under Di ff erent Oxygen Levels. .

Ferreira V, Bueno M, Franco-Luesma E. 2015a. New insights into the chemistry involved in aroma development during wine bottle aging: Slow redox processes and chemical equilibrium shifts. ACS Symp Ser 275-289. doi: 10.1021/bk-2015-1203.ch017.

Ferreira V, Carrascon V, Bueno M, and others. 2015b. Oxygen Consumption by Red Wines. Part I: Consumption Rates, Relationship with Chemical Composition, and Role of SO2. J Agric Food Chem 63:10928-10937. doi: 10.1021/acs.jafc.5b02988.

Ferreira V, Escudero A, Fernández P, Cacho JF. 1997. Changes in the profile of volatile compounds in wines stored under oxygen and their relationship with the browning process. Zeitschrift für Leb und -forsch A 205:392-396. doi: 10.1007/s002170050187.

Ferreira V, López R, Cacho JF. 2000. Quantitative determination of the odorants of young red wines from different grape varieties. J Sci Food Agric 80:1659-1667.

Franco-Luesma E, Ferreira V. 2016a. Reductive off-odors in wines: Formation and release of $\mathrm{H} 2 \mathrm{~S}$ and methanethiol during the accelerated anoxic storage of wines. Food Chem 199:42-50. doi: 10.1016/j.foodchem.2015.11.111.

Franco-Luesma E, Ferreira V. 2014. Quantitative analysis of free and bonded forms of volatile sulfur compouds in wine. Basic methodologies and evidences showing the existence of reversible cation-complexed forms. J Chromatogr A 1359:8-15. doi: 10.1016/j.chroma.2014.07.011.

Franco-Luesma E, Ferreira V. 2016b. Formation and Release of H2S, Methanethiol, and Dimethylsulfide during the Anoxic Storage of Wines at Room Temperature. J Agric Food Chem 64:6317-6326. doi: 10.1021/acs.jafc.6b01638.

Fulcrand H, Atanasova V, Salas E, Cheynier V. 2004. The fate of anthocyanins in wine: Are there determining factors? ACS Symp Ser 886:68-88. doi: 10.1021/bk-20040886.ch006\r10.1021/bk-2004-0886.ch006.

Ghidossi R, Poupot C, Thibon C, and others. 2012. The influence of packaging on wine conservation. Food Control 23:302-311. doi: 10.1016/j.foodcont.2011.06.003.

Godden P, Francis IL, Field J, and others. 2001. Wine bottle closures: physical 
characteristics and effect on composition and sensory properties of a Semillon wine. I. Performance up to 20 months post-bottling. Aust J Grape Wine Res 7:64-105. doi: 10.1111/j.1755-0238.2001.tb00196.x.

Goldstein R. 2009. How long does leftover wine keep in the bottle? Wine-preservation myths and a simple solution. In: Blind Tast. http://blindtaste.com/2009/05/25/howlong-does-leftover-wine-keep-in-the-bottl/. .

Gómez-Plaza E, Gil-Muñoz R, López-Roca JM, and others. 2001. Phenolic compounds and color stability of red wines: Effect of skin maceration time. Am J Enol Vitic 52:266-270.

Goniak OJ, Noble AC. 1987. Sensory study of selected volatile sulfur compounds in white wine. Am J Enol Vitic 38:223-227.

Górecki T, Yu X, Pawliszyn J. 1999. Theory of analyte extraction by selected porous polymer SPME fibres. Analyst 124:643-649. doi: 10.1039/a808487d.

Grant-Preece P, Fang H, Schmidtke LM, Clark AC. 2013. Sensorially important aldehyde production from amino acids in model wine systems: Impact of ascorbic acid, erythorbic acid, glutathione and sulphur dioxide. Food Chem 141:304-312. doi: 10.1016/j.foodchem.2013.02.100.

Gruenwedel DW, Patnaik RK. 1971. Release of hydrogen sulfide and methyl mercaptan from sulfur-containing amino acids. J Agric Food Chem 19:775-779.

Guth H. 1997. Quantitation and Sensory Studies of Character Impact Odorants of Different White Wine Varieties. J Agric Food Chem 43:3027-3032. doi: 10.1021/jf9608433.

Guy N, O’Neill E. 2016. The Best Way to Keep Open Wine Fresh. In: The Sweethome. http://thesweethome.com/reviews/best-way-to-keep-open-wine-fresh/. .

Han G, Ugliano M, Currie B, and others. 2015. Influence of closure, phenolic levels and microoxygenation on Cabernet Sauvignon wine composition after 5 years' bottle storage. J Sci Food Agric 95:36-43. doi: 10.1002/jsfa.6694.

Harbertson JF, Picciotto EA, Adams DO. 2003. Measurement of Polymeric Pigments in Grape Berry Extracts and Wines Using a Protein Precipitation Assay Combined with Bisulfite Bleaching. Am J Enol Vitic 54:301-306.

Iland P, Bruer N, Edwards G, and others. 2013. Chemical analysis of grapes and wine: techniques and concepts, 2nd edn. Patrick Iland Wine Promotions.

Jackowetz JN, Mira de Orduña R. 2013a. Survey of SO2 binding carbonyls in 237 red and white table wines. Food Control 32:687-692. doi: 10.1016/j.foodcont.2013.02.001.

Jackowetz JN, Mira de Orduña R. 2013b. Improved sample preparation and rapid UHPLC analysis of SO2 binding carbonyls in wine by derivatisation to 2,4dinitrophenylhydrazine. Food Chem 139:100-104. doi: 10.1016/j.foodchem.2013.01.094.

Jackson R. 2014. Wine Science: Principles and Applications, 4th ed. Academic Press. Jastrzembski JA, Sacks GL. 2015. Precursors of Hydrogen Sulfide during Wine Storage the Role of Elemental Sulfur Pesticide Residues. In: 66th American Society of Enology and Viticulture National Conference. Portland, OR, .

Jiranek V, Langridge P, Henschke P. 1995. Regulation of hydrogen sulfide liberation in wine-producing Saccharomyces cerevisiae strains by assimilable nitrogen. Appl Environ Microbiol 61:461-467. 
Jongberg S, Gislason NE, Lund MN, and others. 2011. Thiol-quinone adduct formation in myofibrillar proteins detected by LC-MS. J Agric Food Chem 59:6900-6905. doi: 10.1021/jf200965s.

Juan FS, Cacho J, Ferreira V, Escudero A. 2012. Aroma chemical composition of red wines from different price categories and its relationship to quality. J Agric Food Chem 60:5045-5056. doi: 10.1021/jf2050685.

Kontoudakis N, Biosca P, Canals R, and others. 2008. Impact of stopper type on oxygen ingress during wine bottling when using an inert gas cover. Aust J Grape Wine Res 14:116-122. doi: 10.1111/j.1755-0238.2008.00013.x.

Kreitman GY, Danilewicz JC, Jeffery DW, Elias RJ. 2016a. Reaction Mechanisms of Metals with Hydrogen Sulfide and Thiols in Model Wine. Part 2: Iron- and CopperCatalyzed Oxidation. J Agric Food Chem 64:4105-4113. doi: 10.1021/acs.jafc.6b00642.

Kreitman GY, Danilewicz JC, Jeffery DW, Elias RJ. 2016b. Reaction Mechanisms of Metals with Hydrogen Sulfide and Thiols in Model Wine. Part 1: Copper-Catalyzed Oxidation. J Agric Food Chem 64:4095-4104. doi: 10.1021/acs.jafc.6b00642.

Kwasniewski MT, Allison RB, Wilcox WF, Sacks GL. 2011. Convenient, inexpensive quantification of elemental sulfur by simultaneous in situ reduction and colorimetric detection. Anal Chim Acta 703:52-57. doi: 10.1016/j.aca.2011.07.010.

Kwasniewski MT, Sacks GL, Wilcox WF. 2014. Persistence of elemental sulfur spray residue on grapes during ripening and vinification. Am J Enol Vitic 65:453-462. doi: 10.5344/ajev.2014.14027.

Kwasniewski MT, Vanden Heuvel JE, Pan BS, Sacks GL. 2010. Timing of cluster light environment manipulation during grape development affects $\mathrm{C} 13$ norisoprenoid and carotenoid concentrations in Riesling. J Agric Food Chem 58:6841-6849. doi: 10.1021/jf904555p.

Laurie VF, Law R, Joslin WS, Waterhouse AL. 2008. In situ measurements of dissolved oxygen during low-level oxygenation in red wines. Am J Enol Vitic 59:215-219.

Lopes P, Saucier C, Glories Y. 2005. Nondestructive colorimetric method to determine the oxygen diffusion rate through closures used in winemaking. J Agric Food Chem 53:6967-6973. doi: 10.1021/jf0404849.

Lopes P, Silva MA, Pons A, and others. 2009. Impact of oxygen dissolved at bottling and transmitted through closures on the composition and sensory properties of a Sauvignon blanc wine during bottle storage. J Agric Food Chem 57:10261-10270. doi: $10.1021 / \mathrm{jf} 9023257$.

López R, Lapeña AC, Cacho J, Ferreira V. 2007. Quantitative determination of wine highly volatile sulfur compounds by using automated headspace solid-phase microextraction and gas chromatography-pulsed flame photometric detection. Critical study and optimization of a new procedure. J Chromatogr A 1143:8-15. doi: 10.1016/j.chroma.2006.12.053.

Loscos N, Ségurel M, Dagan L, and others. 2008. Identification of S-methylmethionine in Petit Manseng grapes as dimethyl sulphide precursor in wine. Anal Chim Acta 621:24-29. doi: 10.1016/j.aca.2007.11.033.

Mateo-Vivaracho L, Cacho J, Ferreira V. 2008. Improved solid-phase extraction procedure for the isolation and in-sorbent pentafluorobenzyl alkylation of polyfunctional mercaptans. Optimized procedure and analytical applications. J 
Chromatogr A 1185:9-18. doi: 10.1016/j.chroma.2008.01.037.

McIntyre D. 2009. Wine: These Gadgets Keep Opened Bottles Fresher. In: Washington Post. http://www.washingtonpost.com/wpdyn/content/article/2009/03/24/AR2009032400748.html. .

McMillin KW. 2008. Where is MAP Going? A review and future potential of modified atmosphere packaging for meat. Meat Sci 80:43-65. doi: 10.1016/j.meatsci.2008.05.028.

McRae JM, Day MP, Bindon KA, and others. 2015. Effect of early oxygen exposure on red wine colour and tannins. Tetrahedron 71:3131-3137. doi: 10.1016/j.tet.2014.08.059.

McRae JM, Kassara S, Kennedy JA, and others. 2013. Effect of wine $\mathrm{pH}$ and bottle closure on tannins. J Agric Food Chem 61:11618-11627. doi: 10.1021/jf403704f.

Moenne MI, Saa P, Laurie VF, and others. 2014. Oxygen Incorporation and Dissolution During Industrial-Scale Red Wine Fermentations. Food Bioprocess Technol 7:26272636. doi: 10.1007/s11947-014-1257-2.

Moreira N, Lopes P, Ferreira H, and others. 2016. Influence of packaging and aging on the red wine volatile composition and sensory attributes. Food Packag Shelf Life 8:14-23. doi: 10.1016/j.fpsl.2016.02.005.

Musumeci LE, Ryona I, Pan BS, and others. 2015. Quantification of polyfunctional thiols in wine by HS-SPME-GC-MS following extractive alkylation. Molecules 20:1228012299. doi: 10.3390/molecules200712280.

Nevares I, del Alamo M. 2008. Measurement of dissolved oxygen during red wines tank aging with chips and micro-oxygenation. Anal Chim Acta 621:68-78. doi: 10.1016/j.aca.2007.11.042.

Nikolantonaki M, Chichuc I, Teissedre PL, Darriet P. 2010. Reactivity of volatile thiols with polyphenols in a wine-model medium: Impact of oxygen, iron, and sulfur dioxide. Anal Chim Acta 660:102-109. doi: 10.1016/j.aca.2009.11.016.

Nikolantonaki M, Jourdes M, Shinoda K, and others. 2012. Identification of Adducts between an Odoriferous Volatile Thiol and Oxidized Grape Phenolic Compounds: Kinetic Study of Adduct Formation under Chemical and Enzymatic Oxidation Conditions. J Agric Food Chem 60:2647-2656.

Nikolantonaki M, Magiatis P, Waterhouse AL. 2014. Measuring protection of aromatic wine thiols from oxidation by competitive reactions vs wine preservatives with ortho-quinones. Food Chem 163:61-67. doi: 10.1016/j.foodchem.2014.04.079.

Nikolantonaki M, Waterhouse AL. 2012. A Method To Quantify Quinone Reaction Rates with Wine Relevant Nucleophiles. J Agric Food Chem 60:8484-8491. doi: $10.1021 / \mathrm{jf302017j}$.

Null C. 2013. We Can Drink the Rest Tomorrow Citation Info. In: Wired. https://www.wired.com/2013/06/wine-preserve-2/. .

O'Brien V, Francis IL, Osidacz P. 2009. Packaging choices affect consumer enjoyment of wines. Aust New Zeal Wine Ind J 24:48-54.

Oberholster A, Elmendorf BL, Lerno LA, and others. 2015. Barrel maturation, oak alternatives and micro-oxygenation: Influence on red wine aging and quality. Food Chem 173:1250-1258. doi: 10.1016/j.foodchem.2014.10.043.

Oliveira CM, Ferreira ACS, De Freitas V, Silva AMS. 2011. Oxidation mechanisms occurring in wines. Food Res Int 44:1115-1126. doi: 10.1016/j.foodres.2011.03.050. 
Park S-K. 2008. Development of a method to measure hydrogen sulfide in wine fermentation. J Microbiol Biotechnol 18:1550-1554.

Patrianakou M, Roussis IG. 2013. Decrease of Wine Volatile Aroma Esters by Oxidation. South African J Enol Vitic 34:241-246.

Peinado RA, Moreno J, Bueno JE, and others. 2004. Comparative study of aromatic compounds in two young white wines subjected to pre-fermentative cryomaceration. Food Chem 84:585-590. doi: 10.1016/S0308-8146(03)00282-6.

Peterson RG. 1976. Formation of Reduced Pressure in Barrels During Wine Aging. Am J Enol Vitic 27:80-81.

Pineau B, Barbe J-C, Van Leeuwen C, Dubourdieu D. 2007. Which impact for betadamascenone on red wines aroma? J Agric Food Chem 55:4103-4108. doi: 10.1021/jf070120r.

Piñeiro Z, Palma M, Barroso CG. 2004. Determination of terpenoids in wines by solid phase extraction and gas chromatography. Anal Chim Acta 513:209-214. doi: 10.1016/j.aca.2003.12.044.

Pripis-Nicolau L, de Revel G, Bertrand A, Maujean A. 2000. Formation of flavour components by the reaction of amino acid and carbonyl compounds in mild conditions. J Agric Food Chem 48:3761-3766.

Ramamoorthy R, Dutta PK, Akbar SA. 2003. Oxygen sensors: Materials, methods, designs, and applications. J Mater Sci 38:4271-4282. doi: 10.1023/A:1026370729205.

Ramesh MN, Wolf W, Tevini D, Jung G. 1999. Studies on inert gas processing of vegetables. J Food Eng 40:199-205. doi: 10.1016/S0260-8774(99)00056-4.

Ramey D, Ough C. 1980. Volatile ester hydrolysis or formation during storage of model solutions and wines. J Agric Food Chem 28:928-934. doi: 10.1021/jf60231a021.

Revi M, Badeka A, Kontakos S, Kontominas MG. 2014. Effect of packaging material on enological parameters and volatile compounds of dry white wine. Food Chem 152:331-339. doi: 10.1016/j.foodchem.2013.11.136.

Ribéreau-Gayon P. 1975. Aroma of Muscat grape varieties. J Agric Food Chem 23:10421047. doi: 10.1021/jf60202a050.

Rodríguez-Bencomo JJ, Schneider R, Lepoutre JP, Rigou P. 2009. Improved method to quantitatively determine powerful odorant volatile thiols in wine by headspace solidphase microextraction after derivatization. J Chromatogr A 1216:5640-5646. doi: 10.1016/j.chroma.2009.06.005.

Roland A, Delpech S, Dagan L, and others. 2016. Innovative analysis of 3mercaptohexan-1-ol, 3-mercaptohexylacetate and their corresponding disulfides in wine by Stable Isotope Dilution Assay and nano-liquid chromatography tandem mass spectrometry. J Chromatogr A 1468:154-163. doi: 10.1016/j.chroma.2016.09.043.

Sanjeev K, Ramesh MN. 2006. Low oxygen and inert gas processing of foods. Crit Rev Food Sci Nutr 46:423-51. doi: 10.1080/10408390500215670.

Schüttler A, Friedel M, Jung R, and others. 2015. Characterizing aromatic typicality of Riesling wines: merging volatile compositional and sensory aspects. Food Res Int 69:26-37. doi: 10.1016/j.foodres.2014.12.010.

Schutz M, Kunkee RE. 1977. Formation of Hydroge Sulfide from Elemental Sulfur During Fermentation by Wine Yeast. Am J Enol Vitic 28:137-144. 
Segurel MA, Razungles AJ, Riou C, and others. 2005. Ability of possible DMS precursors to release DMS during wine aging and in the conditions of heat-alkaline treatment. J Agric Food Chem 53:2637-2645. doi: 10.1021/jf048273r.

Siebert T, Bramley B, Solomon M. 2009. Hydrogen sulfide: aroma detection threshold study in white and red wine. AWRI Tech Rev 183:14-16.

Siebert TE, Solomon MR, Pollnitz AP, Jeffery DW. 2010. Selective determination of volatile sulfur compounds in wine by gas chromatography with sulfur chemiluminescence detection. J Agric Food Chem 58:9454-9462. doi: 10.1021/jf102008r.

Silva MA, Julien M, Jourdes M, Teissedre PL. 2011. Impact of closures on wine postbottling development: A review. Eur Food Res Technol 233:905-914. doi: 10.1007/s00217-011-1603-9.

Simpson RF. 1978. Aroma and compositional changes in wine with oxidation, storage, and ageing. Vitis 17:274-287.

Singleton V. 1987. Oxygen with Phenols and Related Reactions in Musts, Wines, and Model Systems: Observations and Practical Implications. Am J Enol Vitic 38:69-77.

Singleton V, Trousdale E. 1983. White wine phenolics: varietal and processing differences as shown by HPLC. Am J Enol Vitic 34:27-34.

Singleton V, Trousdale E, Zaya J. 1979. Oxidation of Wines. I. Young White Wines Periodically Exposed to Air. Am J Enol Vitic 30:49-54.

Skouroumounis GK, Kwiatkowski MJ, Francis IL, and others. 2005. The impact of closure type and storge conditions on the composition, colour and flavour properties of a Riesling and a wooded Chardonnay wine during five years' storage. Aust J Grape Wine Res 11:369-377. doi: 10.1111/j.1755-0238.2005.tb00036.x.

Slingsby RW, Kepner RE, Muller CJ, Webb AD. 1980. Some Volatile Componenets of Vitis Vinifera Variety Cabernet Sauvignon Wine. Am J Enol Vitic 31:360-363.

Smith ME, Bekker MZ, Smith PA, Wilkes EN. 2015a. Sources of volatile sulfur compounds in wine. Aust J Grape Wine Res 21:705-712. doi: 10.1111/ajgw.12193.

Smith PA, Mcrae JM, Bindon KA. 2015b. Impact of winemaking practices on the concentration and composition of tannins in red wine. Aust J Grape Wine Res 21:601-614. doi: 10.1111/ajgw.12188.

Solomon M, Geue J, Osidacz P, Siebert T. 2010. Aroma detection threshold study of methanethiol in white and red wine. AWRI Tech Rev 186:8-10.

Teague L. 2016. The Best Way to Preserve Half Drunk Bottles of Wine. In: Wall Str. J. http://www.wsj.com/articles/the-best-way-to-preserve-half-drunk-bottles-of-wine1452540794. .

Thomas C, Boulton R, Silacci M, Gubler D. 1993. The effect of elemental sulfur, yeast strain, and fermentation medium on hydrogen sulfide production during fermentation. Am J Enol Vitic 44:211-216.

Timberlake CF, Bridle P. 1976. Interactions Between Anthocyanins, Phenolic Compounds, and Acetaldehyde and Their Significance in Red Wines. Am J Enol Vitic 27:97-105.

Tominaga T, Blanchard L, Darriet P, Dubourdieu D. 2000. A powerful aromatic volatile thiol, 2-furanmethanethiol, exhibiting roast coffee aroma in wines made from several Vitis vinifera grape varieties. J Agric Food Chem 48:1799-1802. doi: 10.1021/jf990660r. 
Tominaga T, Murat M-L, Dubourdieu D. 1998. Development of a Method for Analyzing the Volatile Thiols Involved in the Characteristic Aroma of Wines Made from Vitis vinifera L. Cv. Sauvignon Blanc. J Agric Food Chem 46:1044-1048. doi: 10.1021/jf970782o.

Tsachaki M, Linforth RST, Taylor AJ. 2005. Dynamic Headspace Analysis of the Release of Volatile Organic Compounds from Ethanolic Systems by Direct APCIMS. J Agric Food Chem 53:8328-8333.

Tsachaki M, Linforth RST, Taylor AJ. 2009. Aroma release from wines under dynamic conditions. J Agric Food Chem 57:6976-6981. doi: 10.1021/jf901174y.

Ugliano M. 2013. Oxygen contribution to wine aroma evolution during bottle aging. $\mathrm{J}$ Agric Food Chem 61:6125-6136. doi: 10.1021/jf400810v.

Ugliano M, Bégrand S, Diéval JB, Vidal S. 2015. Critical oxygen levels affecting wine aroma: Relevant sensory attributes, related aroma compounds, and possible mechanisms. ACS Symp Ser 205-216. doi: 10.1021/bk-2015-1203.ch013.

Ugliano M, Dieval JB, Siebert TE, and others. 2012. Oxygen consumption and development of volatile sulfur compounds during bottle aging of two Shiraz wines. influence of pre- and postbottling controlled oxygen exposure. J Agric Food Chem 60:8561-8570. doi: 10.1021/jf3014348.

Ugliano M, Fedrizzi B, Siebert T, and others. 2009. Effect of nitrogen supplementation and saccharomyces species on hydrogen sulfide and other volatile sulfur compounds in Shiraz fermentation and wine. J Agric Food Chem 57:4948-4955. doi: 10.1021/jf8037693.

Ugliano M, Henschke PA. 2010. Comparison of three methods for accurate quantification of hydrogen sulfide during fermentation. Anal Chim Acta 660:87-91. doi: 10.1016/j.aca.2009.09.049.

Ugliano M, Kolouchova R, Henschke PA. 2011a. Occurrence of hydrogen sulfide in wine and in fermentation: Influence of yeast strain and supplementation of yeast available nitrogen. J Ind Microbiol Biotechnol 38:423-429. doi: 10.1007/s10295-010-0786-6.

Ugliano M, Kwiatkowski M, Vidal S, and others. 2011b. Evolution of 3mercaptohexanol, hydrogen sulfide, and methyl mercaptan during bottle storage of Sauvignon blanc wines. Effect of glutathione, copper, oxygen exposure, and closurederived oxygen. J Agric Food Chem 59:2564-2572. doi: 10.1021/jf1043585.

Vasserot Y, Steinmetz V, Jeandet P. 2003. Study of thiol consumption by yeast lees. Antonie Van Leeuwenhoek 83:201-207. doi: 10.1023/A:1023305130233.

Vilanova M, Martínez C. 2007. First study of determination of aromatic compounds of red wine from Vitis vinifera cv. Castañal grown in Galicia (NW Spain). Eur Food Res Technol 224:431-436. doi: 10.1007/s00217-006-0322-0.

Viviers MZ, Smith ME, Wilkes E, Smith P. 2013. Effects of five metals on the evolution of hydrogen sulfide, methanethiol, and dimethyl sulfide during anaerobic storage of chardonnay and shiraz wines. J Agric Food Chem 61:12385-12396. doi: 10.1021/jf403422x.

Waterhouse AL, Frost S, Ugliano M, and others. 2016. Sulfur Dioxide - Oxygen Consumption Ratio Reveals Differences in Bottled Wine Oxidation. Am J Enol Vitic 67:449-459. doi: 10.5344/ajev.2016.16006.

Waterhouse AL, Laurie VF. 2006. Oxidation of Wine Phenolics: A Critical Evaluation and Hypotheses. Am J Enol Vitic 57:306-313. 
Wildenradt HL, Singleton VL. 1974. The Production of Aldehydes as a Result of Oxidation of Polyphenolic Compounds and its Relation to Wine Aging. Am J Enol Vitic 25:119-126.

Winterhalter P, Sefton M, Williams P. 1990. Volatile C13-Norisoprenoid Compounds in Riesling Wine are Generated by Multiple Precursors. Am J Enol Vitic 41:277-283.

Wirth J, Morel-Salmi C, Souquet JM, and others. 2010. The impact of oxygen exposure before and after bottling on the polyphenolic composition of red wines. Food Chem 123:107-116. doi: 10.1016/j.foodchem.2010.04.008.

Ye DQ, Zheng XT, Xu XQ, and others. 2016. Evolutions of volatile sulfur compounds of Cabernet Sauvignon wines during aging in different oak barrels. Food Chem 202:236-246. doi: 10.1016/j.foodchem.2016.01.139. 


\title{
CHAPTER 2 - IMPACT OF DIFFERENT RESEALING METHODS ON PRESERVING WINE QUALITY AFTER OPENING
}

\begin{abstract}
Numerous products exist to address concerns of wine quality degradation over a period of days after opening a bottle. These closures vary in material, sealing mechanism, or strategy to adjust headspace pressure or gas content. While many anecdotal claims are made as far as the different methods' ability to preserve wine quality or minimize oxygen exposure, little research has been done on the topic. An assortment of strategies for resealing wines were evaluated, including stoppers from different manufactures, re-using the closure the bottle was initially sealed with, as well as modifying the atmosphere of the headspace by applying a vacuum or introducing gas. Headspace (HS) and dissolved oxygen (DO) levels were monitored throughout storage and changes in $\mathrm{SO}_{2}$, acetaldehyde, tannins, anthocyanins, and key volatile aromas were characterized and
\end{abstract} compared among treatments after storage.

In both red and white wine, resealing with a vacuum closure resulted in headspace and dissolved oxygen levels that were significantly less than all other closure types at the end of storage (e.g. $2.12 \pm 0.58 \mathrm{mg} \mathrm{O}_{2} / \mathrm{L} \mathrm{HS}, 1.16 \pm 0.29 \mathrm{mg} \mathrm{O}_{2} / \mathrm{L} \mathrm{DO}$ in vacuum treatment versus $7.44 \pm 0.03 \mathrm{mg} \mathrm{O}_{2} / \mathrm{L} \mathrm{HS}, 5.01 \pm 0.27 \mathrm{mg} \mathrm{O}_{2} / \mathrm{L} \mathrm{DO}$ in Stelvin Reseal). Headspace oxygen was near ambient levels in all other closures when not sparged with inert gas. Vacuum treatment had no deleterious impacts on white wine aroma, but resulted in significant decreases in vitispirane $\mathrm{A} \& \mathrm{~B}$, isoamyl acetate, and linalool in red wine. In white wine treatments which had significantly higher final DO than the controls, significant reductions in bound $\mathrm{SO}_{2}$ were observed after three days of storage, but no significant loss of free $\mathrm{SO}_{2}$ was apparent. In some red wine treatments exposed to similar $\mathrm{HS}$, significant 
loss of free $\mathrm{SO}_{2}$ occurred without changes in bound $\mathrm{SO}_{2}$. In the most extreme oxygen exposure treatment (red wine with 73 hours of exposure to air), greater loss of free $\mathrm{SO}_{2}$ was observed, however free $\mathrm{SO}_{2}$ was still present and no significant decreases in bound $\mathrm{SO}_{2}$ were seen. Significant differences were observed in anthocyanin and tannin levels, but these changes did not follow clear trends based on treatment effects. The only differences in acetaldehyde observed were between white wine under Stelvin closure that had not been opened and all other treatments (22 mg/L versus 29 - $31 \mathrm{mg} / \mathrm{L})$, however red wines gave inconclusive results due to problems with enzymatic analysis of decolorized wines.

\section{Introduction}

A tremendous amount of research, effort, and expense has gone into ensuring that wine is tasted by consumers as a winemaker intended. One of the critical challenges to ensure quality is to minimize or at least manage oxygen exposure throughout a wine's life, from harvest to consumption. While there have been major improvements in the understanding of oxygen ingress throughout vinification (Moenne and others 2014; McRae and others 2015; Smith and others 2015b), packaging (Ghidossi and others 2012; Revi and others 2014; Moreira and others 2016), and the impact closures have on oxygen ingress (Godden and others 2001; O'Brien and others 2009; Silva and others 2011) this all ultimately may not be enough to ensure quality in the glass if the consumer does not consume the entire bottle within hours of opening. It is common practice for wine drinkers in their home to open a bottle and consume the remaining portion days, or longer, after originally opening the bottle. Likewise, this practice is also common in restaurants and winery tasting rooms where wine is poured by the glass, as the alternative would be to discard any unconsumed wine at the end of each day. While there are varied ways of 
reclosing the bottle, ranging from simply reinserting a cork, to methods that involve inert gas or creating a partial vacuum in the headspace, little is known about which, if any, preserve the wine as it was originally intended to be consumed.

In the winery, it is typical to attempt to maintain complete control over the degree of oxygen exposure to a wine throughout the winemaking process, at bottling, and during bottle storage via closure choice (Dimkou and others 2011; Moenne and others 2014; Day and others 2015). Dissolved and headspace oxygen present at bottling and closure-related ingress are important pools from which wine oxygen consumption is fueled during bottle maturation and storage. Excessive levels in bottle can drastically increase the risk of wine being faulted by oxidative spoilage due to problems potentially arising both biotically and abiotically (Ugliano 2013). Nonenzymatic oxidation in wine is catalyzed upon interaction of dissolved oxygen with transition metal ions, copper and iron. The primary products of this series of reactions are $o$-quinones and $\mathrm{H}_{2} \mathrm{O}_{2}$, both of which propagate further oxidation reactions with wine components (Singleton 1987; Danilewicz and Wallbridge 2010). Chemical and organoleptic changes induced by these primary oxidation products can be mitigated through the action of exogenous antioxidants such as $\mathrm{SO}_{2}$ (Danilewicz and Wallbridge 2010; Elias and Waterhouse 2010). Low populations of spoilage microorganisms, such as Acetobacter aceti, may survive in wine at low oxygen concentrations, which may then proliferate with excess oxygen ingress and also create offaromas or hazes (Drysdale and Fleet 1989).

Oxygen consumed by wine will impact wine chemistry differently depending on the concentration of free $\mathrm{SO}_{2}$ (Carrascon and others 2015). Upon initial oxygen consumption, free $\mathrm{SO}_{2}$ is gradually depleted by quenching primary oxidation reactions and 
binding oxidation products such as acetaldehyde. Recent work has hypothesized that when free $\mathrm{SO}_{2}$ concentrations have reached trace levels $(<5-10 \mathrm{mg} / \mathrm{L}$, as measured by the Ripper method), this minimum concentration is sustained by dissociation from the pool of bound $\mathrm{SO}_{2}$ (Ferreira and others 2015b; Waterhouse and others 2016). At this trace concentration, $\mathrm{SO}_{2}$ may no longer provide effective antioxidant protection and strong oxidants freely react with wine components, particularly thiols (glutathione, polyfunctional thiols), polyphenols, and aroma compounds.Several major, undesirable changes in wine quality occur as a result.

Wine with minimal oxygen ingress will undergo subtle aroma evolution over the course of months or years of bottle storage (Silva and others 2011; Ugliano 2013). In many red wines, optimal development in aroma complexity over bottle maturation necessitates a moderate oxygen dose of between $2-5 \mathrm{mg} / \mathrm{L}$ over one year (Ugliano 2013; Day and others 2015). However, in situations such as with a faulty cork closure, which allows large amounts of oxygen infiltrate the bottle a cascade of detrimental reactions can significantly impact an array of important wine aroma compounds (Balboa-Lagunero and others 2011). Fermentation-derived esters (such as isoamyl acetate, phenylethyl acetate, and ethyl hexanoate), $\mathrm{C}_{13}$-norisoprenoids (particularly $\beta$-damascenone), and varietal thiols (4mercapto-4-methyl-2-pentanone, 3-mercaptohexanol, and 3-mercaptohexyl acetate) are among the most important volatile organic compounds responsible for a general "fruity" and "fresh" character in wine (Balboa-Lagunero and others 2011; Ugliano and others 2015). Oxidative degradation of esters occurred under forced oxidation in wine (Patrianakou and Roussis 2013), but does not appear to be an issue under more representative, mild conditions (Carrascon and others 2015; Waterhouse and others 2016). Equilibrium shifts between chemical hydrolysis and esterification are likely responsible for 
non-oxygen driven loss or increase of esters over normal aging conditions (Ramey and Ough 1980). Most likely, loss of fruity aroma associated with oxidation can be explained by decreases in $\beta$-damascenone and varietal thiols and masking by increases in aldehydes. Significant loss of $\beta$-damascenone may occur via two routes: binding by $\mathrm{SO}_{2}$ to form odorless derivatives (Daniel and others 2004) and oxidative degradation (Carrascon and others 2015). However others have found increases in $\beta$-damascenone with increasing oxygen exposure (Ugliano and others 2015).

Part of the challenge in understanding the impact of oxygen on wine quality parameters is both in having methods that measure these reactive compounds as they were in the bottle or the glass and that have the sensitivity to quantify compounds with sensory importance at ultra-trace concentrations. Oxygen exposure can be monitored by quantification of free molecular oxygen in wine (dissolved oxygen, DO), an important parameter that helps inform the winemaker's decisions on future treatment of the wine. Electrochemical methods, such as Clark's electrode (Blanchard and others 2004; Laurie and others 2008; Chinnici and others 2013), and optical probes that operate based on dynamic luminescence quenching are two of the most commonly employed techniques for measuring wine DO (Day and others 2015). Due to the destructive nature of oxygen measurement upon reduction by the Clark electrode, sample must be stirred to continuously replenish oxygen and achieve an accurate response (Ramamoorthy and others 2003). Samples collected for measurement must be handled and stirred carefully to avoid introduction of air that would artificially inflate the DO result. Optical probes offer several advantages over the traditional Clark electrode. First, is the ability to nondestructively measure oxygen content of wine in sealed containers, enabling users to conveniently and 
non-invasively measure oxygen evolution in the same sample over time. Moreover, optical sensors have rapid signal response, require less frequent calibration, and have a longer lifetime. Finally, this same probe and sensor set-up can be used to measure headspace oxygen as well. Several recent studies taking advantage of optical probe technology have directly related levels of total consumed oxygen (TCO) to specific changes in key quality parameters (Dimkou and others 2011; Ugliano and others 2012; Ferreira and others 2015b; Waterhouse and others 2016). For example, Ugliano et al. (2012) varied oxygen exposure, in the form of different micro-oxygenation and closure-derived oxygen treatments, to determine the influence of TCO on volatile sulfur compound development, phenolic composition, and $\mathrm{SO}_{2}$ consumption during one year of bottle aging. Initial wine composition and modifications after repeated cycles of oxygen consumption were extensively characterized by Ferreira, et al (2015) using an optical probe to monitor DO and determine consumption progress and kinetics

Aroma compounds are present in wine at part per million to as low as part per trillion levels, necessitating their isolation and concentration prior to quantification. Two preconcentration techniques are widely used in wine aroma analysis: solid phase extraction (SPE) and solid phase micro-extraction (SPME). SPE utilizes the selective retention of analytes based on choice of nonpolar or polar resin. After sorbent conditioning, sample retention, clean-up, and drying, analytes are eluted off the sorbent with a small amount of organic solvent, commonly dichloromethane, to obtain a concentrated extract. Optimization of sorbent and elution solvent allows for a single SPE procedure to obtain a wide range of wine aroma compounds and effectively remove interferences (such as sugars and phenolics) (Piñeiro and others 2004; Castro and others 2008). Several drawbacks of 
SPE, including the use of toxic solvents for sorbent conditioning and elution, multiple steps that increase potential for analyte loss, and being a time and labor intensive process, prompted the development of SPME (de Fátima Alpendurada 2000). Controlling the polarity and thickness of sorbent coating on the silica support rod allows for selective adsorption with SPME fibers, while desorption is achieved by placing the fiber in a hot GC injection port, thereby eliminating the use of organic solvents. Analyte extraction and desorption are achieved quickly due to the small fiber size; however, this also contributes to one of the main disadvantages with SPME. Competition between analytes for active sites on the coating can lead to nonlinear relationships between the concentration of analyte extracted by the fiber and the true concentration of analyte present in the sample (Górecki and others 1999). Both sample preparation procedures are commonly followed by analysis using gas chromatography with mass spectroscopy (MS) or flame ionization detection.

Significant loss of polyfunctional thiols responsible for the varietal character of Sauvignon Blanc and Cabernet Sauvignon, and also often present above sensory threshold levels in Chenin Blanc and Merlot, occurs by nucleophilic addition reactions with quinones, which form nonvolatile adducts and diminish the intensity of fruity notes in wines (Nikolantonaki and others 2010; Nikolantonaki and Waterhouse 2012). Development of methods to accurately quantify varietal thiols is especially challenging due to the highly reactive nature of the thiol moiety, which is a primary target of quinones formed by polyphenol oxidation as mentioned above (Nikolantonaki and others 2012), susceptible to oxidization resulting in the formation of disulfides (Blanchard and others 2004), and forms complexes with copper (Ugliano and others 2011b; Kreitman and others 2016b). Improvements on the originally proposed analysis method with wine samples 
(Tominaga and others 1998) have addressed concerns with analyte degradation during extraction, poor specificity, and method detection limits above sensory threshold values (Mateo-Vivaracho and others 2008; Rodríguez-Bencomo and others 2009; Musumeci and others 2015; Roland and others 2016), however most procedures are still highly time consuming and/or require specific instrumentation that is not regularly available in the majority of wine research labs.

An increase in "bruised apple" character due to the presence of free acetaldehyde from ethanol oxidation and dissociation from bisulfite-acetaldehyde complexes (Wildenradt and Singleton 1974; Jackowetz and Mira de Orduña 2013a) is another key marker associated with oxidation, but does not always occur at significant levels (Escudero and others 2002; Carrascon and others 2015). Acetaldehyde's extremely high volatility (boiling point of $21^{\circ} \mathrm{C}$ ) makes direct analysis challenging due to potential for analyte loss during sample handling. To overcome this, derivatization followed by GC or HPLC analysis is frequently carried out (Cullere and others 2007; Jackowetz and Mira de Orduña 2013b). Less expensive methods, although not always as sensitive, involve quantitative oxidation by an enzyme followed by spectrophotometric detection of the coenzyme (Bergmeyer 1974). Other odor-active aldehydes, such as methional and phenylacetaldehyde, are also associated with oxidation and contribute "cooked vegetable" and "honey” notes, respectively (Escudero and others 2000; Grant-Preece and others 2013). Strecker degradation from amino acids methionine and phenylalanine (Grant-Preece and others 2013) and release from $\mathrm{SO}_{2}$ complexes (Bueno and others 2016) result in increased concentrations of methional and phenylacetaldehyde. 
Initial concentration of various phenolic species in wine is largely dependent upon oxygen management during fermentation (McRae and others 2015), grape variety, and growing conditions. In the context of important wine mouthfeel and color compounds, anthocyanins appear to be the primary targets of oxidation and are progressively converted to more stable pigments as a result (Wirth and others 2010). Stability of color and mouthfeel compounds is also indirectly promoted by oxygen through the formation of oxidation products, predominantly acetaldehyde, which then participate in acetaldehydemediated reactions of both tannins and anthocyanins (Timberlake and Bridle 1976). Generally, increased oxygen exposure in red wines, whether due to processes during winemaking (such as rotary fermenters, pump-overs, and micro-oxygenation treatment) or post-bottling closure related oxygen, has been found to enhance wine color and soften astringency by increasing color intensity, increasing total phenolics, and decreasing tannins (Ugliano and others 2012; McRae and others 2015). Browning becomes an issue after prolonged exposure to excessive oxygen levels has already resulted in depletion of free $\mathrm{SO}_{2}$ and aroma degradation (Singleton and others 1979; Skouroumounis and others 2005).

Many home wine connoisseurs, bloggers, and writers at popular magazines have carried out informal testing on wines resealed with commonly available closures with the intent of finding the best and worst options (Cesano 2009; Goldstein 2009; McIntyre 2009; Null 2013; Guy and O'Neill 2016; Teague 2016). Of the vacuum closures available, Vacu Vin is the least cost prohibitive and its included in many informal tests. As the vacuum pump is applied, users can smell wine aroma as air from the bottle headspace is released through the pump. Some testers claim this is an indication of irreversible loss of wine bouquet and conclude that vacuums are an inferior closure method that actually damages 
wine quality instead of preserving it (Cesano 2009; McIntyre 2009). Manufacturers of vacuum closures do not mention this aroma "loss", and only tout the superior ability of their method at maintaining wine quality. Considering these negative preconceptions that seem to have developed by some consumers towards vacuum closures, one goal of the present study was to address any potential aroma stripping due to vacuum application.

The changes in $\mathrm{SO}_{2}$, aromas, anthocyanins, and tannins discussed above represent generalized effects of oxidation on wine quality. As previously noted, significant progress has recently been made towards relating precise oxygen levels to specific changes, however additional work is needed to investigate modifications over a period of days. This time scale is especially crucial to better understand deleterious effects of oxygen on quality over the shelf life of a bottle of wine resealed after opening. The present study aimed to achieve two main objectives through an investigation of performance of a variety of popular closure products and the original closures. First, was to determine the impacts of low, moderate, and high oxygen headspace environments on wine quality parameters over short term storage (three days). Second, was to determine the optimal method for preserving wine quality after resealing. Use of an improved closure method offers economic benefit and reduction of wasted wine from oxidative deterioration and spoilage for winery tasting rooms, restaurants, and home wine consumers.

\section{Materials and Methods}

\subsection{Wines and bottling}

Clos du Bois 2013 Cabernet Sauvignon (California) and Jacob's Creek 2014 Dry Riesling (Australia) were purchased from a local wine store. Analytical parameters of the red wine were as follows: $\mathrm{pH} 3.75,0.075 \mathrm{~g} / \mathrm{L}$ residual sugars, 13.5\% (v/v) alcohol, 6.92 
$\mathrm{g} / \mathrm{L}$ tartaric acid, $17.6 \mathrm{ppm}$ free $\mathrm{SO}_{2}, 49.6 \mathrm{ppm}$ total $\mathrm{SO}_{2}$, organic acids: $0.19 \mathrm{~g} / \mathrm{L}$ malic, $0.87 \mathrm{~g} / \mathrm{L}$ lactic, $1.61 \mathrm{~g} / \mathrm{L}$ acetic, $0.12 \mathrm{~g} / \mathrm{L}$ citric, $0.47 \mathrm{~g} / \mathrm{L}$ succinic. Analytical parameters of the white wine were as follows: $\mathrm{pH} 3.03,0.025 \mathrm{~g} / \mathrm{L}$ residual sugars, $11.5 \%$ (v/v) alcohol, 8.59g/L tartaric acid, $11.4 \mathrm{ppm}$ free $\mathrm{SO}_{2}, 83 \mathrm{ppm}$ total $\mathrm{SO}_{2}$, and organic acids: $2.53 \mathrm{~g} / \mathrm{L}$ malic, $0.45 \mathrm{~g} / \mathrm{L}$ lactic, $2.16 \mathrm{~g} / \mathrm{L}$ acetic, $0.27 \mathrm{~g} / \mathrm{L}$ citric, $0.32 \mathrm{~g} / \mathrm{L}$ succinic.

Wines were gently transferred from their original bottles under inert gas to a single $60 \mathrm{~L}$ demijohn. The wine was stored in a refrigerator and allowed to equilibrate under inert atmosphere for two days to ensure homogeneity. From the demijohn, wine was again gently transferred under inert gas into two $11 \mathrm{~L}$ carboys where it was held under inert atmosphere at refrigeration temperature until bottling.

Twenty-one standard $750 \mathrm{~mL}$ flint glass bottles were fitted with two Presens PSt3 oxygen sensors (Presens, Regensburg, Germany) to nondestructively measure headspace oxygen (HS, mg/L) and dissolved oxygen (DO, mg/L). For each of the four experiments ( 2 white, 2 red), fifteen screw cap bottles were sealed with basic Stelvin closures (Amcor Flexibles, Madison, WI) and six cork bottles were sealed with natural agglomerate corks (LD Carlson Company, Kent, Ohio). Headspace of each was sparged with nitrogen at bottling. After bottling, wine was given at least three days to equilibrate before beginning the treatments. All oxygen measurements were taken in triplicate using a NomaSense $\mathrm{O} 2$ P6000 oxygen meter (Nomacorc, Germany). The limit of detection (LOD) was $15 \mu \mathrm{g} / \mathrm{L}$ using this method.

\subsection{Resealing and air exposure treatments}

A total of four experiments were carried out using the same set of 21 bottles equipped with oxygen sensors, the first two with white wine (Exp 1 and 2) and the second 
two with red wine (Exp 3 and 4). For the first three experiments ( 2 whites, 1 red), there were two controls that remained unopened for the duration of the testing, one Stelvin (“Control Stelvin") and one cork (“Control Cork"), and five treatments, all of which were conducted in triplicate. Each bottle undergoing treatment was opened, two 5 oz glasses were poured, and the bottle was left open, undisturbed for 10 minutes. After 10 minutes of exposure to air, the bottle was resealed under closure conditions according to its respective treatment. Treatments included resealing with the original closure ("Stelvin Reseal", "Cork Reseal") and using several widely available closure products: Rabbit Bottle Stoppers (“Rabbit”, Taylor Precision Products, Las Cruces, NM), Joie Expand \& Seal Bottle Stopper ("Flip Top", Joie Shop), Vacu Vin Wine Saver pump and rubber stoppers ("Vacu Vin", International Innovation Company, Indian Trail, NC), and FoodSaver vacuum stoppers (“Strong Vacuum”, Sunbeam Products, Boca Raton, FL). The FoodSaver vacuum stoppers were sealed using a vacuum pump at 20-25 mmHg (KNF Neuberger Inc, Trenton, NJ) to achieve a stronger vacuum than what could be reached using a hand pump or the commercially available FoodSaver vacuum bag sealing system the stoppers were originally designed to be used with.

In the second experiment (Exp 2) the headspace of each treatment (excluding Vacu Vin) was sparged with an inert gas mixture (proprietary blend of argon, nitrogen, and carbon dioxide; Private Preserve, Napa Valley, CA). Initially in Exp 2, gas was applied according to package directions by spraying a one second burst followed by four short bursts, however HS concentrations at the level of the oxygen sensor were only reduced from atmospheric levels to $5-6 \mathrm{mg} / \mathrm{L}$. Given that the sensor spots were fixed in the bottle neck, not directly above the wine surface, the gas may have given the intended protection, 
however we opted to flush the headspace for 20 seconds to ensure that the entire headspace reached concentrations representative of those at the gas-wine interface $(<1 \mathrm{mg} / \mathrm{L}$ HS was achieved in all sparged treatments).

In experiment four (Exp 4), the impacts of extreme air exposure on red wine was investigated. One control and five treatments of increasing air exposure time (10 minutes, 24 hours, and 73 hours) with only two closure types ("Strong Vacuum" and "Stelvin Reseal") were used. Treatments with 10 minutes and 24 hours of exposure time were performed in triplicate with each closure type. The treatment with 73 hours of exposure was never resealed $(n=6)$. This experiment was used to determine the effect of air exposure time, and subsequent larger dosages of oxygen, on the onset of oxidative alterations in wine chemistry and volatile aromas.

\subsection{Monitoring oxygen during storage}

During a storage period of about three days, headspace and dissolved oxygen measurements were taken approximately every eight to twelve hours in each experiment. Wines were stored at room temperature.

\subsection{Chemical Analyses}

\subsubsection{Solvents and Chemical Standards}

Dichloromethane ( $\geq 99.8 \%$, Sigma, St. Louis, MO), methanol ( $\geq 99.9 \%$, Sigma, St. Louis, MO), 2-octanol (99\%+, Acros, New Jersey), $\alpha$-terpineol ( $\geq 97 \%$ Fluka, St. Louis, MO), 1,1,6 trimethyl-1,2 dihydronapthlaene (TDN) ( $\geq 99 \%$, donated by Sacks Lab, Cornell University (Kwasniewski and others 2010)), isoamyl acetate, cis-linalool oxide, furfural, linalool, diethyl succinate, phenylethyl acetate, $\beta$-damascenone, benzyl alcohol, whiskey 
lactone, vanillin, $10 \mathrm{~N} \mathrm{NaOH}$, tartaric acid, Everclear (95\% abv, Luxco Inc, St. Louis, MO), and deionized (DI) water.

\subsubsection{Basic Chemistry}

Wine primary chemistry for both the red and white wine was determined after the initial homogenization step. Residual sugars were determined using Clinitest tablets which have a limit of detection of $0.025 \mathrm{~g} / \mathrm{L}$ glucose (Bayer Corporation, Pittsburg, PA), pH was

measured using HI $2222 \mathrm{pH}$ meter (Hanna Instruments, Woonsocket, RI), titratable acidity was measured by titration with a pH meter (Iland and others 2013), and free and bound $\mathrm{SO}_{2}$ were determined using the aeration-oxidation method (Iland and others 2013). Organic acids were quantified by high performance liquid chromatography system (VARIAN, Inc. ProStar, Palo Alto, Calif.) consisting of a 410 autosampler, 210 pump with in-line degasser, 335 LC dual path diode array UV-Visible detector, and operated via the Galaxie chromatography manager software (Version 1.9.302.530, Agilent Technologies, Santa Clara, Calif.). A Zorbax SB-Aq column (4.6 x $250 \mathrm{~mm}$ with $5 \mathrm{~mm}$ pore size) was operated at $35^{\circ} \mathrm{C}$ (Agilent Technologies, Santa Clara, Calif.). The aqueous mobile phase was 20 $\mathrm{mM}$ sodium phosphate $(0.99 \mathrm{~mL})$ and $100 \%$ acetonitrile $(0.01 \mathrm{~mL})$ at a flow rate of $1 \mathrm{~mL}$ per minute (total run time of 10 minutes). The UV-Visible light detected the standards tartaric, malic, lactic, acetic, and citric acid at $210 \mathrm{~nm}$. Each acid was identified by reference standard and quantified by reference to a 5-point calibration curve ranging from $0.25 \mathrm{~g} / \mathrm{L}-10 \mathrm{~g} / \mathrm{L}$. Sample injection volume was $10 \mu \mathrm{L}$ and concentration $(\mathrm{g} / \mathrm{L})$ was determined using the peak area (mAU.min) and the standard curve for each acid standard. 


\subsubsection{Volatile aroma analysis}

\section{Isolation of volatiles}

Volatile aroma analysis of wines post-treatment was performed by SPE-GC-MS. Solid phase extractions were performed on an Alltech 12-port SPE manifold (Fischer, St. Louis, MO) in duplicate based on a previously published method (Piñeiro and others 2004). Lichrolut EN SPE cartridges (Merck, Billerica, MA) filled with $200 \mathrm{mg}$ of resin were used. Before the extraction procedure, $2 \mathrm{mg} / \mathrm{L}$ 2-octanol was added to each sample as an internal standard. Columns were conditioned with methanol (MeOH), dichloromethane (DCM), and $\mathrm{H}_{2} \mathrm{O}$ before loading the sample. After loading, columns were washed with $\mathrm{H}_{2} \mathrm{O}$ and dried under vacuum for five minutes. DCM was used as the extraction solvent. For white wine, all extractions were performed in duplicate. The sample size for red wine was only sufficient for single extraction.

\section{Identification and quantification}

GC-MS analysis of wine extracts was carried out on a Varian 431-GC and 220-MS equipped with a Varian Combi-Pal autosampler. A $1 \mu \mathrm{L}$ sample of each extract was injected in splitless mode from $0-3$ minutes changing to split mode with a ratio of 99:1 from $4-60$ minutes with an injector temperature of $200{ }^{\circ} \mathrm{C}$ into a base deactivated FS guard column (Bruker, Billerica, MA, $1 \mathrm{~m}, 0.25 \mathrm{~mm}$ i.d.) and DB-WAXETR analytical column (Agilent, Santa Clara, CA, 30 m, 0.25 mm i.d., $0.25 \mu \mathrm{m}$ film thickness). Ultra-high purity helium (AirGas, Radnor, PA) was used as the carrier gas at a flow rate of $1 \mathrm{~mL} / \mathrm{min}$. The oven ramp was as follows: $40^{\circ} \mathrm{C}$ (hold $\left.6 \mathrm{~min}\right), 145^{\circ} \mathrm{C}\left(5^{\circ} \mathrm{C} / \mathrm{min}\right), 175^{\circ} \mathrm{C}\left(2.5^{\circ} \mathrm{C} / \mathrm{min}\right)$, $220^{\circ} \mathrm{C}$ (hold $10 \mathrm{~min}$ ). All injections were performed in duplicate. Volatile compounds were identified by comparison of retention times with pure standards (or from literature for 
vitispirane A\&B due to lack of commercially available standard (Eggers and others 2006)) and by comparison of mass spectral fragmentation patterns with the NIST database (NIST Mass Spectral library version 14).

Solutions of known concentrations of pure standards in model wine (12\% (v/v), 5 $\mathrm{g} / \mathrm{L}$ tartaric acid, $\mathrm{pH}$ adjusted to 3.5 using $5 \mathrm{~N} \mathrm{NaOH}$ ) with $2 \mathrm{mg} / \mathrm{L}$ 2-octanol were prepared. Samples were run through the SPE process and analyzed by the GC-MS method as described above to generate calibration curves. Interpolation of analyte/internal standard relative area in the calibration plots was used to obtain quantitative data. When a pure standard for a given compound was unavailable, compounds were identified by NIST library and retention time, with semi-quantitative data produced by using a calibration curve of a structurally similar analyte.

\subsubsection{Acetaldehyde}

Acetaldehyde was measured in white wine using an enzyme assay following the manufacturer's instructions (Megazyme, Chicago, IL) and UV-vis spectrophotometer at $340 \mathrm{~nm}$. Each sample was measured in duplicate. This method required a decolorizing step for analysis of red wines. It was found that the process of decolorizing with PVPP caused interferences resulting in inaccurately low values for acetaldehyde; therefore, those acetaldehyde measurements were excluded.

\subsubsection{Anthocyanins, Tannins, and Polymeric Pigments}

Adams-Harbertson Assay (Harbertson and others 2003) was performed to quantify potential changes in small and large polymeric pigments in absorbance units (au), anthocyanins in $\mathrm{mg} / \mathrm{L}$ malvidin-3-glucoside equivalents, tannins in $\mathrm{mg} / \mathrm{L}$ catechin 
equivalents, and phenolics in $\mathrm{mg} / \mathrm{L}$ catechin equivalents after treatment in Exp 3. Each sample was measured in duplicate.

\subsection{Statistical Analysis and Data Treatment}

Microsoft Office Excel 2010 (Redmond, WA) was used for basic statistical analyses and to generate aroma calibration curves. One-way ANOVA, Tukey HSD ( $\mathrm{p}<0.05)$, and linear correlations were conducted using MiniTab version 17.1.0 (State College, PA).

\section{Results}

\subsection{Headspace oxygen (HS) and dissolved oxygen (DO)}

After two hours of equilibration time post-bottling, all wines within a given experiment had a similar concentration of dissolved oxygen, while bottles sealed under cork had higher levels of headspace oxygen than the Stelvin bottles (data not shown; 1.5 $3.5 \mathrm{mg} / \mathrm{L}$ in corked bottles vs $<0.5 \mathrm{mg} / \mathrm{L}$ in Stelvin bottles). Unopened control treatments (Control Stelvin and Control Cork) behaved as expected in all experiments, exhibiting no signs of leakage. HS concentrations in the Control Cork wines in Exp 1, 2, and 3 were higher than Control Stelvin and decreased over the course of the storage period, suggesting oxygen consumption by the wine with no significant ingress. HS and DO levels in Control Stelvin wines remained nearly constant throughout storage. Assuming no significant oxygen ingress, Control Stelvin total consumed oxygen (TCO) at 1 week for white wine in Exp 1 and 2 was 0.07 and $0.20 \mathrm{mg} / \mathrm{L}$, respectively, while TCO for red wine in Exp 3 at 5 days was $0.04 \mathrm{mg} / \mathrm{L}$ and in Exp 4 at 10 days was essentially $0 \mathrm{mg} / \mathrm{L}$.

The first time point shown in Figure 2.1 (storage period of 0 hours) was taken after pouring two glasses, exposing the remaining wine to air for 10 minutes (or longer, in Exp 
4), and resealing bottles with the respective closure treatment. Opening the bottle in even the shortest exposure treatments (10 minutes) caused HS to approach ambient oxygen levels, however applying a vacuum or sparging with inert gas reduced concentrations significantly.

\subsubsection{Experiment 1- White wine resealed with popular closures}

Evolution of HS and DO over the course of the three day storage period after resealing wines in Exp 1 are shown in Figure 2.1a. After 10 minutes of exposure to air and resealing, initial HS in Cork Reseal $(7.91 \pm 0.62 \mathrm{mg} / \mathrm{L})$ was significantly higher than Stelvin Reseal $(7.18 \pm 0.02 \mathrm{mg} / \mathrm{L})$ and Flip Top $(7.56 \pm 0.25 \mathrm{mg} / \mathrm{L})$, while the Rabbit closure treatment $(7.11 \pm 0.08 \mathrm{mg} / \mathrm{L})$ was not significantly different from either grouping. No significant differences in initial DO were observed between resealed treatments (mean value of $0.15 \pm 0.16 \mathrm{mg} / \mathrm{L}$ ) and controls (mean value of $0.08 \pm 0.09 \mathrm{mg} / \mathrm{L}$ ). At 1 hour after resealing, there were slight, but still statistically significant, differences in HS and DO among stopper-type closures (Stelvin Reseal, Cork Reseal, Flip Top, and Rabbit), however at 10 hours of storage and after, no significant differences in HS or DO were observed between these treatments. Stelvin Reseal, Cork Reseal, Flip Top, and Rabbit treatments followed nearly identical trends in HS and DO evolution over the course of storage, therefore, oxygen concentrations of these treatments were averaged together as "StopperType Ave" in Figure 2.1a for clarity. HS concentrations of the stopper closures remained relatively constant throughout storage. During the first 10 hours, stopper closure DO values spiked at a rate of $0.30 \mathrm{mg} \mathrm{O} / \mathrm{L} / \mathrm{hr}$ as $\mathrm{HS}$ oxygen solubilized. DO continued to gradually increase until 49 hours, after which concentrations leveled off for the remainder of storage. Strong Vacuum closures evacuated gas from the headspace to reach an initial concentration 
of $1.42 \pm 0.14 \mathrm{mg} \mathrm{O}_{2} / \mathrm{L}$, comparable to levels in the Control Cork, $1.70 \pm 0.03 \mathrm{mg} \mathrm{O}_{2} / \mathrm{L}$. Wines resealed with the Strong Vacuum treatment accumulated DO at a rate of $0.061 \mathrm{mg}$ $\mathrm{O}_{2} / \mathrm{L} / \mathrm{hr}$ for the first 10 hours of storage, about 5 times slower than stopper-type treatments. The average DO accumulation rate for the remaining storage period decreased to 0.014 and $0.046 \mathrm{mg} \mathrm{O}_{2} / \mathrm{L} / \mathrm{hr}$ for Strong Vacuum and stopper-type treatments, respectively.

HS and DO concentrations measured at the end of storage (70 hours) for Exp 1 are shown in Table 2.1. Final DO correlated well with final $H S\left(R^{2}=0.98, p<0.0001\right)$ and initial HS $\left(\mathrm{R}^{2}=0.97, \mathrm{p}<0.0001\right)$. Bottles sealed with the strong vacuum closure maintained significantly lower final HS and DO levels than the stopper-type closure treatments $(2.12$ $\pm 0.58 \mathrm{mg} / \mathrm{L} \mathrm{HS}, 1.16 \pm 0.29 \mathrm{mg} / \mathrm{L} \mathrm{DO}$ vs mean values of $7.61 \pm 0.31 \mathrm{mg} / \mathrm{L} \mathrm{HS}, 4.88 \pm$ $0.30 \mathrm{mg} / \mathrm{L} \mathrm{DO})$. No significant difference in final HS was observed between Strong Vacuum and Control Cork $(1.49 \pm 0.16 \mathrm{mg} / \mathrm{L})$, however both were significantly higher than Control Stelvin $(0.14 \pm 0.09 \mathrm{mg} / \mathrm{L})$. Final DO of Strong Vacuum was significantly higher than Control Stelvin $(0.01 \pm 0.00 \mathrm{mg} / \mathrm{L})$ and Control Cork $(0.26 \pm 0.02 \mathrm{mg} / \mathrm{L})$. Although Strong Vacuum showed the lowest final HS and DO concentrations of the reseal treatments in this experiment, the gradual uptake in HS and DO observed over the 3 day storage period and high standard deviation of final values (coefficient of variation $(\mathrm{CV}=(\mathrm{SD} / \mathrm{mean}) * 100)$ of 27 and $25 \%$ for HS and DO, respectively) suggested that one of the triplicate closures failed to maintain an air-tight seal.

\subsubsection{Experiment 2- White wine sparged with inert gas before resealing}

Figure 2.1b presents the evolution of HS and DO over three days of storage after resealing in Exp 2. After 10 minutes of exposure to air, sparging with inert gas, and resealing, no significant differences in initial HS were observed between Stelvin Reseal 
$(0.53 \pm 0.12 \mathrm{mg} / \mathrm{L})$, Cork Reseal $(0.60 \pm 0.24 \mathrm{mg} / \mathrm{L})$, Rabbit $(0.18 \pm 0.08 \mathrm{mg} / \mathrm{L})$, and Control Stelvin $(0.11 \pm 0.02 \mathrm{mg} / \mathrm{L})$. Application of a strong vacuum closure after sparging did not help to significantly reduce initial HS levels any further $(0.77 \pm 0.14 \mathrm{mg} / \mathrm{L})$. All sparged treatments achieved initial HS levels significantly below Control Cork $(3.00 \pm 1.11$ $\mathrm{mg} / \mathrm{L}$ ). No significant differences in initial DO concentrations were seen among sparged treatments or between sparged treatments and the controls (values ranged from 0 to 0.15 $\mathrm{mg} / \mathrm{L}$ with a mean of $0.05 \mathrm{mg} / \mathrm{L}$ ). At 8 hours after resealing, there were slight, but still statistically significant, differences in DO among stopper-type closures (Stelvin Reseal, Cork Reseal, and Rabbit). For example, Rabbit closure DO (0.14 $\pm 0.01 \mathrm{mg} / \mathrm{L})$ was significantly lower than Cork Reseal $(0.30 \pm 0.09 \mathrm{mg} / \mathrm{L})$. However, at 14 hours of storage and onward, no significant differences in HS or DO were observed between these treatments. Stelvin Reseal, Cork Reseal, and Rabbit treatments followed nearly identical trends in HS and DO evolution over the course of storage; therefore, oxygen concentrations of these three treatments were averaged together as "Stopper-Type Ave" in Figure 2.1b for clarity. HS concentrations for the stopper-type closures remained relatively constant throughout storage. As observed in Exp 1, this experiment also showed that at least one of the triplicate Strong Vacuum stoppers suffered minor leakage, resulting in slight oxygen ingress during storage and a large standard deviation within the treatment $(\mathrm{CV}$ of 68 and $59 \%$ for final HS and DO, respectively). Despite the imperfect seal, HS and DO of the Strong Vacuum treatment remained relatively low over the course of this short term study. HS and DO concentrations measured at the end of storage (74 hours) for Exp 2 are shown in Table 2.1. Final HS and final DO were well correlated $\left(R^{2}=0.82, p<0.0001\right)$. Initial HS was well correlated with final HS $\left(\mathrm{R}^{2}=0.62, \mathrm{p}<0.0001\right)$, but not as well 
correlated with final DO $\left(\mathrm{R}^{2}=0.33, \mathrm{p}=0.006\right)$. Final HS for Strong Vacuum and Control Cork were comparable, with values of $1.78 \pm 1.21$ and $2.24 \pm 0.83 \mathrm{mg} / \mathrm{L}$, respectively. No significant difference in final DO between Strong Vacuum $(0.63 \pm 0.37 \mathrm{mg} / \mathrm{L})$ and Control Cork $(0.19 \pm 0.06 \mathrm{mg} / \mathrm{L})$ was observed, however Strong Vacuum final DO was significantly higher than Control Stelvin $(0.01 \pm 0.00 \mathrm{mg} / \mathrm{L})$. Although the final oxygen concentrations were similar in Strong Vacuum and Control Cork, the sharp increase in Strong Vacuum DO from 49 to 74 hours would likely continue if oxygen ingress through the leak in the closure's seal was not corrected, thus more significantly differentiating the two treatments. From 8 hours after resealing until the end of storage, DO in stopper-type closures maintained very similar levels as observed in Control Cork. No significant differences in final HS and DO were observed between Stelvin Reseal, Cork Reseal, and Rabbit (mean value of $0.40 \pm 0.19 \mathrm{mg} / \mathrm{L}$ HS, $0.17 \pm 0.08 \mathrm{mg} / \mathrm{L} \mathrm{DO}$ ) compared to Control Stelvin $(0.06 \pm 0.01 \mathrm{mg} / \mathrm{L}$ HS, $0.01 \pm 0.00 \mathrm{mg} / \mathrm{L}$ DO $)$ and Control Cork $(2.24 \pm 0.83 \mathrm{mg} / \mathrm{L}$ HS, $0.19 \pm 0.06 \mathrm{mg} / \mathrm{L} \mathrm{DO}$ ) (Table 2.1).

The Vacu Vin treatment (without sparing) was added to Exp 2 to compare its performance with the closure treatments in Exp 1. The small Vacu Vin hand pump removed oxygen from the saturated headspace to achieve a concentration of $3.33 \pm 0.37 \mathrm{mg} / \mathrm{L}$, which was not significantly different from initial HS in Control Cork $(3.00 \pm 1.11 \mathrm{mg} / \mathrm{L})$. Starting at 14 hours of storage, the upward trend in HS and increasingly large standard deviation indicated an apparent leak through the closure itself or in the seal at the bottle interface with one of the replicates. Final HS in the two Vacu Vin replicates without signs of leakage were 3.40 and $3.46 \mathrm{mg} / \mathrm{L}$, while the leaky replicate had a value of $6.62 \mathrm{mg} / \mathrm{L}$. Although the leak became apparent at 14 hours after storage, a corresponding uptake in DO occurred 
only after 49 hours. Final DO for the two replicates without leakage were 1.16 and 0.96 $\mathrm{mg} / \mathrm{L}$, while the leaky replicate had a value of $1.64 \mathrm{mg} / \mathrm{L}$. Compared to the Strong Vacuum treatment in Exp 1, final HS concentrations in Vacu Vin were higher $(4.49 \pm 1.84 \mathrm{mg} / \mathrm{L}$ vs $2.12 \pm 0.58 \mathrm{mg} / \mathrm{L})$ and final DO were similar $(1.26 \pm 0.35 \mathrm{mg} / \mathrm{L}$ vs $1.16 \pm 0.29 \mathrm{mg} / \mathrm{L})$.

\subsubsection{Experiment 3- Red wine resealed with popular closures}

Exp 1 and 2 clearly demonstrated the analogous performance of the various stopper-type closures (Stelvin Reseal, Cork Reseal, Flip Top, and Rabbit), therefore the Flip Top treatment was replaced by the Vacu Vin in Exp 3. Aside from this exception, the same treatments tested in Exp 1 were repeated on a red wine for Exp 3. Changes in HS and DO over three days of storage after resealing in Exp 3 are shown in Figure 2.1c. After air exposure and resealing, no significant differences in initial HS concentrations were observed between Stelvin Reseal $(7.08 \pm 0.02 \mathrm{mg} / \mathrm{L})$, Cork Reseal $(7.48 \pm 0.23 \mathrm{mg} / \mathrm{L})$, and Rabbit $(7.07 \pm 0.03 \mathrm{mg} / \mathrm{L})$ treatments. The Vacu Vin hand pump evacuated bottle headspace oxygen to reach $2.23 \pm 0.21 \mathrm{mg} / \mathrm{L}$, similar to Control Cork HS at $2.92 \pm 0.83$ $\mathrm{mg} / \mathrm{L}$. Application of the Strong Vacuum achieved a significantly lower initial HS level of $1.03 \pm 0.16 \mathrm{mg} / \mathrm{L}$. No significant differences in initial DO concentrations were seen among treatments or between the treatments and controls (values ranged from 0.01 to $0.52 \mathrm{mg} / \mathrm{L}$ with a mean of $0.16 \mathrm{mg} / \mathrm{L})$. At $8,22,30,52$, and 60 hours after resealing there were significant differences in DO of stopper closures (Stelvin Reseal, Cork Reseal, and Rabbit), with Cork Reseal typically having significantly higher values than the others. For example, at 60 hours of storage, DO of Cork Reseal $(3.43 \pm 0.11 \mathrm{mg} / \mathrm{L})$ was significantly higher than Stelvin Reseal $(2.85 \pm 0.38 \mathrm{mg} / \mathrm{L})$ and Rabbit $(2.77 \pm 0.16 \mathrm{mg} / \mathrm{L})$. However, no significant differences in HS values at 60 hours of storage were observed between Cork Reseal (6.55 
$\pm 0.09 \mathrm{mg} / \mathrm{L})$, Stelvin Reseal $(6.45 \pm 0.05 \mathrm{mg} / \mathrm{L})$, and Rabbit $(6.66 \pm 0.02 \mathrm{mg} / \mathrm{L})$. Although significant differences in DO between the stopper-type closures were apparent at some points over the course of storage, these treatments followed nearly identical trends in HS and DO evolution and no significant differences in final values were observed. Therefore, $\mathrm{O}_{2}$ concentrations of Stelvin Reseal, Cork Reseal, and Rabbit were averaged together as "Stopper-Type Ave" in Figure 2.1c.

HS in Control Cork and stopper-type treatments followed a slight downward trend, while Strong Vacuum HS increased at a slow, consistent rate and Vacu Vin remained nearly constant over storage. Relative stability in HS concentrations seen for both vacuum treatments contrasted the high variability observed in the previous two experiments. Leaks in either vacuum stopper seal were not a concern in Exp 3. General trends in evolution of DO were similar in both vacuum treatments and significantly higher than DO in Control Cork for nearly all points over the course of storage (Figure 2.1c). Accumulation of DO in red wine resealed with stopper-type closures was $0.13 \mathrm{mg} \mathrm{O} / \mathrm{L} / \mathrm{hr}$ for the first 8 hours of storage, which was over two times slower than that observed in the white wine resealed by stopper-type closures $(0.30 \mathrm{mg} \mathrm{O} / 2 / \mathrm{Lr}$ for the first 10 hours of storage). However, the average rates of DO accumulation for the remainder of storage were similar, 0.034 and $0.046 \mathrm{mg} \mathrm{O}_{2} / \mathrm{L} / \mathrm{hr}$, for red and white wine, respectively.

Table 2.1 shows final HS and DO concentrations measured at 70 hours in Exp 3. Final HS correlated well with final DO $\left(\mathrm{R}^{2}=0.92, \mathrm{p}<0.0001\right)$. Initial HS and final HS were also well correlated $\left(R^{2}=0.99, p<0.0001\right)$ in this experiment. No significant differences were found in HS between Control Cork $(2.18 \pm 0.50 \mathrm{mg} / \mathrm{L})$ and Vacu Vin $(1.81 \pm 0.17 \mathrm{mg} / \mathrm{L})$ at 70 hours of storage, while Strong Vacuum $(1.27 \pm 0.20 \mathrm{mg} / \mathrm{L})$ was 
significantly lower than Control Cork but not lower than Vacu Vin. All closure treatments and Control Cork had final HS levels significantly higher than Control Stelvin $(0.06 \pm 0.03$ $\mathrm{mg} / \mathrm{L})$. No significant differences were observed in final DO between Strong Vacuum $(0.48$ $\pm 0.07 \mathrm{mg} / \mathrm{L})$, Vacu Vin $(0.41 \pm 0.08 \mathrm{mg} / \mathrm{L})$, Control Stelvin $(0.01 \pm 0.00 \mathrm{mg} / \mathrm{L})$, or Control Cork $(0.06 \pm 0.03 \mathrm{mg} / \mathrm{L})$. Final HS and DO concentrations were significantly higher in Stelvin Reseal, Cork Reseal, and Rabbit (mean value of $6.42 \pm 0.10 \mathrm{mg} / \mathrm{L}$ HS, $3.22 \pm 0.40$ $\mathrm{mg} / \mathrm{L}$ DO) compared to controls and vacuum treatments.

\subsubsection{Experiment 4- Red wine resealed after increased air exposure time}

To simulate improper, yet potentially realistic, storage conditions and determine the impact of larger oxygen dosages on wine quality parameters, three air exposure times were used with only two closure types in Exp 4. HS and DO results for each closure (Stelvin Reseal and Strong Vacuum) are shown in separate figures (Figure 2.1d and 2.1e).

Initial HS concentration for Stelvin Reseal 10 minute was $6.86 \pm 0.08 \mathrm{mg} \mathrm{O}_{2} / \mathrm{L}$. Over the course of storage, HS levels gradually decreased as wine oxygen consumption progressed. Initial HS was slightly greater in the 24 hour exposure and 73 hour unsealed treatments, as they had more time to reach equilibrium with atmospheric oxygen concentrations (mean value of $7.11 \pm 0.04 \mathrm{mg} / \mathrm{L}$ ). After resealing the Stelvin treatment at 24 hours, HS was $7.01 \pm 0.03 \mathrm{mg} / \mathrm{L}$ and began gradually decreasing until the final measurement at 67 hours of $6.37 \pm 0.05 \mathrm{mg} / \mathrm{L}$. Final HS and DO concentrations at 67 hours of storage for resealed treatments and at 73 hours for the unsealed treatment are shown in Table 2.1. No significant differences in final HS were observed among either of the Stelvin Reseal treatments or between Stelvin Reseal treatments and the unsealed treatment. DO accumulation progressed at a slower rate in 10 minute Stelvin Reseal treatment compared 
to the 24 hour and unsealed treatments. Initial DO accumulation rate in the unsealed treatment was $0.13 \mathrm{mg} \mathrm{O}_{2} / \mathrm{L} / \mathrm{hr}$ for the first 8 hours and continued at this rate until 24 hours of exposure, after which the rate of accumulation decreased to an average of $0.03 \mathrm{mg}$ $\mathrm{O}_{2} / \mathrm{L} / \mathrm{hr}$ for the remainder of storage. DO values were similar in 24 hour Stelvin and unsealed treatments for the first 24 hours of storage. Large standard deviations in the 10 minute and 24 hour exposure time treatments become apparent after resealing at 24 hours for the 10 minute exposure treatment and at 30 hours for the 24 hour exposure treatment. In both Stelvin Reseal treatments, DO of one replicate remained lower than the other two over the course of storage. This variability cannot be accounted for due to variability in HS levels within those treatments, as HS standard deviations were low. Furthermore, the unsealed treatment did not exhibit similar variability in DO. Final DO in 73 hours unsealed treatment $(4.31 \pm 0.06 \mathrm{mg} / \mathrm{L})$ was significantly higher than 10 minute exposure Stelvin Reseal $(2.60 \pm 0.91 \mathrm{mg} / \mathrm{L})$, however neither were found to be significantly different from 24 hour exposure Stelvin Reseal (3.02 $\pm 0.49 \mathrm{mg} / \mathrm{L})$ (Table 1).

After 10 minutes of exposure to air and application of the strong vacuum, HS was reduced to $1.22 \pm 0.16 \mathrm{mg} / \mathrm{L}$. This value gradually increased over storage, indicating oxygen ingress through a leak in the seal. HS evolution in the 24 hour exposure Strong Vacuum and unsealed treatments followed similar trends for the first 24 hours. Application of the strong vacuum at 24 hours resulted in removal of approximately $75 \%$ of oxygen in the bottle headspace, and afterwards, HS levels remained relatively constant for the duration of storage. No significant difference in final HS values were observed between Strong Vacuum 24 hour exposure treatment $(1.09 \pm 0.02 \mathrm{mg} / \mathrm{L})$ and the unopened control $(0.10 \pm 0.04 \mathrm{mg} / \mathrm{L})$, however final HS in Strong Vacuum 10 minute $(2.13 \pm 1.16 \mathrm{mg} / \mathrm{L})$ 
was significantly higher than the control. An initial decrease in DO was observed in the Strong Vacuum 10 minute exposure treatment, likely from rapid oxygen consumption, but over the remainder of storage, DO in Strong Vacuum 10 minute exposure gradually increased. For the first 24 hours of storage, trends in DO accumulation were similar in the 24 hour exposure and unsealed treatments. Application of the strong vacuum at 24 hours of exposure removed approximately $75 \%$ of DO as well. Final DO in Strong Vacuum 10 minute exposure $(0.91 \pm 0.60 \mathrm{mg} / \mathrm{L})$ and Strong Vacuum 24 hour exposure $(0.58 \pm 0.11$ $\mathrm{mg} / \mathrm{L})$ treatments showed no significant difference from Control Stelvin $(0.01 \pm 0.00$ mg/L). Final HS and final DO were well correlated in this experiment $\left(\mathrm{R}^{2}=0.88, \mathrm{p}<0.0001\right)$.

\subsection{Sulfur dioxide}

Results for free, bound, and total $\mathrm{SO}_{2}(\mathrm{mg} / \mathrm{L})$ measured after storage for all four experiments are shown in Table 2.2. Significant differences in free and total $\mathrm{SO}_{2}$ were found between some treatments in $\operatorname{Exp} 1,3$, and 4, and significant differences in bound $\mathrm{SO}_{2}$ were observed between some treatments in Exp 1 and 2.

In Exp 1, free $\mathrm{SO}_{2}$ was significantly greater in Control Cork $(24 \pm 1 \mathrm{mg} / \mathrm{L})$ and Strong Vacuum $(24 \pm 1 \mathrm{mg} / \mathrm{L})$ compared to Control Stelvin $(18 \pm 1 \mathrm{mg} / \mathrm{L})$, while the remaining treatments (Stelvin Reseal, Cork Reseal, Rabbit, and Flip Top) with a mean value of $21 \pm 1 \mathrm{mg} / \mathrm{L}$ showed no significant differences from either grouping. Bound $\mathrm{SO}_{2}$ concentrations for Control Cork, Stelvin Reseal, Cork Reseal, Rabbit, and Flip Top (mean value of $74 \pm 2 \mathrm{mg} / \mathrm{L})$ were significantly lower than Control Stelvin $(87 \pm 7 \mathrm{mg} / \mathrm{L})$. Bound $\mathrm{SO}_{2}$ of Strong Vacuum $(82 \pm 3 \mathrm{mg} / \mathrm{L})$ was significantly higher than Cork Reseal $(71 \pm 2$ $\mathrm{mg} / \mathrm{L}$ ), but not significantly different from the other treatments or controls. Control Stelvin 
$(105 \pm 8 \mathrm{mg} / \mathrm{L})$ and Strong Vacuum $(106 \pm 2 \mathrm{mg} / \mathrm{L})$ had significantly higher total $\mathrm{SO}_{2}$ concentrations compared to Cork Reseal $(91 \pm 1 \mathrm{mg} / \mathrm{L})$. No significant differences in total $\mathrm{SO}_{2}$ were observed among Control Cork, Stelvin Reseal, Rabbit, and Flip treatments (mean value of $97 \pm 3 \mathrm{mg} / \mathrm{L}$ ) or when comparing those treatments to Control Stelvin, Strong Vacuum, and Cork Reseal. Linear correlations were found between final DO and bound $\mathrm{SO}_{2}\left(\mathrm{R}^{2}=0.41, \mathrm{p}=0.002\right)$ and total $\mathrm{SO}_{2}\left(\mathrm{R}^{2}=0.43, \mathrm{p}=0.003\right)$, but not free $\mathrm{SO}_{2}\left(\mathrm{R}^{2}=0.03\right.$, $\mathrm{p}=0.434)$. Bound and total $\mathrm{SO}_{2}$ were also well correlated $\left(\mathrm{R}^{2}=0.82, \mathrm{p}<0.0001\right)$.

No significant treatment impacts on either free or total $\mathrm{SO}_{2}$ were observed in Exp 2. Free $\mathrm{SO}_{2}$ concentrations ranged from 19 to $30 \mathrm{mg} / \mathrm{L}$ with a mean value of $24 \mathrm{mg} / \mathrm{L}$ and total $\mathrm{SO}_{2}$ ranged from 103 to $112 \mathrm{mg} / \mathrm{L}$ with an average of $107 \mathrm{mg} / \mathrm{L}$. Levels of bound $\mathrm{SO}_{2}$ were significantly lower in Control Stelvin, Strong Vacuum, Rabbit, and Vacu Vin (mean value of $80 \pm 4 \mathrm{mg} / \mathrm{L}$ ) when compared to Control Cork $(93 \pm 6 \mathrm{mg} / \mathrm{L})$. No significant differences in bound $\mathrm{SO}_{2}$ were observed between Stelvin Reseal $(84 \pm 3 \mathrm{mg} / \mathrm{L})$ and Cork Reseal $(85 \pm 4 \mathrm{mg} / \mathrm{L})$ when compared to the other treatments and controls. A correlation between bound and total $\mathrm{SO}_{2}\left(\mathrm{R}^{2}=0.30, \mathrm{p}=0.014\right)$ was found in this experiment.

Free $\mathrm{SO}_{2}$ was significantly lower in Cork Reseal $(14 \pm 1 \mathrm{mg} / \mathrm{L})$ and Rabbit $(14 \pm 2$ $\mathrm{mg} / \mathrm{L}$ ) compared to Control Stelvin, Control Cork, and Vacu Vin (mean value of $22 \pm 3$ $\mathrm{mg} / \mathrm{L}$ ) in Exp 3. No significant differences in free $\mathrm{SO}_{2}$ were observed between the controls and Vacu Vin compared to Stelvin Reseal (16 $\pm 1 \mathrm{mg} / \mathrm{L})$ and Strong Vacuum $(20 \pm 2 \mathrm{mg} / \mathrm{L})$. No significant differences in bound $\mathrm{SO}_{2}$ were observed in Exp 3 (mean value of $33 \pm 4$ $\mathrm{mg} / \mathrm{L})$. The only significant differences in total $\mathrm{SO}_{2}$ were between Control Cork $(58 \pm 4$ $\mathrm{mg} / \mathrm{L}$ ) compared to Stelvin Reseal (46 $\pm 2 \mathrm{mg} / \mathrm{L})$ and Rabbit $(47 \pm 4 \mathrm{mg} / \mathrm{L})$. Total $\mathrm{SO}_{2}$ concentrations measured in the remaining treatments and Control Stelvin ranged from 50 
to $55 \mathrm{mg} / \mathrm{L}$ with an average value of $52 \mathrm{mg} / \mathrm{L}$. Final DO and free $\mathrm{SO}_{2}$ were well correlated $\left(\mathrm{R}^{2}=0.72, \mathrm{p}<0.0001\right)$, while final $\mathrm{DO}$ and total $\mathrm{SO}_{2}$ also showed a linear relationship $\left(\mathrm{R}^{2}=0.44, \mathrm{p}=0.001\right)$.

In Exp 4, no significant differences between treatments were observed in bound $\mathrm{SO}_{2}$ measurements, and significant differences among treatments were the same in both free and total $\mathrm{SO}_{2}$. Red wine exposed to air for 73 hours had significantly lower free (11 \pm $4 \mathrm{mg} / \mathrm{L})$ and total $\mathrm{SO}_{2}(37 \pm 5 \mathrm{mg} / \mathrm{L})$ concentrations than Control Stelvin $(24 \pm 1$ and $55 \pm$ $4 \mathrm{mg} / \mathrm{L}$, free and total $\mathrm{SO}_{2}$ respectively). Stelvin Reseal with 24 hours exposure also had significantly lower free $(12 \pm 2 \mathrm{mg} / \mathrm{L})$ and total $\mathrm{SO}_{2}(39 \pm 1 \mathrm{mg} / \mathrm{L})$ concentrations compared to Control Stelvin. Decreases of free and total $\mathrm{SO}_{2}$ observed in both 10 minute exposure treatments and the Strong Vacuum 24 hour treatment were not significantly lower than the control. In this experiment, final DO correlated well with free $\mathrm{SO}_{2}\left(\mathrm{R}^{2}=0.51, \mathrm{p}<\right.$ $0.0001)$ and total $\mathrm{SO}_{2}\left(\mathrm{R}^{2}=0.58, \mathrm{p}<0.001\right)$. Total $\mathrm{SO}_{2}$ correlated well with free $\mathrm{SO}_{2}\left(\mathrm{R}^{2}\right.$ $=0.78, \mathrm{p}<0.0001)$ and bound $\mathrm{SO}_{2}\left(\mathrm{R}^{2}=0.54, \mathrm{p}<0.0001\right)$.

\subsection{Acetaldehyde levels in white wine}

No statistically significant differences in acetaldehyde concentration were observed in Exp 1. Concentrations for all controls and treatments ranged from 23 to $31 \mathrm{mg} / \mathrm{L}$ with a mean value of $27 \mathrm{mg} / \mathrm{L}$. The only differences in acetaldehyde observed in Exp 2 were between Control Stelvin $(22 \pm 4.1 \mathrm{mg} / \mathrm{L})$ and all other treatments, including Control Cork. Concentrations for all treatments and Control Cork ranged from 29 to $31 \mathrm{mg} / \mathrm{L}$ with a mean value of $30 \mathrm{mg} / \mathrm{L}$. No correlations between total or bound $\mathrm{SO}_{2}$ and acetaldehyde were found in either experiment. 


\subsection{Anthocyanin, tannin, phenolics, small and large polymeric pigments levels in red wine}

Statistically significant differences in small polymeric pigments (SPP), large polymeric pigments (LPP), anthocyanins, tannins, and phenolics were observed in Exp 3, however clear correlations between closure treatment or final DO were not apparent. Significant differences in SPP were observed between Control Stelvin $(0.91 \pm 0.04$ absorbance units, au) compared to Stelvin Reseal, Cork Reseal, and Strong Vacuum (mean value of $0.70 \pm 0.01 \mathrm{au}$ ). SPP values for Control Cork, Rabbit, and Vacu Vin (mean value of $0.80 \pm 0.05 \mathrm{au}$ ) were not significantly different from any treatments listed above. Values for LPP in both controls (3.0 $\pm 0.2 \mathrm{au})$ were significantly higher than Rabbit and Vacu Vin treatments (mean value of $2.3 \pm 0.1 \mathrm{au}$ ). No significant differences were found among the remaining treatments, LPP values ranged from 2.4 to 2.8 au with a mean of 2.5 au. Control Stelvin had significantly lower anthocyanin levels than Vacu Vin $(157 \pm 11$ vs $184 \pm 14$ mg/L malvidin-3-glucoside equivalents), while the remaining treatments were not statistically different from those two treatments (mean value of $168 \pm 7 \mathrm{mg} / \mathrm{L}$ malvidin-3glucoside eqv) or each other. Tannins in Control Cork (41 $\pm 5 \mathrm{mg} / \mathrm{L}$ catechin eqv) were significantly higher than all reseal treatments (mean value of $27 \pm 3 \mathrm{mg} / \mathrm{L}$ catechin eqv), while Control Stelvin $(33 \pm 4)$ values were similar to Control Cork and all reseal treatments. Phenolics were significantly different between Control Stelvin ( $84 \pm 9 \mathrm{mg} / \mathrm{L}$ catechin eqv) and Cork Reseal ( $70 \pm 2 \mathrm{mg} / \mathrm{L}$ catechin eqv). Phenolics for the remaining treatments ranged from 72 to 78 with a mean value of $74 \mathrm{mg} / \mathrm{L}$ catechin eqv, no significant differences were observed between these treatments or the Control Stelvin and Cork Reseal. 


\subsection{Volatile analysis}

Concentrations and relative peak areas of key aroma compounds measured in white wine (Exp 1) and red wine (Exp 4) are shown in Table 2.3. Isoamyl acetate and $\alpha$-terpineol were present above sensory thresholds in white wine (odor threshold values of $30 \mu \mathrm{g} / \mathrm{L}$ (Guth 1997) and $250 \mu \mathrm{g} / \mathrm{L}$ (Ferreira and others 2000), respectively), while the remaining quantified compounds were present below threshold concentrations and vitispirane $A \& B$, linalool, phenylacetic acid, $\beta$-damascenone, benzyl alcohol, TDN, and vanillin being below the limit of quantification. Closure treatments in Exp 1 did not impact levels of isoamyl acetate, vitispirane $\mathrm{A} \& \mathrm{~B}$, diethyl succinate, $\beta$-damascenone, benzyl alcohol, or TDN. Significant differences among treatments were observed with $\alpha$-terpineol, cis-linalool oxide, furfural, linalool, phenylethyl acetate, phenylacetic acid, and vanillin; yet, distinct correlations between closure method or final oxygen concentration were not apparent with each of these aroma compounds. For example, relative peak areas of phenylethyl acetate were significantly lower in Control Cork $(0.0130 \pm 0.0004)$ and all treatments (mean value of $0.0138 \pm 0.0005)$ compared to Control Stelvin $(0.0162 \pm 0.0012)$. Relative peak area of linalool was significantly lower in Stelvin Reseal, Cork Reseal, Rabbit, and Flip Top treatments (mean value of $0.00033 \pm 0.00004)$ compared to Control Stelvin $(0.00047 \pm$ 0.00004). A correlation between final DO and linalool was found $\left(\mathrm{R}^{2}=0.59, \mathrm{p}<0.0001\right)$, supporting that linalool levels were negatively influenced in part by the higher final DO observed in stopper-type closure treatments. No significant differences in linalool relative peak area were found between Strong Vacuum $(0.00040 \pm 0.00003)$ and either control, but the Strong Vacuum was not significantly different from three of the four stopper-type closures. No significant correlation was found between concentrations of linalool and cis- 
linalool oxide $\left(R^{2}=0.20, p=0.049\right)$. Concentrations of $\alpha$-terpineol were significantly higher in Control Stelvin $(378 \pm 54 \mu \mathrm{g} / \mathrm{L})$ than in Stelvin Reseal $(296 \pm 21 \mu \mathrm{g} / \mathrm{L})$, however no other significant differences between treatments were apparent.

Isoamyl acetate, $\alpha$-terpineol, vanillin, benzyl alcohol, and diethyl succinate were present above sensory thresholds in red wine in Exp 4 (odor threshold values of $30 \mu \mathrm{g} / \mathrm{L}$ (Guth 1997), $250 \mu \mathrm{g} / \mathrm{L}$ (Ferreira and others 2000), $200 \mu \mathrm{g} / \mathrm{L}$ (Guth 1997), $0.62 \mathrm{mg} / \mathrm{L}$ (Vilanova and Martínez 2007), and $1.2 \mathrm{mg} / \mathrm{L}$ (Peinado and others 2004), respectively). Vitispirane A\&B, linalool, phenylacetic acid, and $\beta$-damascenone were present below the limit of quantification. Closure and air exposure treatments in Exp 4 did not impact levels of furfural, $\alpha$-terpineol, benzyl alcohol, vanillin, or whisky lactone. Application of a vacuum resulted in significant decreases in isoamyl acetate, vitispirane $A \& B$, and linalool in at least one of the vacuum treatments, but not consistently across all instances of vacuum application. Significantly lower concentrations of isoamyl acetate were found in Strong Vacuum treatments exposed to air for 10 minutes $(78 \pm 2 \mu \mathrm{g} / \mathrm{L})$ and 24 hours $(74 \pm 3 \mu \mathrm{g} / \mathrm{L})$ when compared to Control Stelvin $(100 \pm 4 \mu \mathrm{g} / \mathrm{L})$. A significant decrease in isoamyl acetate compared to the control was also observed in the treatments receiving 73 hours of air exposure $(75 \pm 4 \mu \mathrm{g} / \mathrm{L})$. Although significant decreases in linalool relative peak area were observed in the Strong Vacuum 10 minute exposure treatment $(0.00035 \pm 0.00005)$ compared to the Stelvin Reseal 10 minutes $(0.00047 \pm 0.00003)$ and 24 hours $(0.00044 \pm$ 0.00002), the remaining treatments and control were not found to be statistically different from Strong Vacuum 10 minute. Significantly lower vitispirane A\&B levels were observed in the 24 hour exposure vacuum treatment $(0.00016 \pm 0.00001)$ and unsealed treatment $(0.00016 \pm 0.000003)$ compared to the control $(0.00020 \pm 0.00002)$ and Stelvin Reseal 10 
minute $(0.00020 \pm 0.00002)$. Relative peak area of $\beta$-damascenone was significantly higher in Strong Vacuum 24 hours $(0.00014 \pm 0.00001)$ compared to all other treatments (mean value of $0.00011 \pm 0.00001)$ excluding Strong Vacuum 10 minute $(0.00013 \pm 0.00002)$. Final DO correlated with phenylacetic acid $\left(\mathrm{R}^{2}=0.49, \mathrm{p}<0.0001\right)$ and phenylethyl acetate $\left(R^{2}=0.32, p=0.007\right)$ in Exp 4. The only significant difference in phenylacetic acid was between the unsealed treatment $(0.00244 \pm 0.00029)$ and all other treatments, including the control (mean value of $0.00363 \pm 0.00022$ ). The only significant difference in phenylethyl acetate was between Strong Vacuum 10 minute $(0.02821 \pm 0.00042)$ and the unsealed treatment $(0.02540 \pm 0.00082)$. Diethyl succinate concentrations were significantly lower in the unsealed treatment $(2.9 \pm 0.1 \mathrm{mg} / \mathrm{L})$ compared to the control $(3.2 \pm 0.0 \mathrm{mg} / \mathrm{L})$ and all treatments excluding Stelvin Reseal 24 hours (mean value of $3.25 \pm 0.18 \mathrm{mg} / \mathrm{L}$ ). No correlation was found between levels of linalool and cis-linalool oxide $\left(R^{2}=0.0004, p=0.931\right)$.

\section{Discussions}

Numerous publications have characterized wine dissolved oxygen levels and oxygen capacity under standard degrees of oxygen exposure encountered with various closure types over long term bottle maturation (Godden and others 2001; Ugliano and others 2012; Han and others 2015), under forced oxidation conditions where wine is saturated with oxygen (Balboa-Lagunero and others 2011; Ferreira and others 2015b), and before bottling with slow, continuous oxygen dosage either through micro-oxygenation treatment (Durner and others 2010; Ugliano and others 2012) or naturally through barrel aging (del Alamo-Sanza and others 2015; Oberholster and others 2015). However, in these studies, chemical analyses focused on long term impacts of oxygen over a period of months 
or years. Little is known about moderate to high dosage of oxygen (from $0.10 \mathrm{mg} / \mathrm{L}$ to atmospheric levels of about $7.5 \mathrm{mg} / \mathrm{L}$ ) and the short term changes this exposure may have on wine over a number of days. These specific conditions are especially relevant to storage of unfinished wine resealed for later consumption and for better understanding the potential rapid deterioration of quality and chemical changes in some wines over such a short period.

\subsection{Oxygen concentrations}

HS and DO concentrations were used to monitor oxygen trends in resealed wines over a 3 day storage period. Although DO does not provide measurement of total consumed oxygen (TCO), shifts in the HS and DO balance over time can be an indication of the progress of wine oxygen consumption. Over an exposure period of 10 minutes, oxygen concentrations in the bottle headspace nearly reached equilibrium with atmospheric oxygen levels in Exp 1 and one treatment in Exp 4 and reached complete equilibrium in the remaining experiments. Differences in initial HS values after exposure are likely due to slight variations in air flow and temperature in the surrounding environment at the time of each experiment. After resealing, additional oxygen may enter the bottle through an imperfect seal or leaks in the closure itself, supplying unwanted headspace oxygen during storage. As gaseous oxygen above the surface diffuses into the wine, the rate that oxygen accumulates in the liquid phase is dependent on the rate of oxygen consumption by wine components. If DO build up occurs at a faster rate than consumption or after a wine has reached its oxygen capacity to consume oxygen, the wine may reach a saturation point where no further oxygen can solubilize. At room temperature, wines reach saturation with approximately $8 \mathrm{mg} / \mathrm{L}$ oxygen (Singleton 1987), and around $5 \mathrm{mg} / \mathrm{L}$ at $20^{\circ} \mathrm{C}$. Oxygen consumption kinetics are largely dependent on the temperature and wine matrix, 
predominately phenolic compounds, $\mathrm{SO}_{2}, \quad$ copper, and iron levels (Danilewicz and Wallbridge 2010; Ferreira and others 2015b).

Stelvin Reseal, Cork Reseal, Rabbit, and Flip Top treatments (collectively called "stopper-type" closures) in Exp 1 and 3 replicated the simple closure conditions most frequently used to reseal bottles. A rapid uptake of DO occurred in white wine stoppertype closure treatments (Exp 1, Figure 2.1a) within the first 10 hours which was likely pulled from the HS pool rather than outside the bottle, then DO gradually continued to build up at a slower rate until reaching a relatively constant concentration of $4.6-5 \mathrm{mg} / \mathrm{L}$ at 49 hours until the end of storage. In other words, given the high HS concentrations, it is likely that oxygen solubilized faster than consumption could occur for the first 10 hours, and afterwards, oxygen consumption rate increased enough to continuously slow DO accumulation for the remainder of storage. Due to minimal concentrations of polyphenols in white wine, the major influences on oxygen consumption kinetics are iron and copper content (Singleton 1987; Danilewicz and others 2008; Carrascon and others 2015). The absence of polyphenols also leads to a lower oxygen capacity and white wine more rapidly exhibiting the deleterious signs of oxidation compared to a red wine exposed to similar conditions (Singleton 1987). Oxygen saturation occurs at approximately $7-7.75 \mathrm{mg} / \mathrm{L}$ in white wines (Danilewicz 2016), indicating that the wine in Exp 1 stopper-type treatments was likely not yet saturated when DO stabilized towards the end of storage. In red wine stopper-type closures (Exp 3, Figure 2.1c), a more gradual increase was seen in the first 40 hours of storage before DO leveled off at $2.9-3.4 \mathrm{mg} / \mathrm{L}$ for the remainder of storage. Given a longer storage period, DO levels would likely continue to steadily increase as consumption slows, until reaching a saturation point around $8 \mathrm{mg} / \mathrm{L}$ (Singleton 1987). 
Polyphenols are considered the most readily oxidizable wine component, and given their abundance in red wine, are generally the first compounds to interact with reactive oxygen species (Singleton 1987; Danilewicz 2011). In Exp 3, the slow uptake in DO for the first 40 hours may correspond to fast oxygen consumption by the oxidation of various phenolic species. From 40 hours until the end of storage, the relative stability in DO concentrations suggests that oxygen consumption began to occur fast enough to prevent DO accumulation. Total consumed oxygen was monitored in red wines saturated with oxygen over repeated cycles by Ferreira, et al (2015), and it was found that consumption within the first 24 hours ranged widely from $0.5-8.2 \mathrm{mg} \mathrm{O}_{2} / \mathrm{L}$ depending on the wine, while most red wines would need about 10 days to consume a second air saturation cycle. Their results help give a general sense of the length of time required for red wine oxygen consumption and support the trend observed in DO evolution in red wines in the present study (Exp 3 stopper-type treatments and $\operatorname{Exp} 4)$.

In the three experiments carried out with Stelvin Reseal, Cork Reseal, Rabbit, and Flip Top closures (Exp 1, 2, and 3), minimal to no statistically significant difference in HS or DO were observed among these treatments throughout the duration of the storage period. It was hypothesized that resealing the bottle with its original closure may result in minor, but still relevant, oxygen ingress through the damaged cork or loss of integrity of the screw cap seal. Although precise measurement of ingress was not carried out, the especially low oxygen headspace conditions in Exp 2 allow a general approximation of ingress through the stopper-type closures. HS levels remained nearly constant for the entire storage period, while DO was nearly constant for the first 24 hours followed by a minor decrease before leveling off again at the final measurement, trends which suggest that even if ingress 
through the screw cap, cork, Rabbit, or Flip Top had occurred, it did not appear to significantly influence DO over short term storage. Certainly, these conclusions cannot be extrapolated to longer storage durations or to damaged closures. Further study is needed to quantify potential ingress through these closures.

In Exp 4, despite two additional days of exposure to atmospheric oxygen levels, the final DO in 73 hours unsealed treatment was not significantly different from the 24 hour Stelvin Reseal treatment nor were the free, bound, or total $\mathrm{SO}_{2}$ levels significantly different from each other or the other treatments. Extended air exposure under room temperature storage conditions was carried out to ensure constantly higher supply of HS available to wine without unnaturally forcing oxidation reactions (through stirring, increased temperature, saturation with pure oxygen gas, etc). The results from this experiment suggested that the limiting step in the wine oxidation process under these conditions was neither concentration/availability of $\mathrm{HS}$ or the rate of oxygen dissolution (DO concentrations were continuing to gradually rise until the end of the 73 hour exposure time) but rather another variable, such as rate of oxygen consumption by wine components.

To even further delay loss of quality and the onset of spoilage over the shelf life of resealed wines, oxygen content in the headspace must be minimized. This can be achieved by either sparging the headspace with inert gas to displace oxygen or by application of a vacuum to forcibly pull the oxygen out. Nitrogen, carbon dioxide, and argon gases are commonly used throughout the food and beverage industries to provide perishable products with a blanket of protection from oxygen during processing (Ramesh and others 1999; Sanjeev and Ramesh 2006) and at packaging (McMillin 2008; Caleb and others 2013) to maintain maximum product freshness. In the context of winemaking, nitrogen gas is 
frequently used to sparge tank headspace, protect white wine from excessive oxygen pickup during pressing (Boselli and others 2010), and to sparge headspace on the bottling line (Kontoudakis and others 2008). Similarly, this practice can be employed when resealing unfinished bottles of wine. As seen in Exp 2, filling empty volume above the wine with a dosage of inert gas blend resulted in final HS and DO conditions that were not significantly different from unopened Stelvin bottles (Table 2.1). The gas used in the present study was a proprietary ratio of nitrogen, which is less dense than oxygen, and carbon dioxide and argon, which are denser than oxygen and will settle directly above the wine surface. With no adverse influences on wine quality due to their minimally reactive nature, in addition to availability for both commercial and consumer use, dosing headspace volume with inert gas (blend or single gas) before resealing with an air-tight closure works well for effectively minimizing further DO pick up during storage. Vacuum pumps specially fitted to attach to wine bottle closures offer another means for oxygen removal before storage. The partial vacuum achieved in Strong Vacuum 24 hour exposure treatment in Exp 4 caused a reduction in oxygen partial pressure above the wine which resulted in movement of oxygen from the liquid (decrease in DO from $3.01 \pm 0.06$ to $0.77 \pm 0.23$ $\mathrm{mg} / \mathrm{L}$ ) into the headspace to restore equilibrium, following Henry's Law. Reduced headspace pressure has been briefly mentioned in regards to wine left undisturbed in barrels for months to years (Peterson 1976), however little other work is available on the topic.

In contrast to the relatively air-tight seals maintained by the Rabbit, Flip Top, original screw cap, and original cork, it should be noted that across all four experiments, in three of the Strong Vacuum treatments and one Vacu Vin treatment, at least one of the experimental triplicates exhibited signs of leakage over the course of storage. These 
replicates were not excluded as outliers because the leakages were still considered to be representative of the inherent variability in vacuum stopper performance. Whether due to variance in manufacturing, positioning of stopper during vacuum application, or strength of the partial vacuum achieved, the minor leaks observed are a caveat for their use, necessitating intermittent monitoring of the seal's integrity and vacuum reapplication when storing wine for more than two days. Despite this, vacuum treatments were still highly successful at minimizing oxygen exposure over short term storage. When functioning properly, both the Vacu Vin and Strong Vacuum closure methods maintained low final DO values, thereby minimizing the potential for oxidative damage over short term storage in the present study. However, further study with a larger number of experimental replicates and longer storage time should be carried out to conclusively determine the true extent of leak occurrence with this closure type.

\subsection{Sulfur dioxide}

Although significant changes in free $\mathrm{SO}_{2}$ weren't apparent in Exp 1, the significant decrease in bound $\mathrm{SO}_{2}$ in most treatments (excluding Strong Vacuum) compared to Control Stelvin could potentially reflect free $\mathrm{SO}_{2}$ consumption and a shift from bound to free forms of $\mathrm{SO}_{2}$ to replenish free $\mathrm{SO}_{2}$ as levels were diminished upon antioxidant protection of wine. Considering the high reactivity of $\mathrm{SO}_{2}$ towards $\mathrm{H}_{2} \mathrm{O}_{2}$ formed during oxidation and low levels of phenolics in white wine, this pathway is in agreement with previous findings (Elias and Waterhouse 2010). While DO rapidly accumulated for the first part of storage in stopper-type treatments under saturated HS, it is likely that wine oxygen consumption by free $\mathrm{SO}_{2}$ was occurring simultaneously at a slower rate than $\mathrm{DO}$ accumulation. 
The opposite was observed in Exp 3, where stopper-type treatments had significantly lower free $\mathrm{SO}_{2}$ than controls and vacuum treatments, but no significant differences in bound $\mathrm{SO}_{2}$ were found. These trends could suggest that free $\mathrm{SO}_{2}$ was being consumed at a faster rate than it could be replenished, or that free $\mathrm{SO}_{2}$ had not yet been depleted to concentrations low enough to cause a shift from bound $\mathrm{SO}_{2}$. A similar trend to Exp 3 was observed in Exp 4, however, a significant reduction in free $\mathrm{SO}_{2}$ compared to Stelvin Control occurred only in the two treatments with most extreme degrees of oxygen exposure (Stelvin Reseal 24 hours and 73 hours unsealed). Additionally, it is somewhat surprising that under such high oxygen conditions, the treatment exposed to air for 73 hours still had $11 \pm 4 \mathrm{mg} / \mathrm{L}$ free $\mathrm{SO}_{2}$ available and no significant decrease in bound $\mathrm{SO}_{2}$ was observed, which would seem likely at this point due to the low levels of free $\mathrm{SO}_{2}$ (Waterhouse and others 2016). On the other hand, higher free $\mathrm{SO}_{2}$ concentrations than expected may be an artifact of the analysis method used to quantify free $\mathrm{SO}_{2}$ in the present work, aeration-oxidation (A-O). A-O, a standard protocol commonly used in wineries and wine research, requires an acidification step for volatization of free $\mathrm{SO}_{2}$ and 15 minutes of aeration to displace $\mathrm{SO}_{2}$ into a $\mathrm{H}_{2} \mathrm{O}_{2}$ trapping solution, which is then followed by titrimetric quantification. Acidification and the aeration period also allow for dissociation, and subsequent quantification, of weakly bound $\mathrm{SO}_{2}$ (Bertrand 1976) such as bisulfiteanthocyanin (Coelho and others 2015) and bisulfite-aldehyde (Bueno and others 2016) complexes, resulting in erroneously high measurements for "free" $\mathrm{SO}_{2}$ in wines with a significant amount of loosely bound $\mathrm{SO}_{2}$ adducts. Typically, this is more problematic in red wines and is a minor, but still relevant issue in white and rosé wines. Although measured as "free $\mathrm{SO}_{2}$ " by common methods (A-O and Ripper), weakly bound compounds 
provide little to no antimicrobial or antioxidant function in the wine (Jackson 2014). Therefore, free $\mathrm{SO}_{2}$ values reported in the present work may overestimate the true availability of free $\mathrm{SO}_{2}$ for protection against oxidation. Utilization of a more selective and precise measurement protocol would more accurately quantify specific $\mathrm{SO}_{2}$ forms and help more clearly differentiate $\mathrm{SO}_{2}$ concentrations between treatments.

The lack of significant differences in free and total $\mathrm{SO}_{2}$ between treatments compared to controls in Exp 2 can likely be attributed to the low oxygen concentrations across all treatments and short length of the study. HS and DO concentrations in the sparged treatments are comparable to conditions in unopened bottles, which after 6 months of storage have been found to undergo loss of free $\mathrm{SO}_{2}$ ranging from 5 to $15 \mathrm{mg} / \mathrm{L}$ (Godden and others 2001). The impact of potential oxygen ingress over periods greater than three days through resealed original closures, Rabbit, and Flip Top closures requires further study, hence the long term bottle storage results from other studies are not representative of how these closures would perform over a similar length of time. More significant treatment impacts on $\mathrm{SO}_{2}$ would likely emerge given more time in the unsparged Vacu Vin treatment, where DO sharply increased after 50 hours of storage, and considering the leak in the sparged Strong Vacuum treatment. Significantly higher concentrations of bound $\mathrm{SO}_{2}$ observed in Control Cork in this experiment are likely due to uncertainty in A-O measurement of $\mathrm{SO}_{2}$ and not due to influences from the treatment itself.

Loss of $\mathrm{SO}_{2}$ can be a rough indicator of the progress of oxidation in some wines. Obviously, given that direct reaction of $\mathrm{SO}_{2}$ and molecular oxygen is not significant in wine conditions, TCO is a superior marker of oxidation than DO in relation to $\mathrm{SO}_{2}$ consumption. However, in the early stages of oxygen consumption, DO can be a 
satisfactory indicator in some situations, as seen by Dimkou et al. (2011) where correlation between free $\mathrm{SO}_{2}$ and $\mathrm{DO}$ concentration was moderately strong at 12 days after bottling in a white wine $\left(\mathrm{R}^{2}=0.79, \mathrm{p}=0.05\right)$, but the strength of this correlation decreased with increasing storage period. In the present work, correlation between DO at the end of storage and free $\mathrm{SO}_{2}$ was not observed in white wine, relatively strong in red in $\operatorname{Exp} 3\left(\mathrm{R}^{2}=0.72\right.$, $\mathrm{p}<0.0001)$, and weaker but still apparent in $\operatorname{Exp} 4\left(\mathrm{R}^{2}=0.51, \mathrm{p}<0.0001\right)$. Stronger relationships between DO after short term storage and free $\mathrm{SO}_{2}$ would potentially be clear in studies carried out with larger sample sizes ( $n>21$ ) or testing a wider variety of wines. Alternatively, several recent publications have addressed the relationship between wine oxygen and $\mathrm{SO}_{2}$ consumption (Carrascon and others 2015; Ferreira and others 2015b; Danilewicz 2016; Waterhouse and others 2016) and from these works, it's becoming more apparent that $\mathrm{SO}_{2}$ consumption does not always occur directly with oxygen consumption, as may be expected given the use of $\mathrm{SO}_{2}$ as the main antioxidant added in wine. For example, stoichiometrically, $6 \mathrm{mg} / \mathrm{L}$ oxygen would require $24 \mathrm{mg} / \mathrm{L} \mathrm{SO}_{2}$ to completely quench the oxygen related reactions. However, Ferreira et al (2015) showed that in red wines with exceptionally fast initial oxygen consumption rates (7.9 - $8.2 \mathrm{mg} / \mathrm{L} / \mathrm{day})$, little to no $\mathrm{SO}_{2}$ consumption occurred over the first cycle of oxygen consumption. This observation could potentially explain the small decreases seen in free and bound $\mathrm{SO}_{2}$ in the present study. On the other hand, wines with slower initial oxygen consumption rates $(0.5$ - $0.8 \mathrm{mg} / \mathrm{L} /$ day) consumed more than $20 \mathrm{mg} / \mathrm{L} \mathrm{SO}_{2}$. Fast initial oxygen consumption is likely attributed to other wine components (such as ascorbic acid) reacting preferentially with quinones over $\mathrm{SO}_{2}$, meaning in these instances $\mathrm{SO}_{2}$ is unable to effectively protect against oxidation of polyphenols (Danilewicz 2016). 


\subsection{Acetaldehyde in white wine}

The sensory threshold for acetaldehyde in wine ranges between $100-125 \mathrm{mg} / \mathrm{L}$ (Silva and others 2011). Concentrations observed in white wine in Exp 1 and 2 were well below threshold, with the highest concentration being $31 \mathrm{mg} / \mathrm{L}$. The lack of large treatment related changes in acetaldehyde makes sense given the relatively mild oxygen conditions in Exp 1 treatments and low oxygen conditions in Exp 2 treatments and when compared to findings in other research (Escudero and others 2002). For example, in 24 of the 27 wines tested by other authors, no significant increases in acetaldehyde were observed in saturated wines stored under an oxygen saturated headspace for one week (Escudero and others 2002). Increases in acetaldehyde result from ethanol oxidation and dissociation of acetaldehyde-bisulfite complexes as the bound pool of $\mathrm{SO}_{2}$ is depleted to replenish levels of free $\mathrm{SO}_{2}$ after quenching oxidation reactions (Wildenradt and Singleton 1974; Jackowetz and Mira de Orduña 2013b). Significant decreases in bound $\mathrm{SO}_{2}$ were observed between Stelvin Control and all reseal treatments excluding Strong Vacuum in Exp 1, however this did not correlate with a significant increase in acetaldehyde for these treatments. Considering that sufficient levels of free $\mathrm{SO}_{2}$ were available to quench any potential acetaldehyde formation and no increase in bound $\mathrm{SO}_{2}$ were observed in either white wine experiment also suggested that de novo formation from ethanol oxidation was not occurring. The higher acetaldehyde concentrations observed in Exp 2 may be due to the fact that Exp 2 was carried out after Exp 1, perhaps allowing more time for minor increases in acetaldehyde to occur during pre-experiment storage of the wine used in Exp 2. 


\subsection{Anthocyanin, tannin, phenolics, small and large polymeric pigments levels in red wine}

Statistically significant differences in small polymeric pigments (SPP), large polymeric pigments (LPP), anthocyanins, tannins, and total phenolics were observed in red wine in Exp 3, however clear correlations between closure treatment or final DO were not apparent. The differences observed may suggest that compositional changes were in fact occurring over the three day period, but additional time, allowing for increased oxygen consumption and progression of subsequent reactions in general, would be necessary for clear differentiation between treatments. Reaction rates of a model quinone with a model phenol were relatively slow compared to the reaction of the quinone with other wine nucleophiles such as varietal thiols and $\mathrm{SO}_{2}$ (Nikolantonaki and Waterhouse 2012), further supporting that impacts on total phenolics will be delayed until after kinetically preferential reactions take place. Increased oxygen exposure indirectly enhances color intensity through consumption of $\mathrm{SO}_{2}$, which minimizes the potential for $\mathrm{SO}_{2}$ bleaching of anthocyanins over storage (Fulcrand and others 2004), also supporting that significant changes in anthocyanin content likely require additional time. Long term changes in phenolic composition under small, controlled oxygen dosages typical of micro-oxygenation, barrel aging, and closure-derived oxygen during long term bottle storage are well studied (Wirth and others 2010; Ugliano and others 2012; Avizcuri and others 2016). For example, wines sealed with closures allowing higher oxygen transmission rates $(12 \mu \mathrm{g} \mathrm{O} /$ bottle/day compared to other treatments with $8,2,1 \mu \mathrm{g} \mathrm{O}_{2} /$ bottle/day) over 10 months of aging underwent significant decreases in anthocyanins, decreases in flavon-3-ol monomers, increases in color intensity, and increases in hue markers for browning (Wirth and others 
2010). Further work is needed to clearly understand the short term chemical and sensory changes in color and mouthfeel compounds under oxygen rich environments relevant to the shelf life of wines resealed for later consumption.

\subsection{Volatile aromas}

Concentrations of the key odor-active compounds that shape the aroma and flavor profile of a young wine are determined by grape cultivar, growing region and climate, and techniques employed during winemaking. The aroma profile of Riesling is predominately characterized by TDN, $\beta$-damascenone, linalool, and linalool oxides (Simpson 1978; Schüttler and others 2015). Cabernet Sauvignon aroma is characterized by methoxypyrazines (particularly 3-isobutyl-2-methoxypyrazine and 3-isopropyl-2methoxypyrazine), polyfunctional thiols (such as 3-mercaptohexanol and its acetate), and $\beta$-damascenone (Slingsby and others 1980; Ferreira and others 2000; Blanchard and others 2004; Pineau and others 2007). Esters formed during fermentation (such as isoamyl acetate, phenylethyl acetate, and diethyl succinate), also contribute to the overall fruity and fresh notes of both white and red wines (Balboa-Lagunero and others 2011; Ugliano and others 2015).

Extensive work has been published and reviewed on the positive and negative roles played by oxygen on modulations in aroma and flavor profile during bottle maturation (Ugliano 2013), with specific impacts of oxygen on overall wine quality still being difficult to define due to matrix interactions with other wine components causing masking or enhancement and differences in the degree of oxygen consumption of a given oxygen dose in different wines. Aging related increases in $\beta$-damascenone, TDN, vitispirane, and other norisoprenoids are likely the result of acid hydrolysis of glycosidically bound precursors 
(Winterhalter and others 1990). TDN and vitispirane are very stable and typically do no undergo oxygen related degradation over aging (Simpson 1978). On the other hand, $\beta$ damascenone concentrations can significantly decrease in cases where binding by $\mathrm{SO}_{2}$ to form odorless derivatives (Daniel and others 2004) and/ or oxidative degradation (Carrascon and others 2015) occur at faster rates than release from glycosylated precursors. But reports regarding $\beta$-damascenone are inconsistent, and some found increases in $\beta$ damascenone with increasing oxygen exposure (Ugliano and others 2015). Fermentationderived esters (isoamyl acetate) and ethyl esters of acids (diethyl succinate) generally increase over aging due to gradual shifts in esterification-hydrolysis equilibrium, with the rate dependent on $\mathrm{pH}$, storage temperature and storage period, and not usually dependent on oxygen (Ramey and Ough 1980). Shifts towards equilibrium occur very slowly under typical wine storage conditions and it may take years to reach full equilibrium (Simpson 1978). For example, larger increases in diethyl succinate occurred in the same Riesling aged at $50{ }^{\circ} \mathrm{C}$ for 1 month $(4.4 \mathrm{mg} / \mathrm{L})$ compared to $15^{\circ} \mathrm{C}$ for 2 months $(2.4 \mathrm{mg} / \mathrm{L})$, and similar increases occurred when the wine was stored under both air $(4.4 \mathrm{mg} / \mathrm{L})$ and nitrogen (3.8 $\mathrm{mg} / \mathrm{L})$ at $50^{\circ} \mathrm{C}$ (Simpson 1978). Succinic acid is a major acid in Riesling (Simpson 1978) thus accounting for increases in diethyl succinate from esterification over long term aging. Other work also supports the lack of oxygen damage specifically to isoamyl acetate and fermentation-derived esters in general over long term storage (Carrascon and others 2015; Ugliano and others 2015; Waterhouse and others 2016); therefore, short term changes would not be expected. Most likely, loss of general fruity aroma associated with oxidation can be explained by decreases in $\beta$-damascenone and varietal thiols coupled with masking effects by increased levels of odiferous aldehydes (particularly methional, 
phenylacetaldehyde, and acetaldehyde) (Ferreira and others 1997; Escudero and others 2002; Balboa-Lagunero and others 2011; Ugliano 2013).

\subsubsection{Short term oxygen related impacts on volatile aromas}

A general assessment of aromas was carried out to characterize potential impacts of closure method or oxygen damage over short term storage (Table 2.3). Closure treatments on white wine (Exp 1) did not impact levels of $\beta$-damascenone, vitispirane A\&B, TDN, diethyl succinate, isoamyl acetate, or benzyl alcohol. The lack of treatment influence on vitispirane $\mathrm{A} \& \mathrm{~B}$ and TDN is in agreement with other work that has found these norisoprenoids to be relatively stable against oxidative degradation over aging (Simpson 1978). Oxidative degradation or binding by free $\mathrm{SO}_{2}$ of $\beta$-damascenone did not appear to be an issue over short term storage in white wine, likely due to minimal oxidation and $\mathrm{SO}_{2}$ more favorably binding to more abundant, reactive compounds. The lack of oxygen related decreases in isoamyl acetate and diethyl succinate in Exp 1 is in agreement with other works (Simpson 1978; Carrascon and others 2015; Ugliano and others 2015; Waterhouse and others 2016). Significant differences among treatments in white wine were observed with $\alpha$-terpineol, cis-linalool oxide, furfural, linalool, phenylethyl acetate, phenylacetic acid, and vanillin. Distinct correlations between closure method were not apparent with these aroma compounds and correlations between final oxygen concentration was only apparent in the case of linalool. Furthermore, many of the differences observed may be statistically significant but have little practical implications. For example, Stelvin Reseal had significantly lower concentrations of $\alpha$-terpineol than Control Stelvin, however neither were significantly different from the remaining treatments. Final DO levels were significantly greater in Stelvin Reseal than Control Stelvin, yet, the other stopper 
treatments also had greater final DO but no significant decreases in $\alpha$-terpineol. Linalool is generally more sensitive to oxidation (Ribéreau-Gayon 1975; Bordiga and others 2013), and treatments with the highest final DO (Stelvin Reseal, Cork Reseal, Rabbit, and Flip Top) had significantly lower linalool concentrations than Control Stelvin. Only a very weak correlation between linalool and cis-linalool oxide levels was found $\left(R^{2}=0.20, p=0.049\right)$, likely because not all linalool oxide isomers were quantified. The remaining compounds with significant differences between treatments were not necessarily expected to be oxygen sensitive based on other studies: furfural, phenylethyl acetate, phenylacetic acid, and vanillin (Chatonnet and others 1999; Ugliano and others 2015). Differences between treatments for these compounds may be due to poor reproducibility during extraction or the concentrations near the method detection limit making accurate quantification more challenging.

Closure and air exposure treatments on red wine (Exp 4) did not impact levels of furfural, $\alpha$-terpineol, benzyl alcohol, vanillin, or whisky lactone. These compounds are known to be relatively stable against oxidative degradation over aging as mentioned above, particularly oak-derived furfural, vanillin, and whisky lactone (Chatonnet and others 1999), with vanillin and furfural concentrations increasing under increased oxygen exposure (Slingsby and others 1980; Balboa-Lagunero and others 2011; Ferreira 2014). Significant decreases in phenylacetic acid, phenylethyl acetate, and diethyl succinate were observed in the 73 hours unsealed treatment, with phenylacetic acid and phenylethyl acetate levels being correlated with final $\mathrm{DO}\left(\mathrm{R}^{2}=0.49, \mathrm{p}<0.0001\right.$ and $\mathrm{R}^{2}=0.32, \mathrm{p}=0.007$, respectively), and therefore seemed to be partially the result of increased oxygen exposure. However, these compounds are not necessarily expected to be oxygen sensitive (Simpson 
1978; Carrascon and others 2015; Ugliano and others 2015; Waterhouse and others 2016). Decreases in phenylethyl acetate and diethyl succinate may be related to oxidative degradation of acetic acid/ phenylethyl alcohol and succinic acid, respectively, resulting in increased hydrolysis to shift equilibrium to replenish the lost compound. Significant differences observed with the remaining compounds do not seem to follow trends based on closure type or final DO concentrations.

\subsubsection{Effects of vacuum closure method on volatile aromas}

Anecdotal concerns have been raised over vacuum closure systems removing aromas as oxygen is pulled from the headspace, thereby diminishing the aromatic intensity of wine that these systems often claim to preserve. Effect of vacuum strength on potential aroma deterioration and the overall effectiveness of vacuum as a resealing method was tested by utilizing two vacuum closure systems in this study. The Vacu Vin closure system removed oxygen to achieve initial HS concentrations of 3.33 and $2.23 \mathrm{mg} / \mathrm{L}$ in the white and red wine experiments, respectively. The Strong Vacuum treatment achieved and maintain significantly stronger vacuum levels, with initial HS concentrations ranging between 1.03 and $1.72 \mathrm{mg} / \mathrm{L}$. Furthermore, results from the Strong Vacuum 24 hour exposure treatment in Exp 4 showed removal of nearly $75 \%$ of the DO (Figure 2.1e). Pulling dissolved oxygen from solution essentially decreases the pool of molecular oxygen available to form damaging reactive species. No correlations between strong vacuum treatment and deterioration of aroma compounds were observed in white wine (Exp 1), while only minimal deleterious impacts to red wine aroma were observed (Exp 4). Statistically significant decreases in isoamyl acetate were observed in both vacuum treatments (and the 73 hours of air exposure), Strong Vacuum 24 hours exposure (and the 
73 hours of air exposure) in vitispirane A\&B, and Strong Vacuum 10 minutes exposure for linalool. Although decreases were seen in at least one strong vacuum treatment for each of these compounds, the practical impact on sensory quality of the wine was not assessed with a formal sensory test, but is likely negligible. Further analytical and sensory testing should be carried out to better understand the impact of vacuum closures on wine sensory quality. However, from the results observed in the present study, the vacuum's ability to delay oxidative spoilage by reducing $\mathrm{HS}$ and DO likely outweighs any small damage on aroma it may have.

Any decrease in concentration of volatile aroma compounds by Vacu Vin or Strong Vacuum closures is likely due to decreased concentrations in the headspace as air is pulled out during vacuum application, thus causing a disruption in equilibrium concentrations between the gas and liquid phases. Studies utilizing dynamic headspace dilution with realtime analysis in ethanolic solutions suggest that aroma release from the liquid will likely replenish the majority of aroma lost by the disruption as equilibrium is reachieved. In ethanolic solutions, ethanol acts to enhance mass transfer of volatiles from the liquid to air phase compared to aqueous solutions due to decreased surface tension, with aroma release dependent on the air-liquid partition coefficient $\left(\mathrm{K}_{\mathrm{al}}\right)$ of individual volatiles. Under dynamic conditions where the headspace was continuously diluted with inert gas, there was an initial decrease in headspace concentrations of volatiles until steady state conditions were reachieved and final HS concentrations were maintained at levels close to the original equilibrium concentrations or slightly below, dependent on $\mathrm{K}_{\mathrm{al}}$ (Tsachaki and others 2005). Studies carried out in real wines found that components of the wine matrix (such as certain proteins) result in greater decreases in final HS concentrations at steady-state conditions 
(Tsachaki and others 2009). After 10 minutes of dynamic headspace dilution, final steadystate concentrations of volatiles spiked into red and white wine were significantly depleted compared to model ethanolic solutions. For 1-octen-3-one, eucalyptol, and ethyl-2butenoate after dynamic headspace dilution, concentrations between $47-60 \%$ of original headspace equilibrium values were found in spiked wines compared to $91-97 \%$ of original values in spike ethanolic solutions. Whereas final concentrations for $p$-cymene were only 4-9\% of original values spiked in wine compared to $12 \%$ of original concentrations spiked in an ethanolic solution. Differences in the net effect of headspace dilution between aromas are the result of different physiochemical properties (characterized by $\mathrm{K}_{\mathrm{al}}$ ) (Tsachaki and others 2005), while the differences between simple ethanol solutions and wine may be due to the presence of certain proteins altering the air-liquid barrier properties (Tsachaki and others 2009). Results from these headspace dilution studies could help explain the impact of vacuum closure treatment on significantly decreasing concentrations of certain aromas while resulting in no change of others in red wine in Exp 4. Further studies are needed to ascertain the impact on a wider range of volatile aromas, the potential of repeated vacuum treatment on the same wine to further deplete aromas, and the effect that the strength of vacuum used has on aroma decrease. This study was a first step in assessing vacuum impacts on aroma relative to the beneficial ability to decrease oxygen in bottles during storage.

\section{Conclusions}

Excessive air exposure leads to wine spoilage while low to moderate exposure over months to years promotes wine complexity through enhancements in flavor, color stability, and mouthfeel. The minor oxygen induced changes from dosages that lie in between those 
two extremes over just several days of exposure are less well understood. In the present work, white wine was exposed to initial HS concentrations after resealing ranging from as high as $7.91 \pm 0.62 \mathrm{mg} / \mathrm{L}$ (Rabbit closure treatment) to as low as $0.18 \pm 0.08 \mathrm{mg} / \mathrm{L}$ (Rabbit closure treatment sparged with an inert gas blend). After three days of storage, all white wine treatments had final DO levels ranging between $5.02 \pm 0.41 \mathrm{mg} / \mathrm{L}$ (Rabbit closure) to $0.11 \pm 0.01 \mathrm{mg} / \mathrm{L}$ (Rabbit closure treatment sparged with an inert gas blend). No significant increases in acetaldehyde concentration were observed under these oxygen conditions (Exp $1 \&$ 2). Red wine (Exp 3) was exposed to between $7.48 \pm 0.23 \mathrm{mg} / \mathrm{L}$ (Cork Reseal closure treatment) to $1.03 \pm 0.16 \mathrm{mg} / \mathrm{L}$ (Strong Vacuum closure treatment) initial HS concentrations after resealing, with final DO after three days of storage ranging from 3.44 $\pm 0.29 \mathrm{mg} / \mathrm{L}$ (Rabbit closure) to $0.41 \pm 0.08 \mathrm{mg} / \mathrm{L}$ (Vacu Vin closure). Significant differences in small polymeric pigments, large polymeric pigments, anthocyanins, and tannins were found; however, the influence of oxygen on these differences did not follow clear trends (Exp 3). Potential oxygen related decreases in linalool were observed in white wine (Exp 1) and in phenylethyl acetate, phenylacetic acid, and diethyl succinate in red wine (Exp 4).

Considering the lack of significant changes in acetaldehyde, mouthfeel, and color compounds, and only minimal impacts on volatile aromas, this work demonstrated the vital role $\mathrm{SO}_{2}$ plays in protecting wine quality against significant oxidative damage in the early stages of oxygen exposure. In white wine treatments with significantly higher final DO than the controls, significant reductions in bound $\mathrm{SO}_{2}$ were observed after three days of storage, but no significant reductions in free $\mathrm{SO}_{2}$. In some red wine treatments exposed to similar HS, significant loss of free $\mathrm{SO}_{2}$ occurred without changes in bound $\mathrm{SO}_{2}$. In the most 
extreme oxygen exposure treatment (red wine with 73 hours of exposure to air), greater loss of free $\mathrm{SO}_{2}$ was apparent, however free $\mathrm{SO}_{2}$ was still present and still no significant decreases in bound $\mathrm{SO}_{2}$ were seen.

Keeping the original closure seal intact until ready to consume the entire bottle is the gold standard in enjoying wine at the level of quality the winemaker intended. Obviously, this ideal situation is not always realistic for home wine consumers or winery tasting rooms and restaurants that serve wine by the glass. Therefore, a satisfactory method for maintaining the original quality, or as close to it as possible, of the unfinished portion of wine after several days of storage is needed. In the present study, oxygen ingress through leaks in the closure or at the bottle-closure interface were not a significant issue over short term storage when resealing with the original screw cap, original cork, Rabbit, or Flip Top closures. Resealing with both Rabbit and Flip Top closures provided an equivalent air-tight seal to that of the bottle's original closure and offered no additional benefits in preserving wine quality. Through simply preventing further oxygen ingress, Rabbit and Flip Top closure methods are satisfactory for maintaining wine quality over short term storage (approximately three days). However, because this function is already achieved by resealing with the original screw cap or cork, the purchased alternative stoppers do not provide inherent advantages, but would serve well if replacing damaged or lost original closures. Further steps to preserving wine quality beyond simply resealing with the original closure can be taken by using inert gas to sparge the headspace directly above the wine or applying a vacuum closure to remove oxygen from the environment. Minimal deleterious effect of vacuum application on wine aroma was observed in red wine and no negative impacts were apparent in white wine. 
Results from the present study represent the first steps in better understanding short term impacts of oxygen exposure on quality over the shelf life of wine resealed for later consumption, but several limitations should be noted. For instance, only a small number of volatiles representative of key wine aroma classes were measured, no formal sensory testing was conducted to determine the perceivable implications of closure or oxygen treatment, and wines stripped of $\mathrm{SO}_{2}$ were not tested to demonstrate the potential for more extreme changes to occur over this period in wines not adequately protected by $\mathrm{SO}_{2}$. Finally, wines were stored at room temperature in the present study, but the changes in composition should also be examined in wines stored under refrigeration temperatures, as it would be expected that cooler temperatures decrease oxygen solubility and the rate of unwanted oxidation reactions. In the future, further tests should be carried out to address these questions.

\section{References}

Balboa-Lagunero T, Arroyo T, Cabellos JM, Aznar M. 2011. Sensory and olfactometric profiles of red wines after natural and forced oxidation processes. Am J Enol Vitic 62:527-5365. doi: 10.5344/ajev.2011.10080.

Bekker MZ, Day MP, Holt H, and others. 2016a. Effect of oxygen exposure during fermentation on volatile sulfur compounds in Shiraz wine and a comparison of strategies for remediation of reductive character. Aust J Grape Wine Res 22:24-35. doi: 10.1111/ajgw.12172.

Bekker MZ, Mierczynska-Vasilev A, Smith PA, Wilkes EN. 2016b. The effects of pH and copper on the formation of volatile sulfur compounds in Chardonnay and Shiraz wines post-bottling. Food Chem 207:148-156. doi: 10.1016/j.foodchem.2016.03.060.

Benkwitz F, Nicolau L, Lund C, and others. 2012. Evaluation of key odorants in Sauvignon blanc wines using three different methodologies. J Agric Food Chem 60:6293-6302. doi: 10.1021/jf300914n.

Blanchard L, Darriet P, Dubourdieu D. 2004. Reactivity of 3-Mercaptohexanol in Red Wine: Impact of Oxygen, Phenolic Fractions, and Sulfur Dioxide. Am J Enol Vitic 55:115-120. 
Bobet RA, Noble AC, Boulton RB. 1990. Kinetics of the ethanethiol and diethyl disulfide interconversion in wine-like solutions. J Agric Food Chem 38:449-452. doi: $10.1021 / \mathrm{jf00092a025.}$

Boselli E, Di Lecce G, Alberti F, Frega NG. 2010. Nitrogen gas affects the quality and the phenolic profile of must obtained from vacuum-pressed white grapes. LWT Food Sci Technol 43:1494-1500. doi: 10.1016/j.lwt.2010.03.006.

Bracher PJ, Snyder PW, Bohall BR, Whitesides GM. 2011. The Relative Rates of ThiolThioester Exchange and Hydrolysis for Alkyl and Aryl Thioalkanoates in Water. Orig Life Evol Biosph 41:399-412. doi: 10.1007/s11084-011-9243-4.

Bueno M, Carrascon V, Ferreira V. 2016. Release and Formation of Oxidation-Related Aldehydes during Wine Oxidation. J Agric Food Chem 64:608-617. doi: 10.1021/acs.jafc.5b04634.

Caillé S, Samson A, Wirth J, and others. 2010. Sensory characteristics changes of red Grenache wines submitted to different oxygen exposures pre- and post-bottling. Anal Chim Acta 660:35-42. doi: 10.1016/j.aca.2009.11.049.

Chatonnet P, Cutzach I, Pons M, Dubourdieu D. 1999. Monitoring Toasting Intensity of Barrels by Chromatographic Analysis of Volatile Compounds from Toasted Oak Wood. J Agric Food Chem 47:4310-4318.

Chen Y, Jastrzembski JA, Sacks GL. 2016. Copper-Complexed Hydrogen Sulfide in Wine: Measurement by Gas Detection Tubes and Comparison of Release Approaches. Am J Enol Vitic. doi: 10.5344/ajev.2016.16024.

Chinnici F, Sonni F, Natali N, Riponi C. 2013. Oxidative evolution of (+)-catechin in model white wine solutions containing sulfur dioxide, ascorbic acid or gallotannins. Food Res Int 51:59-65. doi: 10.1016/j.foodres.2012.11.013.

Clark AC, Grant-Preece P, Cleghorn N, Scollary GR. 2015. Copper(II) addition to white wines containing hydrogen sulfide: Residual copper concentration and activity. Aust J Grape Wine Res 21:30-39. doi: 10.1111/ajgw.12114.

Cullere L, Cacho J, Ferreira V. 2007. An Assessment of the Role Played by Some Oxidation-Related Aldehydes in Wine Aroma. J Agric Food Chem 55:876-881.

Danilewicz JC. 2016. Reaction of oxygen and sulfite in wine. Am J Enol Vitic 67:13-17. doi: 10.5344/ajev.2015.15069.

Danilewicz JC. 2007. Interaction of sulfur dioxide, polyphenols, and oxygen in a winemodel system: Central role of iron and copper. Am J Enol Vitic 58:53-60.

Danilewicz JC, Seccombe JT, Whelan J. 2008. Mechanism of Interaction of Polyphenols, Oxygen, and Sulfur Dioxide in Model Wine and Wine. Am J Enol Vitic 59:128136.

Danilewicz JC, Wallbridge PJ. 2010. Further Studies on the Mechanism of Interaction of Polyphenols, Oxygen, and Sulfite in Wine. Am J Enol Vitic 61:166-175. 
Darias-Martín JJ, Rodríguez O, Díaz E, Lamuela-Raventós RM. 2000. Effect of skin contact on the antioxidant phenolics in white wine. Food Chem 71:483-487. doi: 10.1016/S0308-8146(00)00177-1.

Day MP, Schmidt SA, Smith PA, Wilkes EN. 2015. Use and impact of oxygen during winemaking. Aust J Grape Wine Res 21:693-704. doi: 10.1111/ajgw.12199.

del Alamo-Sanza M, Laurie VF, Nevares I. 2015. Wine evolution and spatial distribution of oxygen during storage in high-density polyethylene tanks. J Sci Food Agric 95:1313-1320. doi: 10.1002/jsfa.6824.

Dimkou E, Ugliano M, Dieval JB, and others. 2011. Impact of Headspace Oxygen and Closure on Sulfur Dioxide, Color, and Hydrogen Sulfide Levels in a Riesling Wine. Am J Enol Vitic 62:261-269. doi: 10.5344/ajev.2011.11006.

Eschenbruch R. 1974. Sulfite and Sulfide formation during winemaking - A Review. Am J Enol Vitic 25:23-27.

Escudero A, Asensio E, Cacho J, Ferreira V. 2002. Sensory and chemical changes of young white wines stored under oxygen. An assessment of the role played by aldehydes and some other important odorants. Food Chem 77:325-331. doi: 10.1016/S0308-8146(01)00355-7.

Escudero A, Campo E, Farina L, and others. 2007. Analytical characterization of the aroma of five premium red wines. Insights into the role of odor families and the concept of fruitiness of wines. J Agric Food Chem 55:4501-4510. doi: 10.1021/jf0636418.

Escudero A, Hernández-Orte P, Cacho J, Ferreira V. 2000. Clues about the Role of Methional As Character Impact Odorant of Some Oxidized Wines. J Agric Food Chem 48:4268-4272. doi: 10.1021/jf991177j.

Fang Y, Qian MC. 2005. Sensitive quantification of sulfur compounds in wine by headspace solid-phase microextraction technique. J Chromatogr A 1080:177-185. doi: 10.1016/j.chroma.2005.05.024.

Ferreira V, Bueno M, Franco-Luesma E. 2015a. New insights into the chemistry involved in aroma development during wine bottle aging: Slow redox processes and chemical equilibrium shifts. ACS Symp Ser 275-289. doi: 10.1021/bk-2015-1203.ch017.

Ferreira V, Carrascon V, Bueno M, and others. 2015b. Oxygen Consumption by Red Wines. Part I: Consumption Rates, Relationship with Chemical Composition, and Role of SO2. J Agric Food Chem 63:10928-10937. doi: 10.1021/acs.jafc.5b02988.

Ferreira V, Escudero A, Fernández P, Cacho JF. 1997. Changes in the profile of volatile compounds in wines stored under oxygen and their relationship with the browning process. Zeitschrift für Leb und -forsch A 205:392-396. doi: $10.1007 / \mathrm{s} 002170050187$.

Ferreira V, López R, Cacho JF. 2000. Quantitative determination of the odorants of young red wines from different grape varieties. J Sci Food Agric 80:1659-1667. 
Franco-Luesma E, Ferreira V. 2016. Reductive off-odors in wines: Formation and release of H2S and methanethiol during the accelerated anoxic storage of wines. Food Chem 199:42-50. doi: 10.1016/j.foodchem.2015.11.111.

Franco-Luesma E, Ferreira V. 2014. Quantitative analysis of free and bonded forms of volatile sulfur compouds in wine. Basic methodologies and evidences showing the existence of reversible cation-complexed forms. J Chromatogr A 1359:8-15. doi: 10.1016/j.chroma.2014.07.011.

Fulcrand H, Atanasova V, Salas E, Cheynier V. 2004. The fate of anthocyanins in wine: Are there determining factors? ACS Symp Ser 886:68-88. doi: 10.1021/bk-20040886.ch006\r10.1021/bk-2004-0886.ch006.

Godden P, Francis IL, Field J, and others. 2001. Wine bottle closures: physical characteristics and effect on composition and sensory properties of a Semillon wine. I. Performance up to 20 months post-bottling. Aust J Grape Wine Res 7:64-105. doi: 10.1111/j.1755-0238.2001.tb00196.x.

Gómez-Plaza E, Gil-Muñoz R, López-Roca JM, and others. 2001. Phenolic compounds and color stability of red wines: Effect of skin maceration time. Am J Enol Vitic 52:266-270.

Goniak OJ, Noble AC. 1987. Sensory study of selected volatile sulfur compounds in white wine. Am J Enol Vitic 38:223-227.

Grant-Preece P, Fang H, Schmidtke LM, Clark AC. 2013. Sensorially important aldehyde production from amino acids in model wine systems: Impact of ascorbic acid, erythorbic acid, glutathione and sulphur dioxide. Food Chem 141:304-312. doi: 10.1016/j.foodchem.2013.02.100.

Guth H. 1997. Quantitation and Sensory Studies of Character Impact Odorants of Different White Wine Varieties. J Agric Food Chem 43:3027-3032. doi: 10.1021/jf9608433.

Han G, Ugliano M, Currie B, and others. 2015. Influence of closure, phenolic levels and microoxygenation on Cabernet Sauvignon wine composition after 5 years' bottle storage. J Sci Food Agric 95:36-43. doi: 10.1002/jsfa.6694.

Jackowetz JN, Mira de Orduña R. 2013. Survey of SO2 binding carbonyls in 237 red and white table wines. Food Control 32:687-692. doi: 10.1016/j.foodcont.2013.02.001.

Jackson R. 2014. Wine Science: Principles and Applications, 4th ed. Academic Press.

Jastrzembski JA, Sacks GL. 2015. Precursors of Hydrogen Sulfide during Wine Storage the Role of Elemental Sulfur Pesticide Residues. In: 66th American Society of Enology and Viticulture National Conference. Portland, OR, .

Jiranek V, Langridge P, Henschke P. 1995. Regulation of hydrogen sulfide liberation in wine-producing Saccharomyces cerevisiae strains by assimilable nitrogen. Appl Environ Microbiol 61:461-467.

Juan FS, Cacho J, Ferreira V, Escudero A. 2012. Aroma chemical composition of red 
wines from different price categories and its relationship to quality. J Agric Food Chem 60:5045-5056. doi: 10.1021/jf2050685.

Kreitman GY, Danilewicz JC, Jeffery DW, Elias RJ. 2016b. Reaction Mechanisms of Metals with Hydrogen Sulfide and Thiols in Model Wine. Part 2: Iron- and CopperCatalyzed Oxidation. J Agric Food Chem 64:4105-4113. doi: 10.1021/acs.jafc.6b00642.

Kreitman GY, Danilewicz JC, Jeffery DW, Elias RJ. 2016a. Reaction Mechanisms of Metals with Hydrogen Sulfide and Thiols in Model Wine. Part 1: Copper-Catalyzed Oxidation. J Agric Food Chem 64:4095-4104. doi: 10.1021/acs.jafc.6b00642.

Kwasniewski MT, Allison RB, Wilcox WF, Sacks GL. 2011. Convenient, inexpensive quantification of elemental sulfur by simultaneous in situ reduction and colorimetric detection. Anal Chim Acta 703:52-57. doi: 10.1016/j.aca.2011.07.010.

Kwasniewski MT, Sacks GL, Wilcox WF. 2014. Persistence of elemental sulfur spray residue on grapes during ripening and vinification. Am J Enol Vitic 65:453-462. doi: 10.5344/ajev.2014.14027.

Laurie VF, Law R, Joslin WS, Waterhouse AL. 2008. In situ measurements of dissolved oxygen during low-level oxygenation in red wines. Am J Enol Vitic 59:215-219.

Lopes P, Saucier C, Glories Y. 2005. Nondestructive colorimetric method to determine the oxygen diffusion rate through closures used in winemaking. J Agric Food Chem 53:6967-6973. doi: 10.1021/jf0404849.

Lopes P, Silva MA, Pons A, and others. 2009. Impact of oxygen dissolved at bottling and transmitted through closures on the composition and sensory properties of a Sauvignon blanc wine during bottle storage. J Agric Food Chem 57:10261-10270. doi: $10.1021 / \mathrm{j} f 9023257$.

López R, Lapeña AC, Cacho J, Ferreira V. 2007. Quantitative determination of wine highly volatile sulfur compounds by using automated headspace solid-phase microextraction and gas chromatography-pulsed flame photometric detection. Critical study and optimization of a new procedure. J Chromatogr A 1143:8-15. doi: 10.1016/j.chroma.2006.12.053.

McRae JM, Day MP, Bindon KA, and others. 2015. Effect of early oxygen exposure on red wine colour and tannins. Tetrahedron 71:3131-3137. doi: 10.1016/j.tet.2014.08.059.

McRae JM, Kassara S, Kennedy JA, and others. 2013. Effect of wine $\mathrm{pH}$ and bottle closure on tannins. J Agric Food Chem 61:11618-11627. doi: 10.1021/jf403704f.

Moenne MI, Saa P, Laurie VF, and others. 2014. Oxygen Incorporation and Dissolution During Industrial-Scale Red Wine Fermentations. Food Bioprocess Technol 7:26272636. doi: 10.1007/s11947-014-1257-2.

Moreira N, Lopes P, Ferreira H, and others. 2016. Influence of packaging and aging on the red wine volatile composition and sensory attributes. Food Packag Shelf Life 8:14-23. doi: 10.1016/j.fpsl.2016.02.005. 
Nevares I, del Alamo M. 2008. Measurement of dissolved oxygen during red wines tank aging with chips and micro-oxygenation. Anal Chim Acta 621:68-78. doi: 10.1016/j.aca.2007.11.042.

Nikolantonaki M, Chichuc I, Teissedre PL, Darriet P. 2010. Reactivity of volatile thiols with polyphenols in a wine-model medium: Impact of oxygen, iron, and sulfur dioxide. Anal Chim Acta 660:102-109. doi: 10.1016/j.aca.2009.11.016.

Nikolantonaki M, Magiatis P, Waterhouse AL. 2014. Measuring protection of aromatic wine thiols from oxidation by competitive reactions vs wine preservatives with ortho-quinones. Food Chem 163:61-67. doi: 10.1016/j.foodchem.2014.04.079.

Nikolantonaki M, Waterhouse AL. 2012. A Method To Quantify Quinone Reaction Rates with Wine Relevant Nucleophiles. J Agric Food Chem 60:8484-8491. doi: 10.1021/jf302017j.

Oberholster A, Elmendorf BL, Lerno LA, and others. 2015. Barrel maturation, oak alternatives and micro-oxygenation: Influence on red wine aging and quality. Food Chem 173:1250-1258. doi: 10.1016/j.foodchem.2014.10.043.

Oliveira CM, Ferreira ACS, De Freitas V, Silva AMS. 2011. Oxidation mechanisms occurring in wines. Food Res Int 44:1115-1126. doi: 10.1016/j.foodres.2011.03.050.

Park S-K. 2008. Development of a method to measure hydrogen sulfide in wine fermentation. J Microbiol Biotechnol 18:1550-1554.

Patrianakou M, Roussis IG. 2013. Decrease of Wine Volatile Aroma Esters by Oxidation. South African J Enol Vitic 34:241-246.

Pineau B, Barbe J-C, Van Leeuwen C, Dubourdieu D. 2007. Which impact for betadamascenone on red wines aroma? J Agric Food Chem 55:4103-4108. doi: 10.1021/jf070120r.

Pripis-Nicolau L, de Revel G, Bertrand A, Maujean A. 2000. Formation of flavour components by the reaction of amino acid and carbonyl compounds in mild conditions. J Agric Food Chem 48:3761-3766.

Ramamoorthy R, Dutta PK, Akbar SA. 2003. Oxygen sensors: Materials, methods, designs, and applications. J Mater Sci 38:4271-4282. doi: 10.1023/A:1026370729205.

Ribéreau-Gayon P. 1975. Aroma of Muscat grape varieties. J Agric Food Chem 23:10421047. doi: 10.1021/jf60202a050.

Schutz M, Kunkee RE. 1977. Formation of Hydroge Sulfide from Elemental Sulfur During Fermentation by Wine Yeast. Am J Enol Vitic 28:137-144.

Siebert T, Bramley B, Solomon M. 2009. Hydrogen sulfide: aroma detection threshold study in white and red wine. AWRI Tech Rev 183:14-16.

Siebert TE, Solomon MR, Pollnitz AP, Jeffery DW. 2010. Selective determination of volatile sulfur compounds in wine by gas chromatography with sulfur 
chemiluminescence detection. J Agric Food Chem 58:9454-9462. doi: $10.1021 /$ jf102008r.

Silva MA, Julien M, Jourdes M, Teissedre PL. 2011. Impact of closures on wine postbottling development: A review. Eur Food Res Technol 233:905-914. doi: 10.1007/s00217-011-1603-9.

Simpson RF. 1978. Aroma and compositional changes in wine with oxidation, storage, and ageing. Vitis 17:274-287.

Singleton V. 1987. Oxygen with Phenols and Related Reactions in Musts, Wines, and Model Systems: Observations and Practical Implications. Am J Enol Vitic 38:69-77.

Singleton V, Trousdale E. 1983. White wine phenolics: varietal and processing differences as shown by HPLC. Am J Enol Vitic 34:27-34.

Singleton V, Trousdale E, Zaya J. 1979. Oxidation of Wines. I. Young White Wines Periodically Exposed to Air. Am J Enol Vitic 30:49-54.

Skouroumounis GK, Kwiatkowski MJ, Francis IL, and others. 2005. The impact of closure type and storge conditions on the composition, colour and flavour properties of a Riesling and a wooded Chardonnay wine during five years' storage. Aust J Grape Wine Res 11:369-377. doi: 10.1111/j.1755-0238.2005.tb00036.x.

Slingsby RW, Kepner RE, Muller CJ, Webb AD. 1980. Some Volatile Componenets of Vitis Vinifera Variety Cabernet Sauvignon Wine. Am J Enol Vitic 31:360-363.

Smith ME, Bekker MZ, Smith PA, Wilkes EN. 2015. Sources of volatile sulfur compounds in wine. Aust J Grape Wine Res 21:705-712. doi: 10.1111/ajgw.12193.

Solomon M, Geue J, Osidacz P, Siebert T. 2010. Aroma detection threshold study of methanethiol in white and red wine. AWRI Tech Rev 186:8-10.

Thomas C, Boulton R, Silacci M, Gubler D. 1993. The effect of elemental sulfur, yeast strain, and fermentation medium on hydrogen sulfide production during fermentation. Am J Enol Vitic 44:211-216.

Timberlake CF, Bridle P. 1976. Interactions Between Anthocyanins, Phenolic Compounds, and Acetaldehyde and Their Significance in Red Wines. Am J Enol Vitic 27:97-105.

Tominaga T, Blanchard L, Darriet P, Dubourdieu D. 2000. A powerful aromatic volatile thiol, 2-furanmethanethiol, exhibiting roast coffee aroma in wines made from several Vitis vinifera grape varieties. J Agric Food Chem 48:1799-1802. doi: 10.1021/jf990660r.

Tominaga T, Murat M-L, Dubourdieu D. 1998. Development of a Method for Analyzing the Volatile Thiols Involved in the Characteristic Aroma of Wines Made from Vitis vinifera L. Cv. Sauvignon Blanc. J Agric Food Chem 46:1044-1048. doi: 10.1021/jf970782o.

Ugliano M. 2013. Oxygen contribution to wine aroma evolution during bottle aging. J 
Agric Food Chem 61:6125-6136. doi: 10.1021/jf400810v.

Ugliano M, Bégrand S, Diéval JB, Vidal S. 2015. Critical oxygen levels affecting wine aroma: Relevant sensory attributes, related aroma compounds, and possible mechanisms. ACS Symp Ser 205-216. doi: 10.1021/bk-2015-1203.ch013.

Ugliano M, Dieval JB, Siebert TE, and others. 2012. Oxygen consumption and development of volatile sulfur compounds during bottle aging of two Shiraz wines. influence of pre- and postbottling controlled oxygen exposure. J Agric Food Chem 60:8561-8570. doi: 10.1021/jf3014348.

Ugliano M, Fedrizzi B, Siebert T, and others. 2009. Effect of nitrogen supplementation and saccharomyces species on hydrogen sulfide and other volatile sulfur compounds in Shiraz fermentation and wine. J Agric Food Chem 57:4948-4955. doi: 10.1021/jf8037693.

Ugliano M, Henschke PA. 2010. Comparison of three methods for accurate quantification of hydrogen sulfide during fermentation. Anal Chim Acta 660:87-91. doi: 10.1016/j.aca.2009.09.049.

Ugliano M, Kolouchova R, Henschke PA. 2011a. Occurrence of hydrogen sulfide in wine and in fermentation: Influence of yeast strain and supplementation of yeast available nitrogen. J Ind Microbiol Biotechnol 38:423-429. doi: 10.1007/s10295-010-0786-6.

Ugliano M, Kwiatkowski M, Vidal S, and others. 2011b. Evolution of 3mercaptohexanol, hydrogen sulfide, and methyl mercaptan during bottle storage of Sauvignon blanc wines. Effect of glutathione, copper, oxygen exposure, and closurederived oxygen. J Agric Food Chem 59:2564-2572. doi: 10.1021/jf1043585.

Vasserot Y, Steinmetz V, Jeandet P. 2003. Study of thiol consumption by yeast lees. Antonie Van Leeuwenhoek 83:201-207. doi: 10.1023/A:1023305130233.

Viviers MZ, Smith ME, Wilkes E, Smith P. 2013. Effects of five metals on the evolution of hydrogen sulfide, methanethiol, and dimethyl sulfide during anaerobic storage of chardonnay and shiraz wines. J Agric Food Chem 61:12385-12396. doi: 10.1021/jf403422x.

Waterhouse AL, Laurie VF. 2006. Oxidation of Wine Phenolics: A Critical Evaluation and Hypotheses. Am J Enol Vitic 57:306-313.

Wildenradt HL, Singleton VL. 1974. The Production of Aldehydes as a Result of Oxidation of Polyphenolic Compounds and its Relation to Wine Aging. Am J Enol Vitic 25:119-126.

Winterhalter P, Sefton M, Williams P. 1990. Volatile C13-Norisoprenoid Compounds in Riesling Wine are Generated by Multiple Precursors. Am J Enol Vitic 41:277-283.

Wirth J, Morel-Salmi C, Souquet JM, and others. 2010. The impact of oxygen exposure before and after bottling on the polyphenolic composition of red wines. Food Chem 123:107-116. doi: 10.1016/j.foodchem.2010.04.008. 


\section{Figures and Tables}

Figure 2.1 Headspace and dissolved oxygen $(\mathrm{mg} / \mathrm{L})$ for all experiments over three days of storage (hours). a) $\operatorname{Exp} 1$, b) $\operatorname{Exp} 2$, c) $\operatorname{Exp} 3$, d) Exp 4 Stelvin Reseal treatments, and e) Exp 4 Strong Vacuum treatments. Error bars represent the standard deviation of three replicates (with the exception of Stopper-Type Average in Exp 1, 2, and 3 where $n=12$, 9, and 9 respectively and 73 hours unsealed in $\operatorname{Exp} 4$, where $n=6$ ).
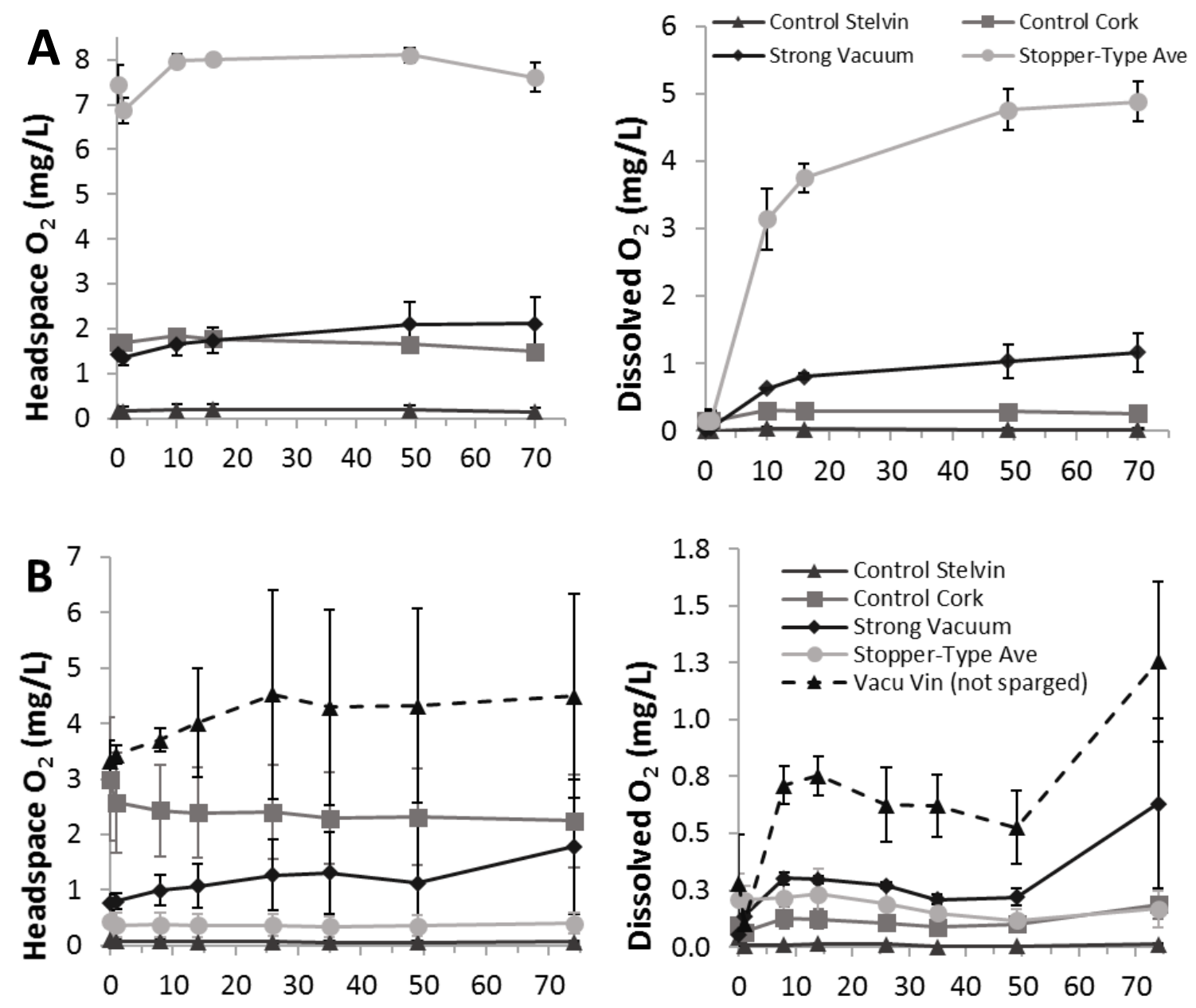

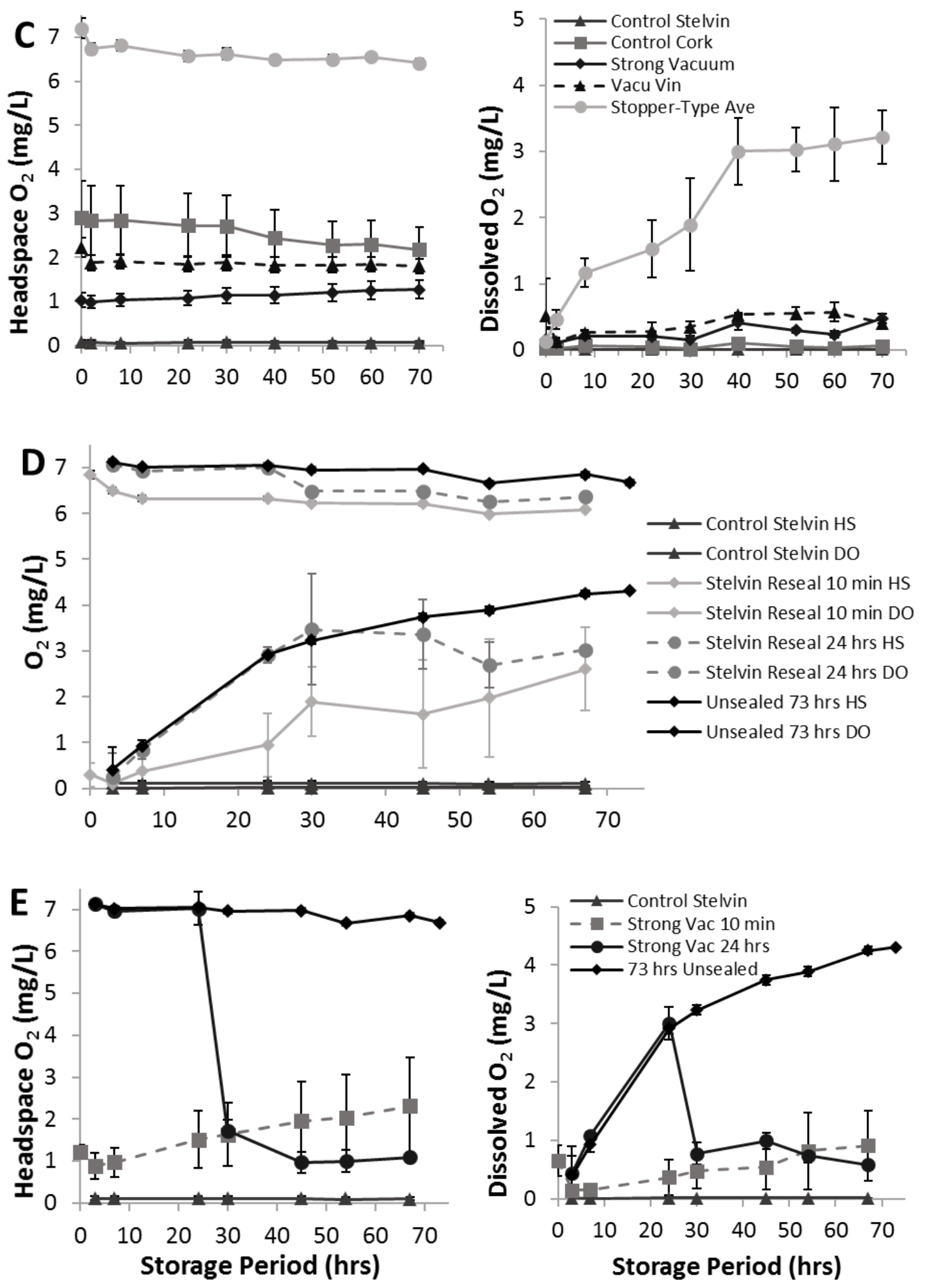
Table 2.1 Final headspace and dissolved oxygen $(\mathrm{mg} / \mathrm{L})$ after three days of storage for each of the four experiments with white and red wine.

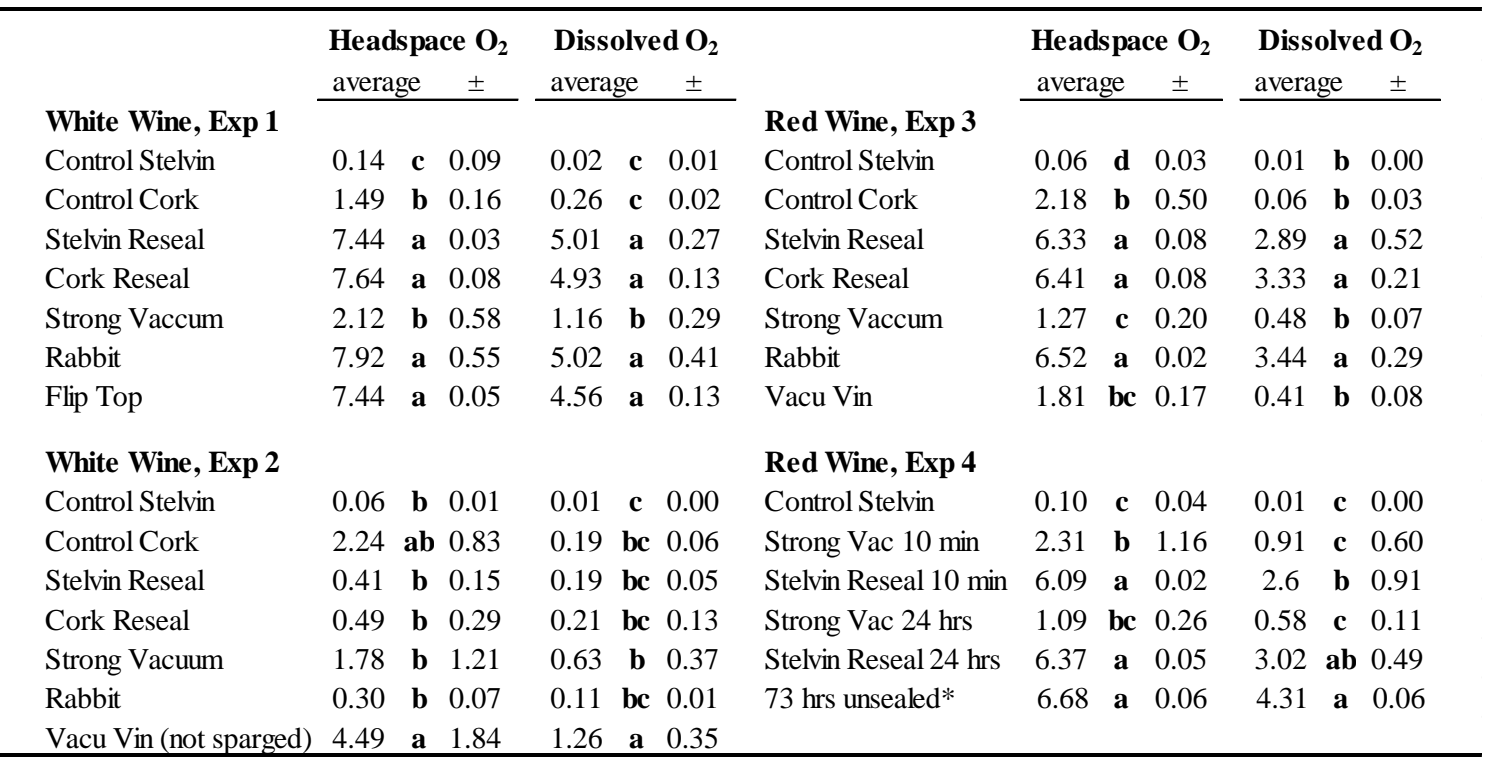

Averages within a column of the same experiment that do not share a letter are significantly different (Tukey's

HSD Test, $p<0.05$ ). All averages and standard deviations are taken with $n=3$, excluding $* n=6$.

Table 2.2 Free, bound, and total $\mathrm{SO}_{2}(\mathrm{mg} / \mathrm{L})$ measured post-storage for each of the four experiments with white and red wine.

\begin{tabular}{|c|c|c|c|c|c|c|c|c|c|c|c|c|c|c|c|c|c|c|c|}
\hline \multirow[b]{2}{*}{ White Wine, $\operatorname{Exp} 1$} & \multicolumn{3}{|c|}{$\begin{array}{r}\text { Free } \mathbf{S O}_{2} \\
\text { average } \quad \pm\end{array}$} & \multicolumn{3}{|c|}{$\begin{array}{l}\text { Bound } \mathbf{S O}_{2} \\
\text { average } \pm\end{array}$} & \multicolumn{3}{|c|}{$\begin{array}{c}\text { Total } \mathbf{S O}_{2} \\
\text { average } \quad \pm\end{array}$} & \multirow{2}{*}{ Red Wine, Exp 3} & \multicolumn{3}{|c|}{$\begin{array}{c}\text { Free } \mathbf{S O}_{2} \\
\text { average } \quad \pm\end{array}$} & \multicolumn{3}{|c|}{$\begin{array}{l}\text { Bound } \mathbf{S O}_{2} \\
\text { average } \quad \pm\end{array}$} & \multicolumn{3}{|c|}{$\begin{array}{r}\text { Total } \mathbf{S O}_{2} \\
\text { average } \quad \pm\end{array}$} \\
\hline & & & & & & & & & & & & & & & & & & & \\
\hline Control Stelvin & 18 & b & 1 & 87 & $\mathbf{a}$ & 6 & 105 & $\mathbf{a}$ & 8 & Control Stelvin & 21 & $\mathbf{a}$ & 5 & 34 & $\mathbf{a}$ & 3 & 55 & ab & 3 \\
\hline Control Cork & 24 & $\mathbf{a}$ & 1 & 76 & bc & 4 & 100 & $\mathbf{a b}$ & 5 & Control Cork & 22 & $\mathbf{a}$ & 2 & 36 & $\mathbf{a}$ & 4 & 58 & $\mathbf{a}$ & 4 \\
\hline Stelvin Reseal & 20 & ab & 2 & 74 & bc & 3 & 94 & ab & 4 & Stelvin Reseal & 16 & abc & 1 & 30 & a & 3 & 46 & b & 2 \\
\hline Cork Reseal & 20 & ab & 1 & 71 & c & 2 & 91 & b & 1 & Cork Reseal & 14 & c & 1 & 36 & a & 5 & 50 & ab & 6 \\
\hline Strong Vaccum & 24 & $\mathbf{a}$ & 1 & 82 & ab & 3 & 106 & $\mathbf{a}$ & 2 & Strong Vaccum & 20 & ab & 2 & 31 & a & 2 & 51 & ab & 1 \\
\hline Rabbit & 21 & ab & 4 & 74 & bc & 4 & 95 & ab & 6 & Rabbit & 14 & bc & 2 & 33 & $\mathbf{a}$ & 4 & 47 & b & 4 \\
\hline Flip Top & 22 & $\mathbf{a b}$ & 3 & 76 & bc & 0 & 98 & ab & 3 & Vacu Vin & 21 & $\mathbf{a}$ & 1 & 31 & $\mathbf{a}$ & 4 & 51 & ab & 4 \\
\hline White Wine, Exp 2 & & & & & & & & & & Red Wine, Exp 4 & & & & & & & & & \\
\hline Control Stelvin* & 22 & $\mathbf{a}$ & 1 & 80 & b & 2 & 103 & $\mathbf{a}$ & 1 & Control Stelvin & 24 & $\mathbf{a}$ & 1 & 31 & $\mathbf{a}$ & 4 & 55 & $\mathbf{a}$ & 4 \\
\hline Control Cork & 19 & $\mathbf{a}$ & 3 & 93 & $\mathbf{a}$ & 6 & 112 & $\mathbf{a}$ & 6 & Strong Vac 10 min & 19 & $\mathbf{a b}$ & 2 & 28 & $\mathbf{a}$ & 4 & 47 & ab & 4 \\
\hline Stelvin Reseal & 23 & $\mathbf{a}$ & 2 & 83 & $\mathbf{a b}$ & 3 & 106 & $\mathbf{a}$ & 4 & Stelvin Reseal $10 \mathrm{~min}$ & 15 & $\mathbf{a b}$ & 7 & 27 & $\mathbf{a}$ & 1 & 42 & ab & 7 \\
\hline Cork Reseal & 25 & $\mathbf{a}$ & 2 & 85 & $\mathbf{a b}$ & 4 & 109 & $\mathbf{a}$ & 6 & Strong Vac 24 hrs & 14 & $\mathbf{a b}$ & 1 & 30 & $\mathbf{a}$ & 6 & 45 & ab & 8 \\
\hline Strong Vacuum* & 24 & $\mathbf{a}$ & 4 & 79 & b & 1 & 104 & $\mathbf{a}$ & 3 & Stelvin Reseal 24 hrs & 12 & b & 2 & 27 & $\mathbf{a}$ & 2 & 39 & b & 1 \\
\hline Rabbit & 25 & $\mathbf{a}$ & 2 & 83 & b & 2 & 108 & $\mathbf{a}$ & 2 & $73 \mathrm{hrs}$ unsealed** & 11 & b & 4 & 26 & a & 5 & 37 & b & 5 \\
\hline Vacu Vin (not sparged) & 24 & $\mathbf{a}$ & 3 & 80 & b & 1 & 104 & a & 4 & & & & & & & & & & \\
\hline
\end{tabular}


Table 2.3 Relative peak area or concentration of volatile aroma compounds after three days of storage in white wine resealed with different closure treatments (Exp 1) and in red wine with different air exposure time and closure treatments $(\operatorname{Exp} 4)$.

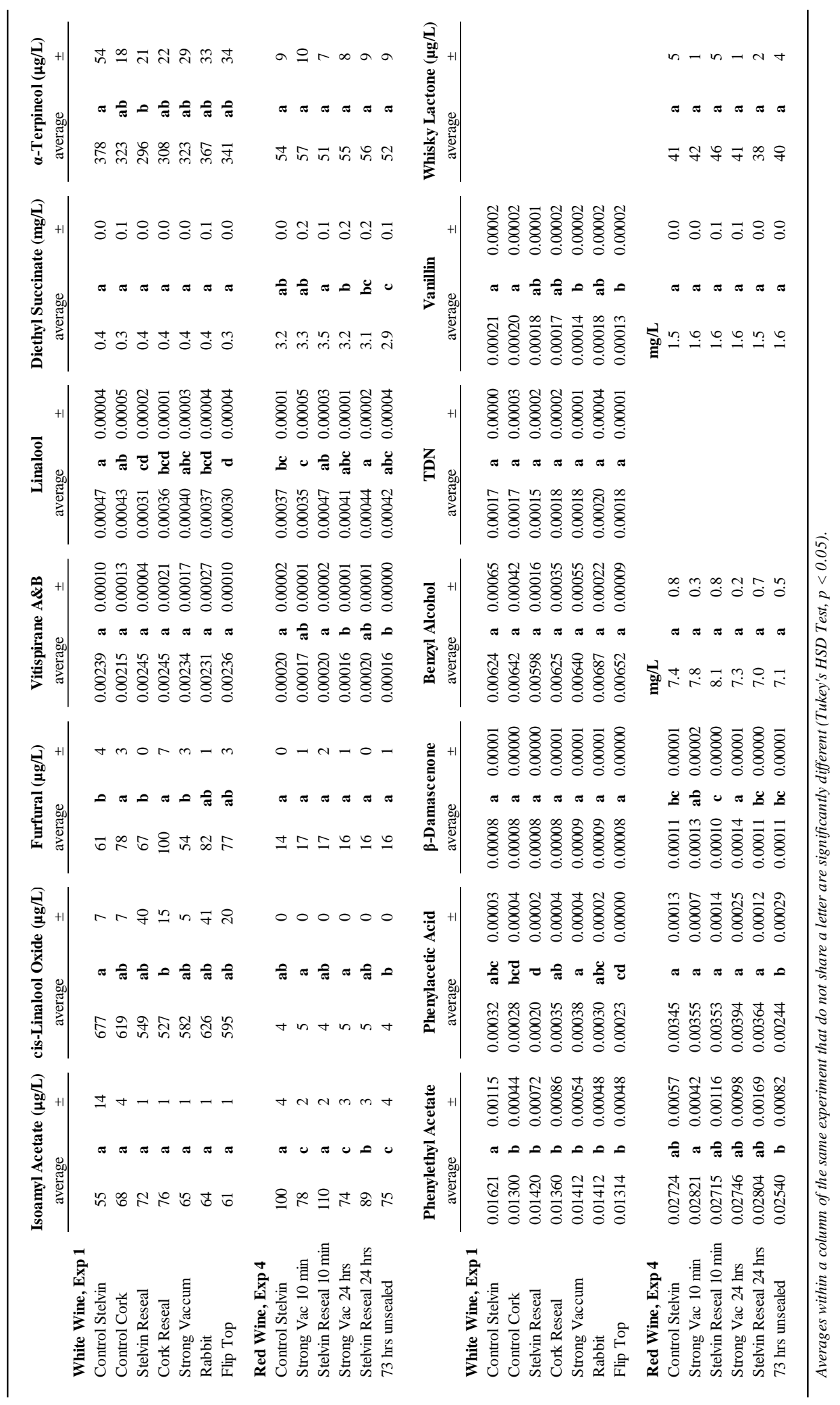




\title{
CHAPTER 3 - EMERGENCE OF H2S FROM PRECURSORS IN WINE AFTER ACCELERATED AGING
}

\begin{abstract}
A convenient accelerated aging assay was developed to characterize the potential for $\mathrm{H}_{2} \mathrm{~S}$ to accumulate in wine during low oxygen bottle storage. Wine samples $(40 \mathrm{~mL})$ were incubated at $80{ }^{\circ} \mathrm{C}$ for 1 hour, then $\mathrm{H}_{2} \mathrm{~S}$ was measured using gas detection tubes. The assay was used to evaluate $\mathrm{H}_{2} \mathrm{~S}$ emergence from hypothesized precursor compounds in three wines ( 2 red, 1 white). Significant increases in $\mathrm{H}_{2} \mathrm{~S}$ production after accelerated aging was found in at least one wine spiked with cysteine, sulfur dioxide, methyl thioacetate, dimethyl disulfide, and a model quinone- $\mathrm{H}_{2} \mathrm{~S}$ adducts mixture $\left(\mathrm{H}_{2} \mathrm{~S}-4 \mathrm{MeC}\right)$, but not in wines with added glutathione. For example, $\mathrm{H}_{2} \mathrm{~S}$ emergence in Syrah with $10 \mathrm{mg} / \mathrm{L}$ cysteine $(41.0 \pm 3.3 \mu \mathrm{g} / \mathrm{L})$ was significantly greater than control $(21.8 \pm 1.2 \mu \mathrm{g} / \mathrm{L})$ after accelerated aging treatment. Emergence of $\mathrm{H}_{2} \mathrm{~S}$ from $\mathrm{H}_{2} \mathrm{~S}-4 \mathrm{MeC}$ adducts in both red wines were lower than control wines, while emergence in white wine was significantly greater than the control, potentially suggesting that $\mathrm{H}_{2} \mathrm{~S}-4 \mathrm{MeC}$ adducts may play a larger role in white wine $\mathrm{H}_{2} \mathrm{~S}$ post-bottling emergence. Addition of a strong reducing agent (TCEP) also resulted in $\mathrm{H}_{2} \mathrm{~S}$ emergence from an unknown pool of precursors, with lower emergence in a Syrah with sulfurous off-odors compared to a fault-free Cabernet Sauvignon.
\end{abstract}

\section{Introduction}

Winemakers may choose to seal bottles with screw cap closures as an alternative to natural cork due to their lower cost, convenience for consumers, eliminating the risk of cork taint (Godden and others 2001; O'Brien and others 2009), greater consistency over aging (Godden and others 2001; Ugliano 2013), and preservation of fresh and fruity aromas (Godden and others 2001; Lopes and others 2009). Wines that are sealed under screw cap 
closures which prevent nearly all oxygen ingress during bottle storage $\left(<0.5 \mathrm{mg} \mathrm{O}_{2} / \mathrm{L} /\right.$ year (Lopes and others 2009; Ugliano 2013)) typically consume the majority of oxygen present at bottling after $2-3$ months (Dimkou and others 2011), which creates a nearly anaerobic environment within the bottle and can lead to unintended issues with wine quality. Under low oxygen conditions where the approximate ingress of oxygen is $<1.5 \mathrm{mg} / \mathrm{L} /$ year (Ugliano 2013), certain wines that were fault-free before bottling develop undesirable sulfurous off-odors, commonly known as "reductive" odors, after months or years of storage (Godden and others 2001; Lopes and others 2009; Dimkou and others 2011; Ugliano and others 2011b; Ugliano 2013). The occurrence of this fault is regarded as a major concern for the wine industry due to its widespread prevalence. Hydrogen sulfide $\left(\mathrm{H}_{2} \mathrm{~S}\right)$ and methanethiol $(\mathrm{MeSH})$ have been identified above sensory threshold concentrations in "reduced" wines (Siebert and others 2010) and are responsible for contributing rotten egg, sewage, and rotten cabbage odors. The aroma detection threshold for $\mathrm{H}_{2} \mathrm{~S}$ in white and red wine is 1.6 and $1.1 \mu \mathrm{g} / \mathrm{L}$, respectively (Siebert and others 2009), and 3.1 and $1.8 \mu \mathrm{g} / \mathrm{L}$ for $\mathrm{MeSH}$ in white and red wine, respectively (Solomon and others 2010). Dimethyl sulfide (DMS) has also been found above threshold levels (25 $\mu \mathrm{g} / \mathrm{L}$ (Goniak and Noble 1987)) in some "reduced" wines (Siebert and others 2010), where it contributes rotten cabbage and canned corn odors, but the chemical pathway of formation of DMS from precursors is relatively well understood (Segurel and others 2005; Loscos and others 2008). Other volatile sulfur compounds (VSCs) found in wine, such as ethanethiol, methyl thioacetate, ethyl thioacetate, dimethyl disulfide, and diethyl disulfide, are rarely found at concentrations above their sensory threshold values (Siebert and others 
2010) and therefore are not considered as key contributors to sulfurous odors associated with "reduced" wine.

Under normal wine fermentation conditions, $\mathrm{H}_{2} \mathrm{~S}$ is produced by yeast at levels sufficient for its function as an intermediate metabolite in the biosynthesis of sulfurcontaining amino acids and small peptides (Eschenbruch 1974). This pathway is disrupted when insufficient levels of nitrogen are available, causing $\mathrm{H}_{2} \mathrm{~S}$ production to outpace metabolic demand and diffusion of excess $\mathrm{H}_{2} \mathrm{~S}$ from the cell into the wine (Jiranek and others 1995). In addition, other factors besides nutrient availability also impact $\mathrm{H}_{2} \mathrm{~S}$ formed during fermentation, including yeast strain differences in sulfite reductase activity (Jiranek and others 1995; Ugliano and others 2009; Ugliano and others 2011a), presence of metal ions (Eschenbruch 1974), fermentation temperature (Schutz and Kunkee 1977), and elemental sulfur $\left(\mathrm{S}^{0}\right)$ residue from fungicide sprayed on grapes during the growing season (Schutz and Kunkee 1977; Thomas and others 1993). Excess $\mathrm{H}_{2} \mathrm{~S}$ present after fermentation can be controlled by sparing with inert gas to physically displace $\mathrm{H}_{2} \mathrm{~S}$, aeration to promote formation of oxidation products (quinones) which readily bind with $\mathrm{H}_{2} \mathrm{~S}$ to form nonvolatile adducts (Nikolantonaki and Waterhouse 2012), or addition of lees (Vasserot and others 2003). Copper fining with copper sulfate or copper citrate has also traditionally been used to trap thiols and is a standard technique in winemaking texts (Jackson 2014); however, its actual efficacy has recently been called into question (Clark and others 2015; Bekker and others 2016b).

Although there seems to be some correlation between $\mathrm{H}_{2} \mathrm{~S}$ accumulated late in fermentation and its concentrations in wine before bottling (Ugliano and others 2009), explanations for the post-bottling occurrence of $\mathrm{H}_{2} \mathrm{~S}$ in defect-free wines at the time of 
bottling do not appear to be directly related to $\mathrm{H}_{2} \mathrm{~S}$ produced during fermentation (Ugliano and others 2011a). The majority of recent studies have traced back the emergence of $\mathrm{H}_{2} \mathrm{~S}$ during low-oxygen bottle maturation to pools of reversibly bound nonvolatile thiol-copper complexes, with evidence for binding by other metal ions ( $\mathrm{Mn}, \mathrm{Fe}$, and $\mathrm{Zn}$ ) also apparent (Franco-Luesma and Ferreira 2016a; Kreitman and others 2016b; Bekker and others 2016c). Trace concentrations of metal ions are naturally present in wine, and levels may increase from contact with winery equipment, use of pesticides or herbicides that contain metal, or copper fining treatment. Insights into the chemical mechanism for the binding reactions of $\mathrm{H}_{2} \mathrm{~S}$ with metals have emerged from recent investigations in model wine systems (Kreitman and others 2016a; Kreitman and others 2016b). Mechanisms or conditions for the reverse reaction have not yet been examined in wine, but cleavage of the copper-thiol bond could potentially occur in the presence of more chemically favorable wine components, such as polyphenols, or is dependent on the redox state. Regardless of the precise mechanism, nonlinear emergence of $\mathrm{H}_{2} \mathrm{~S}$ and $\mathrm{MeSH}$ throughout bottle maturation (Ugliano and others 2011b; Viviers and others 2013; Bekker and others 2016b) demonstrates the complexity of how these complexes are dynamically bound and released over time. Bound forms of $\mathrm{H}_{2} \mathrm{~S}$ accounted for similar proportions of total $\mathrm{H}_{2} \mathrm{~S}$ in red wine compared to white and rosé wines (an average of $94 \%$ and $92 \%$, respectively) in a survey of 24 Spanish wines. After an accelerated aging procedure, increase in total $\mathrm{H}_{2} \mathrm{~S}$ over aging was dominated by release from bound forms in red wines (90\% in red vs 58\% in white and rosé) and formation from unknown precursors dominated in white wine (42\% in white and rosé vs $10 \%$ in red) (Franco-Luesma and Ferreira 2016a). Though $\mathrm{H}_{2} \mathrm{~S}$-metal complexes appear to be responsible for a significant pool of $\mathrm{H}_{2} \mathrm{~S}$, identification of other precursors 
involved in generating $\mathrm{H}_{2} \mathrm{~S}$ would help to further our understanding of post-bottling emergence of unwanted off-odors, particularly in white wines.

A number of compounds have been proposed to account for the remaining sources of $\mathrm{H}_{2} \mathrm{~S}$ and $\mathrm{MeSH}$ not attributed to metal complexes. Potentially reversibly bound thiolquinone adducts (Nikolantonaki and Waterhouse 2012; Smith and others 2015a), thioacetates (Bracher and others 2011), cysteine (Pripis-Nicolau and others 2000; Bekker and others 2016c), glutathione (Bekker and others 2016c), methionine (Pripis-Nicolau and others 2000), sulfur dioxide (Danilewicz 2007; Lopes and others 2009), elemental sulfur (Jastrzembski and Sacks 2015), disulfides (Bobet and others 1990), and polysulfides (Chen and others 2016) have also been briefly mentioned as hypothetical precursors based on known enzymatic and chemical reactions (Smith and others 2015a), though, studies have yet to specifically examine the majority of these compounds in the context of their potential as sources of $\mathrm{H}_{2} \mathrm{~S}$ or MeSH during wine bottle storage. Oxidation of polyphenols in wine results in the formation of highly reactive intermediate species, quinones and $\mathrm{H}_{2} \mathrm{O}_{2}$ (Singleton 1987; Waterhouse and Laurie 2006). Wine relevant nucleophiles, including $\mathrm{H}_{2} \mathrm{~S}$ and other thiols, react rapidly with quinones in model wine conditions (Nikolantonaki and Waterhouse 2012). Formation of odorless $\mathrm{H}_{2} \mathrm{~S}$ adducts with quinones in real wine was found to be less favorable than the formation of $\mathrm{SO}_{2}$-quinone adducts, simply due to the higher concentrations of $\mathrm{SO}_{2}$ in wine (Bekker and others 2016a). $\mathrm{H}_{2} \mathrm{~S}$-quinone adducts may still be formed during fermentation or in wines with low $\mathrm{SO}_{2}$ concentrations, therefore the reversibility of this compound should be explored. Hydrolysis of thioacetates occurs very slowly within the $\mathrm{pH}$ range relevant to wine (Bracher and others 2011) which could result in the release of the thiol moiety over bottle storage. Reduction of disulfides to their 
corresponding thiols under low oxygen conditions has been shown in model wine (Bobet and others 1990), but results from a study where MeSH and DMDS concentrations were monitored over 1 year of bottle storage observed trends that contradicted a direct equilibrium between MeSH and DMDS (Ugliano and others 2012). Reactions of cysteine and methionine with certain $\alpha$-dicarbonyl compounds (glyoxal or methylglyoxal, for example) have been shown to form $\mathrm{H}_{2} \mathrm{~S}$ or $\mathrm{MeSH}$ under model wine conditions after 4 weeks of storage at room temperature (Pripis-Nicolau and others 2000). Cysteine and glutathione spiked into model wine ( $\mathrm{pH}$ 3.6), both with and without added copper, stored at $20{ }^{\circ} \mathrm{C}$ in an anaerobic environment for 6 months were found to produce $\mathrm{H}_{2} \mathrm{~S}$ concentrations slightly above the odor detection threshold in red wine (Bekker and others 2016c). The conversion rate from potential precursors to $\mathrm{H}_{2} \mathrm{~S}$ or MeSH is no doubt strongly dependent on complex interactions with wine components (such as metal ions, quinones, tannins), length of storage, and $\mathrm{pH}$. Furthermore, the actual concentrations of $\mathrm{H}_{2} \mathrm{~S}$ and $\mathrm{MeSH}$ at a given time are dependent on reactivity with other wine components as well (Franco-Luesma and Ferreira 2014).

A further challenge associated with studying post-bottle emergence of VSCs is their quantification, which is difficult due to their presence at low concentrations in wine and high reactivity (López and others 2007). In the context of wine analysis, static headspace (HS) and solid-phase microextraction (SPME) appear to be the two most common sampling methods for VSCs. Static HS paired with gas chromatography (GC) and sulfur chemoluminescence detection (SCD) has been cited several times (Siebert and others 2010; Ugliano and others 2012). Methods using SPME with GC and pulsed flame photometric detection (PFPD) have also been developed (Fang and Qian 2005; López and others 2007). 
Instrumental methods allow for automatization, enabling high sample throughput in the research lab environment, however they are cost prohibitive and require highly skilled analysts, making them unrealistic for basic winery labs. Gas detection tubes, first used in the mining industry to monitor levels of toxic $\mathrm{H}_{2} \mathrm{~S}$ in the air, have also been used to monitor evolution of $\mathrm{H}_{2} \mathrm{~S}$ over fermentation (Park 2008; Ugliano and Henschke 2010), to quantify $\mathrm{H}_{2} \mathrm{~S}$ generated by elemental sulfur residue in grape must (Kwasniewski and others 2011), and to quantify $\mathrm{H}_{2} \mathrm{~S}$ released from copper complexes in wine (Chen and others 2016). Optimization of a convenient, sensitive, and reliable method for assessing a wine's risk of $\mathrm{H}_{2} \mathrm{~S}$ emergence during bottle storage would not only be useful for implementation in winery labs, but would also be helpful in elucidating the chemical origin of $\mathrm{H}_{2} \mathrm{~S}$ released over bottle storage. Considering that VSC emergence is a slow process occurring over months to years of storage, an accelerated method for determining risk is a prerequisite for usefulness and implementation by winemakers. An accelerated aging procedure under strict oxygen-free conditions was developed that involved incubation of wines at $50{ }^{\circ} \mathrm{C}$ for 3 weeks (Franco-Luesma and Ferreira 2016a). Acceptable correlation of $\mathrm{H}_{2} \mathrm{~S}, \mathrm{MeSH}$, and DMS concentrations between wines aged at $50{ }^{\circ} \mathrm{C}$ and $25^{\circ} \mathrm{C}$ were found, suggesting that the $50{ }^{\circ} \mathrm{C}$ assay is effective for evaluating the tendency that a given wine may have for VSC emergence over aging in low oxygen environments (Franco-Luesma and Ferreira 2016a; Franco-Luesma and Ferreira 2016b). For example, $\mathrm{H}_{2} \mathrm{~S}$ concentrations after 1 year at $25{ }^{\circ} \mathrm{C}$ were $57 \%$ lower than concentrations at 12.5 days at $50{ }^{\circ} \mathrm{C}$, with $R^{2}=0.83(p<0.0001)$.

A winery level pre-bottling test of susceptibly for accumulating $\mathrm{H}_{2} \mathrm{~S}$ or MeSH over aging does not currently exist nor are there any corrective actions a winemaker can take 
when this problem is identified post-bottling. The lack of preventative and corrective measures to address this fault is mainly due to the fact that the compounds and mechanisms behind the emergence of $\mathrm{H}_{2} \mathrm{~S}$ and $\mathrm{MeSH}$ during low oxygen bottle storage are not fully understood. The present study aimed to develop a convenient test for assessing the risk a wine may have for developing $\mathrm{H}_{2} \mathrm{~S}$ issues over aging and investigate the emergence of $\mathrm{H}_{2} \mathrm{~S}$ after accelerated aging and treatment with a reducing agent in wines spiked with hypothesized precursors.

\section{Materials and Methods}

\subsection{Solvents and chemical standards}

4-methylcatechol, acetonitrile, periodic acid, amberlyst A-26 resin, tetrahydrofuran, anhydrous ethyl ether, tris(2-carboxyethyl)phosphine (TCEP), polyethylene glycol 400, elemental sulfur, Alka-Seltzer tablets (Bayer Healthcare, Morristown, $\mathrm{NJ}$ ), $\mathrm{H}_{2} \mathrm{~S}$ gas ( 1 and $500 \mathrm{mg} / \mathrm{L}$ canisters, balanced with $\mathrm{N}_{2}$ ), methyl thioacetate (96\% purity), dimethyl disulfide, cysteine, glutathione, methanol, potassium metabisulfite, $10 \mathrm{~N} \mathrm{NaOH}$, tartaric acid, Everclear (95\% abv, Luxco Inc, St. Louis, MO), and distilled, deionized (DI) water.

\subsection{Wines and model wine}

Three wines were used in preliminary experiments: Syrah (2014, pH 3.8), Chambourcin (Missouri, 2015), and Sauvignon Blanc (Monkey Bay Winery, New Zealand, 2014). Syrah and Chambourcin wines were produced at the University of MissouriColumbia research winery, and the Sauvignon Blanc was purchased from a local wine store. Model wine was prepared with a $12 \%(\mathrm{v} / \mathrm{v})$ ethanol in deionized water solution, 5 $\mathrm{g} / \mathrm{L}$ tartaric acid, and $\mathrm{pH}$ adjusted to 3.5 using $5 \mathrm{~N} \mathrm{NaOH}$. For a second study, Cabernet 
Sauvignon (Ravage Winery, California, 2014, 13.5\% (v/v) alcohol) and Pinot Grigio (Gnarly Head Winery, California, 2015, 13\% (v/v) alcohol) were purchased from a local wine store. Wines were selected based on price range ( $\$ 6$ and $8 /$ bottle), good representation of general wines, and fault-free (no reductive off-odors). The same Syrah (2014) was also used in this second study.

\subsection{Synthesis of $\mathrm{H}_{2} \mathrm{~S}-4$-methylcatechol adduct mixture}

\subsubsection{Preparation of 4-methyl-1,2-benzoquinone by periodate resin}

The reaction was carried out according to previously published methods (Jongberg and others 2011; Nikolantonaki and Waterhouse 2012). First, periodate resin was prepared as follows: amberlyst A-26 resin (18 $\mathrm{g})$ was mixed with $50 \mathrm{~mL}$ deionized (Milli-Q) water, then $9.9 \mathrm{~g}$ periodic acid was added and the mixture was stirred at room temperature for two hours. Excess water was drained, resin was rinsed with four aliquots of $200 \mathrm{~mL}$ water, two aliquots of tetrahydrofuran, and two aliquots of $100 \mathrm{~mL}$ anhydrous ethyl ether. Then resin was dried over vacuum for 30 minutes (Jongberg and others 2011). To form the model quinone, 4-methyl-1,2-benzoquinone (Q4MeC), 4-methylcatechol (7.8 $\mathrm{mg}$ ) was dissolved in $2.5 \mathrm{~mL}$ of acetonitrile by stirring under inert atmosphere for 10 minutes. Periodate resin $(100 \mathrm{mg})$ was added and allowed to react while stirring under inert atmosphere for 5 minutes. The reaction mixture was transferred to a vial, then the resin was washed with a $1.0-1.5 \mathrm{~mL}$ aliquot of acetonitrile, which was collected and added to vial with reaction mixture (Nikolantonaki and Waterhouse 2012). The quinone solution was stored in a vial sparged with nitrogen, chilled, and ideally used within 30 minutes. 


\subsubsection{Preparation of $\mathrm{H}_{2} \mathrm{~S}-4$-methylcatechol adducts mixture}

In the publication used for $\mathrm{Q} 4 \mathrm{MeC}$ synthesis (Nikolantonaki and Waterhouse 2012), $1 \mathrm{mM}$ Q4MeC was reacted with an excess $(4 \mathrm{mM})$ of $\mathrm{H}_{2} \mathrm{~S}$ in the form of $\mathrm{Na}_{2} \mathrm{~S} \cdot 9 \mathrm{H}_{2} \mathrm{O}$ to prepare the $\mathrm{H}_{2} \mathrm{~S}-4 \mathrm{MeC}$ adducts mixture. In the present work, to avoid impurities from $\mathrm{Na}_{2} \mathrm{~S} \cdot 9 \mathrm{H}_{2} \mathrm{O}$ in the final product, $\mathrm{H}_{2} \mathrm{~S}-4$-methylcatechol $\left(\mathrm{H}_{2} \mathrm{~S}-4 \mathrm{MeC}\right)$ adducts mixture was prepared using a gas canister to bubble gaseous $\mathrm{H}_{2} \mathrm{~S}$ into model wine with Q4MeC. In a $120 \mathrm{~mL}$ graduated beaker, $3 \mathrm{~mL}$ of the $\mathrm{Q} 4 \mathrm{MeC}$ reaction mixture was brought up to $80 \mathrm{~mL}$ with model wine. This beaker was sealed with a two-holed rubber stopper, where one allowed PEEK tubing (red striped, $1 / 16$ " o.d., 0.005 " i.d., approximately $5 \mathrm{ft}$ long) to enter the beaker and another allowed air to exit the system into a 4LL Gastec tube to monitor escaping $\mathrm{H}_{2} \mathrm{~S}$ levels. The PEEK tubing was submerged into the solution slightly above the bottom of the beaker. A flow from the $500 \mathrm{mg} / \mathrm{L} \mathrm{H}_{2} \mathrm{~S}$ gas canister of approximately 10 $15 \mathrm{~mL} / \mathrm{min}$ was measured using an electric flowmeter. Using this flow rate, it was calculated that approximately $1.5 \times 10^{-4} \mathrm{~mol} \mathrm{H}_{2} \mathrm{~S} /$ min were produced by the canister. At significantly faster flow rates (such as $60 \mathrm{~mL} / \mathrm{min}$ ), the solution would quickly become saturated with $\mathrm{H}_{2} \mathrm{~S}$ resulting in excessive levels exiting the beaker (as determined by color change on attached gas detection tube) and at some points, causing the stopper to pop off from pressure build up. At slower flow rates than $10 \mathrm{~mL} / \mathrm{min}$, achieving the required $\mathrm{H}_{2} \mathrm{~S}$ doses would take a number of hours. The necessary $\mathrm{H}_{2} \mathrm{~S}$ dose was calculated using the rough final concentration of quinone provided by the authors of the synthesis procedure: one reaction, as completed above, results in a $\mathrm{Q} 4 \mathrm{MeC}$ concentration of approximately $23 \mathrm{mM}$, so diluted to a volume of $80 \mathrm{~mL}$ gives a concentration of about $0.86 \mathrm{mM} \mathrm{Q} 4 \mathrm{MeC}$ 
and would require a 4-fold excess of $\mathrm{H}_{2} \mathrm{~S}$ at $3.44 \mathrm{mM}$, which was achieved by about 25 minutes of $\mathrm{H}_{2} \mathrm{~S}$ dosing from the canister as described above.

\subsection{Measurement of $\mathrm{H}_{2} \mathrm{~S}$ with colorimetric gas detection tubes}

Gas detection tubes with two levels of sensitivity were used to measure $\mathrm{H}_{2} \mathrm{~S}$ after accelerated aging treatments, Gastec 4LL and 4LT (Nextteq, Tampa, FL). Tubes are filled with a metal salt (lead acetate in 4LL and mercury chloride in 4LT) and inert packing material which undergoes a colorimetric reaction with $\mathrm{H}_{2} \mathrm{~S}$ as it moves into the tube. The length of color change along the tube (measured in $\mathrm{mm}$ ) is proportional to the quantity of $\mathrm{H}_{2} \mathrm{~S}$ present $(\mathrm{y}=0.234 \mathrm{x}-0.435$ for $4 \mathrm{LL}$ and $0.5 \mathrm{~mm}=1.25 \mu \mathrm{g} / \mathrm{L}$ for $4 \mathrm{LT})$.

$\mathrm{H}_{2} \mathrm{~S}$ measurements were carried out by attaching the tube to an apparatus built as described in a previous publication (Kwasniewski and others 2011). One Alka-Seltzer tablet was added to the $40 \mathrm{~mL}$ sample and the lid was quickly sealed. Carbon dioxide generated by the tablet pushed $\mathrm{H}_{2} \mathrm{~S}$ gas through the apparatus into the gas detection tube. Tablets also served to buffer samples at $\mathrm{pH}$ 6. To ensure complete transfer of $\mathrm{H}_{2} \mathrm{~S}$, a second tablet was added about 5 minutes after the first and allowed to react for another 5 minutes before the length of color change on the detection tube was recorded. The apparatus was checked for leaks on a regular basis.

Interference in the $\mathrm{H}_{2} \mathrm{~S}$ reaction with mercury chloride in 4LT was reported by $\mathrm{MeSH}$ at $50 \mu \mathrm{g} / \mathrm{L}$ (Ugliano and Henschke 2010) and a linear response for MeSH levels between $0-0.477 \mu \mathrm{M}$ was also observed (Chen and others 2016). Potential interferences by $\mathrm{HSO}_{3}{ }^{-}, \mathrm{SO}_{4}{ }^{2-}$, and disulfides have been addressed and found not to impact $\mathrm{H}_{2} \mathrm{~S}$ measurement in neither 4LL nor 4LT tubes at the $\mathrm{pH}$ of this procedure (Ugliano and Henschke 2010; Kwasniewski and others 2011; Chen and others 2016). 


\subsection{Accelerated aging procedure}

Graduated glass beakers $(120 \mathrm{~mL})$ with screw cap lids were selected as aging vessels due to their heat-resistance and compatibility with the $\mathrm{H}_{2} \mathrm{~S}$ measurement apparatus. Wine (Syrah, Chambourcin) or model wine samples $(40 \mathrm{~mL})$ in $120 \mathrm{~mL}$ glass beakers were sparged with $\mathrm{N}_{2}$, tightly sealed, and incubated in a water bath at $50,65,80$ or $100{ }^{\circ} \mathrm{C}$ for various time periods between 10 minutes to 2 weeks. This method is roughly based on a previous publication (Franco-Luesma and Ferreira 2016a). Two beakers were fitted with two Presens PSt3 oxygen sensors (Presens, Regensburg, Germany) to measure headspace and dissolved oxygen, filled with $40 \mathrm{~mL}$ model wine, and incubated with samples in order to verify that the vessels were air tight throughout the treatment. After sample incubation, beakers were removed from the bath, 50 and $65^{\circ} \mathrm{C}$ treatments were measured as quickly as possible after removing, and 80 and $100{ }^{\circ} \mathrm{C}$ treatments were allowed to cool for approximately 5 - 10 minutes to avoid excessive foaming after Alka-Seltzer tablet addition. Analysis of $\mathrm{H}_{2} \mathrm{~S}$ was carried out as described above. Incubation temperatures of $50{ }^{\circ} \mathrm{C}$ for 1 week and $80^{\circ} \mathrm{C}$ for 1 hour were selected for further accelerated aging experiments.

\subsection{Emergence of $\mathrm{H}_{2} \mathrm{~S}$ after accelerated aging of model wine and wine spiked with potential $\mathrm{H}_{2} \mathrm{~S}$ precursors}

Compounds previously hypothesized as potential precursors for $\mathrm{H}_{2} \mathrm{~S}$ under accelerated aging and normal aging conditions were selected for use in the present study. Each was spiked into wine (Syrah, Cabernet Sauvignon, or Pinot Grigio) and model wine at concentrations near or above the upper limits of their normal wine levels. Concentrations used for hypothesized precursors are as follows: $10 \mathrm{mg} / \mathrm{L}$ cysteine (cys), $100 \mathrm{mg} / \mathrm{L}$ glutathione (glu), $10 \mathrm{~mL}$ aliquot of $\mathrm{H}_{2} \mathrm{~S}-4 \mathrm{MeC}$ adducts mixture (synthesized following the 
above method), $100 \mathrm{mg} / \mathrm{L}$ elemental sulfur $\left(\mathrm{S}^{0}\right), 1 \mathrm{mg} / \mathrm{L}$ methyl thioacetate (MTA), 50 $\mathrm{mg} / \mathrm{L}$ sulfur dioxide $\left(\mathrm{SO}_{2}\right), 50 \mu \mathrm{g} / \mathrm{L}$ dimethyl disulfide (DMDS). Samples for each precursor were prepared in triplicate as follows: an aliquot of the precursor solution was added to the beaker, then the volume was brought up to $40 \mathrm{~mL}$ with wine or model wine. Free $\mathrm{H}_{2} \mathrm{~S}$ concentrations were obtained by measuring $\mathrm{H}_{2} \mathrm{~S}$ at room temperature. For accelerated aging, samples were incubated in a water bath at $50{ }^{\circ} \mathrm{C}$ for 1 week or $80^{\circ} \mathrm{C}$ for 1 hour. Addition of TCEP was another strategy used to determine $\mathrm{H}_{2} \mathrm{~S}$ emergence from model wine, wine, and wine spiked with precursors. In TCEP treatments, one Alka-Seltzer tablet was added to sparge the beaker and buffer the sample to $\mathrm{pH} 6$, then after bubbling subsided, $20-25 \mathrm{mg}$ of TCEP was added and given 15 minutes to react. One tablet was added after the reaction time, and a second tablet 5 minutes later. $\mathrm{H}_{2} \mathrm{~S}$ concentrations were erroneously high in the majority of $\mathrm{S}^{0}$ treatments in accelerated aging and TCEP experiments, likely due to impurity in the commercial reagent, therefore those results are not considered in this work.

\subsection{Statistical Analysis and Data Treatment}

Microsoft Office Excel 2010 (Redmond, WA) was used for basic statistical analyses. MiniTab version 17.1.0 (State College, PA) was used for 1-way ANOVA and Tukey HSD $(\mathrm{p}<0.05)$.

\section{Results}

\subsection{Emergence of $\mathrm{H}_{2} \mathrm{~S}$ in wines after accelerated aging}

The impact of incubating wine at elevated temperatures on $\mathrm{H}_{2} \mathrm{~S}$ emergence to model aging at an accelerated rate was evaluated on a "reduced" Syrah with an intense rotten egg odor (Figure 3.1). Bottled control samples $(750 \mathrm{~mL}$, sealed with screw caps) were stored 
at cellar temperature $\left(15.5^{\circ} \mathrm{C}\right)$ and measured at the same time increments as treatments kept at higher temperatures. $\mathrm{H}_{2} \mathrm{~S}$ concentrations in the control stayed constant $(10.4 \mu \mathrm{g} / \mathrm{L})$ until increasing to $12.5 \mu \mathrm{g} / \mathrm{L}$ at 1 week. Slightly larger values were observed in wine aged at $50{ }^{\circ} \mathrm{C}$ compared to the control. After 80 minutes at $50{ }^{\circ} \mathrm{C}$, emergence of $\mathrm{H}_{2} \mathrm{~S}$ gradually increased from $12.5 \mu \mathrm{g} / \mathrm{L}$ for the duration of the aging time period, reaching a value of 34.4 $\pm 4.0 \mu \mathrm{g} / \mathrm{L}$ at 2 weeks. Emergence of $\mathrm{H}_{2} \mathrm{~S}$ while aging at $65^{\circ} \mathrm{C}$ followed similar trends as $50{ }^{\circ} \mathrm{C}$ with slightly higher values until the final measurement at 240 minutes where levels in $65^{\circ} \mathrm{C}$ decreased to nearly the same value as observed in $50{ }^{\circ} \mathrm{C}$. Long term measurements of $\mathrm{H}_{2} \mathrm{~S}$ emergence at $65{ }^{\circ} \mathrm{C}$ were not taken due to the similarities between $50{ }^{\circ} \mathrm{C}$. Concentrations of $\mathrm{H}_{2} \mathrm{~S}$ emerging after aging at $80{ }^{\circ} \mathrm{C}$ were higher, but followed similar general trends in increases over the aging period. Over the first 30 minutes of model aging at $100{ }^{\circ} \mathrm{C}, \mathrm{H}_{2} \mathrm{~S}$ levels sharply increased to $35.0 \pm 1.5 \mu \mathrm{g} / \mathrm{L}$, then gradually increased again at 80 minutes to $39.3 \pm 1.5 \mu \mathrm{g} / \mathrm{L}$ where they remained constant for the remainder of the aging period. After 2 week of aging at $50{ }^{\circ} \mathrm{C}(34.4 \pm 4.0 \mu \mathrm{g} / \mathrm{L}), \mathrm{H}_{2} \mathrm{~S}$ emergence was similar to the maximum value reached during aging at $80{ }^{\circ} \mathrm{C}$ during the first 4 hours $(31.8 \mu \mathrm{g} / \mathrm{L}$ at 80 minutes) and slightly less than the maximum value during aging at $100{ }^{\circ} \mathrm{C}(39.3 \pm 1.5 \mu \mathrm{g} / \mathrm{L})$.

A similar experiment using only two temperatures $\left(50\right.$ and $\left.100{ }^{\circ} \mathrm{C}\right)$ was carried out on a Chambourcin with no sulfurous off-odors (Figure 3.2). Production of $\mathrm{H}_{2} \mathrm{~S}$ at $50{ }^{\circ} \mathrm{C}$ did not occur until 240 minutes of aging $(4.0 \mu \mathrm{g} / \mathrm{L})$. Measurements were also taken at 24 hours, 1 week, 2 weeks, and 3 weeks at $50{ }^{\circ} \mathrm{C}$ and were found to be $0,11.5 \pm 1.2,10.4$, and 14.7 $\mu \mathrm{g} / \mathrm{L}$, respectively. Aging at $100{ }^{\circ} \mathrm{C}$ resulted in a similar trend in emergence as to what was 
observed in 80 and $100{ }^{\circ} \mathrm{C}$ with Syrah, where a relatively large increase in concentrations of $\mathrm{H}_{2} \mathrm{~S}$ emerged within the first 80 minutes followed by a more gradual increase. Emergence of $\mathrm{H}_{2} \mathrm{~S}$ at 240 minutes of incubation at $100{ }^{\circ} \mathrm{C}$ was measured at $26.8 \pm 1.2 \mu \mathrm{g} / \mathrm{L}$ in the Chambourcin.

\section{2 $\mathrm{H}_{2} \mathrm{~S}-4 \mathrm{MeC}$ adducts reaction mixture analysis}

Preliminary analysis by UPLC MALDI-Q-TOF indicated that various dimers, trimers, and larger polymers of the adduct were likely present in the $\mathrm{H}_{2} \mathrm{~S}-4 \mathrm{MeC}$ reaction mixture. Structures of products responsible for those peaks were not determined. The initial polyphenol, 4-methylcatechol, was also present in the reaction mixture, which may be due to incomplete conversion to the quinone and/or conversion from the quinone back to the phenol. No further purification was carried out after synthesis in order to more easily explore the potential reversible nature of all forms of the adduct as a whole. Furthermore, the reaction mixture did not contain other impurities that would interfere with potential emergence of $\mathrm{H}_{2} \mathrm{~S}$ from the adducts.

\subsection{Emergence of $\mathrm{H}_{2} \mathrm{~S}$ after accelerated aging in model wine and wines spiked with hypothesized precursors}

\subsubsection{Preliminary tests in wine}

Preliminary results for the emergence of $\mathrm{H}_{2} \mathrm{~S}$ from three wines (Syrah, Chambourcin, Sauvignon Blanc) spiked with hypothesized precursors are shown in Table 3.1. Due to the small sample size ( $\mathrm{n}=2$ in most treatments), statistical analyses were not carried out. However, several general and interesting trends can be noted from this data. Initial $\mathrm{H}_{2} \mathrm{~S}$ values taken in control wines without heating were $10.4 \mu \mathrm{g} / \mathrm{L}$ in Syrah and not detectable in both Chambourcin and Sauvignon Blanc. Comparing initial concentrations to 
the control after 1 hour of incubation at $80{ }^{\circ} \mathrm{C}$, the red wines appeared to have larger pools from which $\mathrm{H}_{2} \mathrm{~S}$ can be released during aging than white, as suggested by the larger increases in $\mathrm{H}_{2} \mathrm{~S}$ emergence in Syrah and Chambourcin. These preliminary results may also point to the potential for interactions between other components in wine which promote or inhibit $\mathrm{H}_{2} \mathrm{~S}$ emergence from certain precursors over aging. For example, treatments where cysteine and methyl thioacetate (MTA) were spiked in Chambourcin resulted in approximately twice the $\mathrm{H}_{2} \mathrm{~S}$ concentration after aging $(20.6 \pm 0.9$ and $22.5 \pm 1.8 \mu \mathrm{g} / \mathrm{L}$, cysteine and MTA respectively) compared to the control $(10.8 \pm 0.7 \mu \mathrm{g} / \mathrm{L})$. A similarly large increase was not observed with MTA in white or Syrah and potentially seen with cysteine in both, but large standard deviations make it more difficult to determine. A relatively large increase compared to the control was also observed in white wine spiked with glutathione ( 3.8 compared to $12.5 \pm 5.3 \mu \mathrm{g} / \mathrm{L})$, but not in Syrah $(21.8 \pm 1.2$ compared to $22.2 \pm 1.5 \mu \mathrm{g} / \mathrm{L}$ ). Again, due to the small sample size these interesting differences were noted and additional studies were carried out to further investigate their occurrence.

\subsubsection{Tests in model wine}

Several hypothesized precursors were spiked into model wine and treated under the same accelerated aging and reducing agent conditions as experiments with wine samples (Table 3.2). Due to the small sample size ( $n=2$ in most treatments), statistical analyses were not carried out and only general trends should be noted from this data. At $50{ }^{\circ} \mathrm{C}$, heat or acid related degradation of cysteine, glutathione, or $\mathrm{H}_{2} \mathrm{~S}-4 \mathrm{MeC}$ did not appear to result in the formation of $\mathrm{H}_{2} \mathrm{~S}$. Trace levels in cysteine and glutathione, moderate concentration in MTA, and no formation of $\mathrm{H}_{2} \mathrm{~S}$ from $\mathrm{H}_{2} \mathrm{~S}-4 \mathrm{MeC}$ were observed at $80^{\circ} \mathrm{C}$. No emergence of $\mathrm{H}_{2} \mathrm{~S}$ occurred from glutathione or $\mathrm{H}_{2} \mathrm{~S}-4 \mathrm{MeC}$ at $100{ }^{\circ} \mathrm{C}$, while trace levels emerged with 
cysteine and moderate levels with MTA again. Treatment of the spiked model wine with a strong reducing agent (TCEP) resulted in relatively similar emergence of $\mathrm{H}_{2} \mathrm{~S}$ from all hypothesized precursors tested.

\subsubsection{Tests in wine}

Figure 3.3 summarizes $\mathrm{H}_{2} \mathrm{~S}$ emergence in Syrah spiked with hypothesized precursors at room temperature (free $\left.\mathrm{H}_{2} \mathrm{~S}\right)$, after accelerated aging $\left(50{ }^{\circ} \mathrm{C}\right.$ for 1 week and $80{ }^{\circ} \mathrm{C}$ for 1 hour), and after addition of a reducing agent (TCEP). Due to large variability or lack of sufficient replicate measurements $(\mathrm{n}<3)$, results for Control, $\mathrm{H}_{2} \mathrm{~S}-4 \mathrm{MeC}$ adducts, and MTA at $50{ }^{\circ} \mathrm{C}$ are not displayed in Figure 3.3. Mean values with standard deviation and significant differences in $\mathrm{H}_{2} \mathrm{~S}$ emergence in Syrah between hypothesized precursors within the same aging treatment are shown in Table 3.3. At room temperature, significantly lower levels of $\mathrm{H}_{2} \mathrm{~S}$ emerged in glutathione, $\mathrm{H}_{2} \mathrm{~S}-4 \mathrm{MeC}$ adducts, MTA, $\mathrm{SO}_{2}$, DMDS (mean value of $8.7 \pm 1.2 \mu \mathrm{g} / \mathrm{L})$ compared to the control $(14.7 \mu \mathrm{g} / \mathrm{L})$. After accelerated aging treatment at $80^{\circ} \mathrm{C}$, cysteine $(41.0 \pm 3.3 \mu \mathrm{g} / \mathrm{L})$ was found to have significantly higher levels

of $\mathrm{H}_{2} \mathrm{~S}$ formation compared to all other hypothesized precursors (ranging between $15.4 \pm$ 1.2 to $29.6 \pm 2.2 \mu \mathrm{g} / \mathrm{L})$ and the control $(21.8 \pm 1.2 \mu \mathrm{g} / \mathrm{L})$. Emergence from Syrah spiked with $\mathrm{H}_{2} \mathrm{~S}-4 \mathrm{MeC}$ adducts $(15.4 \pm 1.2 \mu \mathrm{g} / \mathrm{L})$ was significantly lower than all other hypothesized precursors and the control at $80{ }^{\circ} \mathrm{C}$. The only significant difference observed in Syrah after TCEP addition was between $\mathrm{H}_{2} \mathrm{~S}-4 \mathrm{MeC}$ adducts $(15.4 \pm 1.2 \mu \mathrm{g} / \mathrm{L})$ compared to the other precursors and control (mean value of $21.0 \pm 1.5 \mu \mathrm{g} / \mathrm{L}$ ).

Accelerated aging treatments at $50^{\circ} \mathrm{C}$ for 1 week and $80^{\circ} \mathrm{C}$ for 1 hour and treatment with TCEP were also carried out on a Pinot Grigio and Cabernet Sauvignon spiked with hypothesized precursors to measure emergence of $\mathrm{H}_{2} \mathrm{~S}$ in a red and white wine without 
"reductive" off odors (Table 3.4). Free $\mathrm{H}_{2} \mathrm{~S}$ in control white was $10 \pm 3.5 \mu \mathrm{g} / \mathrm{L}$ and undetectable in control red wine. In white wine at $50{ }^{\circ} \mathrm{C}$, no significant differences in $\mathrm{H}_{2} \mathrm{~S}$ emergence were observed between control, glutathione, or $\mathrm{SO}_{2}$ (mean value of $12.8 \pm 1.3$ $\mu \mathrm{g} / \mathrm{L})$. Emergence from $\mathrm{H}_{2} \mathrm{~S}-4 \mathrm{MeC}$ adducts $(25.9 \pm 1.9 \mu \mathrm{g} / \mathrm{L})$ was found to be significantly greater than all other hypothesized precursors and control, while emergence from MTA $(6.8 \pm 1.3 \mu \mathrm{g} / \mathrm{L})$ was significantly lower than all others and control. In general, $\mathrm{H}_{2} \mathrm{~S}$ emergence at $50{ }^{\circ} \mathrm{C}$ from the Cabernet Sauvignon was lower than values found in Pinot Grigio. No significant differences between the Cabernet Sauvignon control, glutathione, or DMDS were found at $50{ }^{\circ} \mathrm{C}$. In red wine spiked with $\mathrm{SO}_{2}(12.5 \pm 1.3 \mu \mathrm{g} / \mathrm{L}), \mathrm{H}_{2} \mathrm{~S}$ emergence was significantly higher than all other treatments except MTA $(10.4 \pm 0.7 \mu \mathrm{g} / \mathrm{L})$.

\section{Discussions}

This study had two main goals: 1) develop a convenient test for assessing the risk a wine may have for developing $\mathrm{H}_{2} \mathrm{~S}$ issues over aging and 2) investigate the emergence of $\mathrm{H}_{2} \mathrm{~S}$ after accelerated aging or treatment with a reducing agent in wines spiked with hypothesized precursors. The assay developed in the present study was based on previous work monitoring $\mathrm{H}_{2} \mathrm{~S}$ emergence during accelerated model aging under oxygen free conditions at $50{ }^{\circ} \mathrm{C}$ for $2-3$ weeks (Franco-Luesma and Ferreira 2016a). In an effort to minimize wait time involved in the test, elevated incubation temperatures were evaluated to determine the impact on $\mathrm{H}_{2} \mathrm{~S}$ emergence over a shorter aging period. By decreasing incubation time from 3 weeks to 1 hour, paired with the use of an inexpensive, convenient

method for $\mathrm{H}_{2} \mathrm{~S}$ measurement instead of SPME-GC-PFPD, the procedure by FrancoLuesma and Ferreira (2016a) was converted to an assay that can be easily performed and provide useful information for winemakers. Recent publications have focused on $\mathrm{H}_{2} \mathrm{~S}$ 
formation over bottle aging from a single pool of metal complexes (Franco-Luesma and Ferreira 2016a; Kreitman and others 2016b; Bekker and others 2016c). To investigate other possible pools of $\mathrm{H}_{2} \mathrm{~S}$, compounds not yet studied for their potential to form $\mathrm{H}_{2} \mathrm{~S}$ during aging were spiked in three wines for accelerated aging and reducing agent treatment.

\subsection{Trends in emergence of $\mathrm{H}_{2} \mathrm{~S}$ in two red wines during accelerated aging}

Emergence of $\mathrm{H}_{2} \mathrm{~S}$ from two red wines, a "reduced" Syrah and fault-free Chambourcin, was characterized over time at various temperatures (see Figures 3.1 and 3.2). In general, trends in $\mathrm{H}_{2} \mathrm{~S}$ evolution at $100{ }^{\circ} \mathrm{C}$ during the first 4 hours of aging were relatively similar in both wines. The fast production of $\mathrm{H}_{2} \mathrm{~S}$ during the first part of aging could correspond to release of $\mathrm{H}_{2} \mathrm{~S}$ from more loosely bound complexes or less stable precursor molecules. The early rapid release was followed by a short period of slow increase, which could suggest further depletion of the same first pool before emergence from other compounds which require more time and/ or energy for bonds to break or reactions to occur. Although the general trends were similar, initial $\mathrm{H}_{2} \mathrm{~S}$ emergence occurred more rapidly in Syrah than Chambourcin, and eventually leveled off, whereas levels in Chambourcin continued to increase until the final measurement at 4 hours. Free $\mathrm{H}_{2} \mathrm{~S}$ before aging was $10.4 \mu \mathrm{g} / \mathrm{L}$ in Syrah and not detectable in Chambourcin. Interestingly, differences in the initial concentrations were comparable to differences in the maximum values of $\mathrm{H}_{2} \mathrm{~S}$ produced at $100 \quad{ }^{\circ} \mathrm{C} \quad(39.3 \quad \pm \quad 1.5$ and $26.8 \quad \pm \quad 1.2 \mu \mathrm{g} / \mathrm{L}$, in the Syrah and Chambourcin).

Minimal increases in $\mathrm{H}_{2} \mathrm{~S}$ emergence occurred during 4 hours of aging at 50 and $65^{\circ} \mathrm{C}$, intermediate increases were seen at $80^{\circ} \mathrm{C}$ and more extreme increases at $100{ }^{\circ} \mathrm{C}$. A relationship between temperature is be expected, but whether the increases are due to 
increased reaction rates of the same reactions at both temperature ranges or triggering new reactions is uncertain. To address concerns that heat decomposition of cysteine, glutathione, MTA, or $\mathrm{H}_{2} \mathrm{~S}-4 \mathrm{MeC}$ adducts could be responsible for the observed increases in $\mathrm{H}_{2} \mathrm{~S}$ generation at 80 and $100^{\circ} \mathrm{C}$, aging with these compounds spiked into model wine was conducted. Results from these tests are shown in Table 2 and confirmed that significant levels of $\mathrm{H}_{2} \mathrm{~S}$ were not produced by glutathione and cysteine at 80 or $100{ }^{\circ} \mathrm{C}$, which is in agreement with other work (Gruenwedel and Patnaik 1971). Heat related reversibility was not apparent for $\mathrm{H}_{2} \mathrm{~S}-4 \mathrm{MeC}$ adducts at any of the temperatures tested. MTA was found to be highly sensitive to elevated temperatures, however the large response may potentially be due to MeSH formed by acid hydrolysis (Bracher and others 2011). High concentrations of $\mathrm{MeSH}$ are known to interfere with $\mathrm{HgCl}_{2}$ in $4 \mathrm{LT}$ gas detection tubes (Ugliano and Henschke 2010; Kwasniewski and others 2011; Chen and others 2016). Additionally, the MTA concentrations used in this work $(70 \mu \mathrm{g} / \mathrm{L}$ in model wine and $1 \mathrm{mg} / \mathrm{L}$ in experiments discussed later) are well above normal wine levels of non-detectable to $20 \mu \mathrm{g} / \mathrm{L}$, with a maximum around $150 \mu \mathrm{g} / \mathrm{L}$ (Fang and Qian 2005; Ye and others 2016), which may further exaggerate the production of MeSH from MTA under the conditions here.

Incubation for 1 hour at $80^{\circ} \mathrm{C}$ was selected for further accelerated aging tests based on similar concentrations achieved by 80 minutes at $80{ }^{\circ} \mathrm{C}(31.8 \mu \mathrm{g} / \mathrm{L})$ compared to 2 weeks of aging at $50{ }^{\circ} \mathrm{C}(34.4 \pm 4.0 \mu \mathrm{g} / \mathrm{L})$ in Syrah. Logistically, maintaining a water bath at $100{ }^{\circ} \mathrm{C}$ would require frequent monitoring and refilling to maintain water levels after evaporation, making $80{ }^{\circ} \mathrm{C}$ a more practical temperature as well. Franco-Luesma and Ferreira (2016a) hypothesized that large increases in free and total forms of $\mathrm{H}_{2} \mathrm{~S}$ and MeSH that they observed when testing accelerated aging at $70{ }^{\circ} \mathrm{C}$ were due to degradation of 
cysteine and methionine. However, no data was presented in the paper to support their decision. Furthermore, our results from model wine tests with cysteine and glutathione confirmed that decomposition purely from elevated temperatures $\left(80\right.$ and $\left.100^{\circ} \mathrm{C}\right)$ was not a significant source of $\mathrm{H}_{2} \mathrm{~S}$, although methionine was not tested. We felt that accelerated aging at $80{ }^{\circ} \mathrm{C}$ would simply increase rates of reactions that would occur more slowly at normal temperatures and therefore provide a valid indication of a wine's tendency for $\mathrm{H}_{2} \mathrm{~S}$ emergence over bottle aging.

Given the complexity of reactions involved in the generation of $\mathrm{H}_{2} \mathrm{~S}$ under accelerated and normal aging conditions, the purpose of this assay is not to determine the precise quantity of $\mathrm{H}_{2} \mathrm{~S}$ that will emerge over normal bottle aging, but to assess the predisposition of a given wine for developing "reduction" problems. In order to make that information actionable for winemakers, the next steps include identifying bound complexes and molecular precursors that are responsible for liberating $\mathrm{H}_{2} \mathrm{~S}$. Afterwards, future work can focus on development of preventative and corrective treatments that can then be used on wines with the tendency for $\mathrm{H}_{2} \mathrm{~S}$ emergence.

\subsection{Emergence of $\mathrm{H}_{2} \mathrm{~S}$ after accelerated aging in wines spiked with}

\section{hypothesized precursors}

\subsubsection{Preliminary tests in wine}

Results in model wine testing of cysteine, glutathione, MTA, and $\mathrm{H}_{2} \mathrm{~S}-4 \mathrm{MeC}$ adducts demonstrated that elevated temperatures during model aging was not alone responsible for $\mathrm{H}_{2} \mathrm{~S}$ emergence from cysteine, glutathione, or $\mathrm{H}_{2} \mathrm{~S}-4 \mathrm{MeC}$ adducts. This suggest that if these compounds are in fact potential precursors in wine, interaction with other wine components not present in model wine is also required for reactions which 
convert these precursors and form $\mathrm{H}_{2} \mathrm{~S}$. Preliminary accelerated aging tests ( 1 hour of incubation at $80{ }^{\circ} \mathrm{C}$ ) of several precursors spiked into three wines were carried out (see Table 3.1) to investigate the influence of wine type on $\mathrm{H}_{2} \mathrm{~S}$ emergence from precursors. Free $\mathrm{H}_{2} \mathrm{~S}$ values taken in control wines without heating were $10.4 \mu \mathrm{g} / \mathrm{L}$ in Syrah and not detectable in both Chambourcin and Sauvignon Blanc. Comparing free $\mathrm{H}_{2} \mathrm{~S}$ concentrations to the control after 1 hour of incubation at $80{ }^{\circ} \mathrm{C}$, the two red wines appeared to have larger pools from which $\mathrm{H}_{2} \mathrm{~S}$ can be released during aging than white, as suggested by the larger increases in $\mathrm{H}_{2} \mathrm{~S}$ emergence in control Syrah and Chambourcin. This observation is the opposite trend than in other work which found that $\mathrm{H}_{2} \mathrm{~S}$ emergence over accelerated aging at $50{ }^{\circ} \mathrm{C}$ for 3 weeks was generally higher in white wines than red (Franco-Luesma and Ferreira 2016a). Differences in $\mathrm{H}_{2} \mathrm{~S}$ emergence from precursors among the three wines may point to the potential for interactions between other components in wine which promote or inhibit $\mathrm{H}_{2} \mathrm{~S}$ emergence from certain precursors over aging, and demonstrate the strong dependence of $\mathrm{H}_{2} \mathrm{~S}$ formation on wine type, in agreement with other studies (Chen and others 2016; Franco-Luesma and Ferreira 2016a). Large standard deviations in some treatments, small sample size, and limited number of precursors examined make it difficult to clearly draw conclusions from this preliminary test, therefore further experiments were conducted and the results are discussed below.

\subsubsection{Tests in wine}

Trends in $\mathrm{H}_{2} \mathrm{~S}$ emergence from hypothesized precursors in Syrah, Pinot Grigio, and Cabernet Sauvignon were examined after aging at $50{ }^{\circ} \mathrm{C}$ for 1 week, at $80^{\circ} \mathrm{C}$ for 1 hour, and/ or treatment with TCEP (Figure 3.3, Tables 3.3 and 3.4). It was hypothesized that under accelerated aging conditions, one or more precursors may form larger concentrations 
of $\mathrm{H}_{2} \mathrm{~S}$ than others, which could suggest that those precursors may be a source of $\mathrm{H}_{2} \mathrm{~S}$ or may act as mediators of emergence from other compounds over bottle aging. Significantly greater emergence of $\mathrm{H}_{2} \mathrm{~S}$ compared to the control was observed in at least one wine after accelerated aging for cysteine, $\mathrm{SO}_{2}$, and $\mathrm{H}_{2} \mathrm{~S}-4 \mathrm{MeC}$ adducts, but not glutathione.

Significant increases in $\mathrm{H}_{2} \mathrm{~S}$ emergence in Syrah was observed with cysteine after aging at $80{ }^{\circ} \mathrm{C}$ compared to the control (Table 3.3). In Pinot Grigio and Cabernet Sauvignon, significantly higher $\mathrm{H}_{2} \mathrm{~S}$ emergence was also seen in cysteine treatments at 50 ${ }^{\circ} \mathrm{C}$ (but not in Cabernet at $80{ }^{\circ} \mathrm{C}$ ) (Table 3.4). Furthermore, in the preliminary studies with the same Syrah and a Chambourcin, higher $\mathrm{H}_{2} \mathrm{~S}$ concentrations were also observed in cysteine treatments, but not with Sauvignon Blanc (Table 3.1). Based on a previous study where cysteine was spiked into model wine (Bekker and others 2016c), formation of $1.2-$ $1.4 \mu \mathrm{g} / \mathrm{L} \mathrm{H}_{2} \mathrm{~S}$ after storage at $20^{\circ} \mathrm{C}$ in oxygen-free conditions for 6 months occurred and was not significantly impacted by copper or $\mathrm{pH}$. Reactions of cysteine with certain $\alpha-$ dicarbonyl compounds have also been shown to form $\mathrm{H}_{2} \mathrm{~S}$ under model wine conditions after 4 weeks of storage at room temperature (Pripis-Nicolau and others 2000). From previous work (Gruenwedel and Patnaik 1971) under more basic $\mathrm{pH}$ conditions (pH 5.8) at $100{ }^{\circ} \mathrm{C}$ in an oxygen-free atmosphere, cysteine in presence of catalytic concentrations of $\mathrm{Fe}^{3+}$ produced similar amounts of $\mathrm{H}_{2} \mathrm{~S}$ compared to cysteine without metal, which might also indicate that metal catalyzed decomposition may not be an issue at elevated temperatures in wines. Considering the trends observed in the present study as well, it is possible that appreciable formation of $\mathrm{H}_{2} \mathrm{~S}$ from cysteine is highly dependent on interactions with wine components, other than copper and iron ions, that may be present in sufficient concentrations in some wines but not others. 
Significant increase in $\mathrm{H}_{2} \mathrm{~S}$ emergence in Syrah was also observed with $\mathrm{SO}_{2}$ after aging at $80{ }^{\circ} \mathrm{C}$ compared to the control (Table 3.3). In Cabernet Sauvignon, significantly higher $\mathrm{H}_{2} \mathrm{~S}$ emergence was also seen in $\mathrm{SO}_{2}$ treatments compared to the control at $50{ }^{\circ} \mathrm{C}$, but not at $80{ }^{\circ} \mathrm{C}$ nor in Pinot Grigio at $50{ }^{\circ} \mathrm{C}$ (Table 3.4). Interactions between $\mathrm{SO}_{2}$ and copper may result in direct or indirect increases in $\mathrm{H}_{2} \mathrm{~S}$. $\mathrm{SO}_{2}$ can cause reduction of $\mathrm{Cu}^{2+}$ to $\mathrm{Cu}^{+}$(Danilewicz 2007), which could result in copper favoring complexation with another compound, thus releasing $\mathrm{H}_{2} \mathrm{~S}$. Reduction of $\mathrm{SO}_{2}$ directly to $\mathrm{H}_{2} \mathrm{~S}$ by $\mathrm{Cu}^{2+}$ has also been proposed as a source of post-bottle $\mathrm{H}_{2} \mathrm{~S}$ (Lopes and others 2009). Therefore, considering results in the present study and the mechanisms suggested by others, $\mathrm{SO}_{2}$ cannot be ruled out as a potential precursor, but further testing should be carried out to more clearly determine a trend.

Other precursors that were observed to result in significantly larger emergence compared to the control were DMDS in Pinot Grigio after aging at $50{ }^{\circ} \mathrm{C}$ and in Cabernet Sauvignon after aging at $80^{\circ} \mathrm{C}$, and MTA in Cabernet Sauvignon after aging at $50^{\circ} \mathrm{C}$. The effect of heat decomposition on DMDS was not established with studies in model wine, so potential degradation into MeSH may have resulted in a false positive due to known interferences of MeSH with mercury chloride in the 4LT gas detection tubes. However, measurements of Pinot Grigio treatments were taken with 4LL gas detection tubes, which contain lead acetate and do not suffer from interferences unless MeSH concentrations are roughly 20 times greater than $\mathrm{H}_{2} \mathrm{~S}$. Furthermore, previous work has found DMDS to remain stable under low oxygen aging conditions even when MeSH levels increased, which suggests that reduction of DMDS may not be a source of MeSH at normal aging temperatures under low oxygen storage (Ugliano and others 2012). The larger emergence 
from MTA in Cabernet Sauvignon after aging at $50{ }^{\circ} \mathrm{C}$ (measured with $4 \mathrm{LT}$ tubes) may be due to interferences with MeSH as well, from interactions of MTA with other wine components which may promote $\mathrm{H}_{2} \mathrm{~S}$ formation, or from MTA degradation that forms $\mathrm{H}_{2} \mathrm{~S}$ by an unknown pathway.

Wines spiked with $\mathrm{H}_{2} \mathrm{~S}-4 \mathrm{MeC}$ adducts were found to have either the highest or lowest $\mathrm{H}_{2} \mathrm{~S}$ emergence within a given aging or TCEP treatment. From the three wines studied here, in both red wines significantly lower levels of $\mathrm{H}_{2} \mathrm{~S}$ emerged after aging compared to the control. For example, after accelerated aging at $80^{\circ} \mathrm{C}, \mathrm{H}_{2} \mathrm{~S}$ in Syrah spiked with $\mathrm{H}_{2} \mathrm{~S}-4 \mathrm{MeC}$ adducts was $15.4 \pm 1.2 \mu \mathrm{g} / \mathrm{L}$, which was significantly lower than the control, $21.8 \pm 1.2 \mu \mathrm{g} / \mathrm{L}$. In the white wine, the opposite was observed, where significantly higher levels of $\mathrm{H}_{2} \mathrm{~S}$ emerged after aging compared to the control $(25.9 \pm 1.9$ vs $12.5 \mu \mathrm{g} / \mathrm{L})$. A broader survey of wines should be conducted to further investigate the potential relationship in emergence or binding of $\mathrm{H}_{2} \mathrm{~S}$ by $\mathrm{H}_{2} \mathrm{~S}-4 \mathrm{MeC}$ adducts in red wine compared to white wine. Previous work has shown that a larger portion of $\mathrm{H}_{2} \mathrm{~S}$ generated over aging by white is from complexes or precursors other than metal- $\mathrm{H}_{2} \mathrm{~S}$ complexes (Franco-Luesma and Ferreira 2016a), and considering the significant emergence from $\mathrm{H}_{2} \mathrm{~S}-4 \mathrm{MeC}$ adducts in white wine in this study, it may be speculated that $\mathrm{H}_{2} \mathrm{~S}-4 \mathrm{MeC}$ adducts could play a role in emergence in other white wines. Reaction rates for the addition of $\mathrm{SO}_{2}$ and $\mathrm{H}_{2} \mathrm{~S}$ to quinones are nearly identical (Nikolantonaki and Waterhouse 2012), but recent work has shown that formation of $\mathrm{SO}_{2}$ adducts with quinones are more favorable than $\mathrm{H}_{2} \mathrm{~S}$ at wine relevant concentrations (Bekker and others 2016a). Although results from this study may point towards $\mathrm{H}_{2} \mathrm{~S}-4 \mathrm{MeC}$ adducts as a reversible pool of $\mathrm{H}_{2} \mathrm{~S}$ in white wine, concentrations 
of thiol-quinone adducts in wine are not known, so its potential contribution to increases in $\mathrm{H}_{2} \mathrm{~S}$ may not be significant at wine relevant concentrations.

Considering that significant $\mathrm{H}_{2} \mathrm{~S}$ formation was observed in cysteine treatments, it may seem likely that the cysteine residue in glutathione could also act as a precursor to $\mathrm{H}_{2} \mathrm{~S}$. Other authors found low levels of $\mathrm{H}_{2} \mathrm{~S}$ formed in model wine with added glutathione after storage at $20^{\circ} \mathrm{C}$ in oxygen-free conditions for 6 months (Bekker and others 2016c). However, no significant differences in $\mathrm{H}_{2} \mathrm{~S}$ emergence were observed for wines with added glutathione compared to the control in the three wines and conditions studied here. Further experiments with glutathione additions in wine should be carried out to verify the results found here.

Concentrations of $\mathrm{H}_{2} \mathrm{~S}$ were slightly higher in control Syrah treated with TCEP $(19.7 \pm 1.2 \mu \mathrm{g} / \mathrm{L})$ compared to free $\mathrm{H}_{2} \mathrm{~S}(14.2 \mu \mathrm{g} / \mathrm{L})$ (Table 3.3), while the difference was much more extreme in control Chambourcin with no detectable levels of free $\mathrm{H}_{2} \mathrm{~S}$ and $110.4 \pm 2.6 \mu \mathrm{g} / \mathrm{L} \mathrm{H}_{2} \mathrm{~S}$ after TCEP addition (Table 3.4). TCEP is a reducing agent commonly used in protein analysis that selectively cleaves sulfur-sulfur bonds in disulfides to form two free thiols (Burns and others 1991). In model wine with copper complexed $\mathrm{H}_{2} \mathrm{~S}$, TCEP resulted in only $35 \%$ recovery of $\mathrm{H}_{2} \mathrm{~S}$ (Chen and others 2016), suggesting that the majority of $\mathrm{H}_{2} \mathrm{~S}$ produced by TCEP treatment in wine is from unknown precursors, which were hypothesized by the authors to be mixed disulfide and polysulfide adducts formed from sulfur pesticide residue. The small amount of $\mathrm{H}_{2} \mathrm{~S}$ recovered in the model wine with copper- $\mathrm{H}_{2} \mathrm{~S}$ complex may be the result of dissociation of more loosely bound forms of the complex due to the shift in $\mathrm{pH}$ during measurement. Treatment of spiked model wine with TCEP in the present work resulted in relatively similar emergence of $\mathrm{H}_{2} \mathrm{~S}$ from all 
hypothesized precursors tested (Table 3.2), which may suggest the presence of $\mathrm{S}^{0}$ residues on glassware used in those experiments or other unknown mechanisms.

Total increase in $\mathrm{H}_{2} \mathrm{~S}$ from unknown complexed forms and/or precursors in Pinot Grigio and Cabernet Sauvignon after accelerated aging treatments at $50{ }^{\circ} \mathrm{C}$ for 1 week was 2.5 and $4.2 \mu \mathrm{g} / \mathrm{L} \mathrm{H}_{2} \mathrm{~S}$, respectively. After accelerated aging at $80{ }^{\circ} \mathrm{C}$ for 1 hour, total $\mathrm{H}_{2} \mathrm{~S}$ increase was $19.2 \mu \mathrm{g} / \mathrm{L}$ according to results shown in Figure 3.1 and $7.1 \mu \mathrm{g} / \mathrm{L}$ from results shown in Table 3.3 in Syrah and $34.6 \mu \mathrm{g} / \mathrm{L}$ in Cabernet Sauvignon (Table 3.4). Total increase in $\mathrm{H}_{2} \mathrm{~S}$ (complexed forms + precursors) reported by other authors was an average of $16.2 \mu \mathrm{g} / \mathrm{L}$ in 15 red wines and $22.5 \mu \mathrm{g} / \mathrm{L}$ in 8 white and rosé wines after 3 weeks of aging at $50{ }^{\circ} \mathrm{C}$ (Franco-Luesma and Ferreira 2016a). Values found in our study for total increase in $\mathrm{H}_{2} \mathrm{~S}$ were well below those reported by Franco-Luesma and Ferreira (2016a) in most cases, which may suggest that the assay developed here does not measure release of $\mathrm{H}_{2} \mathrm{~S}$ from metal complexes. On the other hand, differences may also be due to the strong dependence of $\mathrm{H}_{2} \mathrm{~S}$ emergence on wine type or potential analyte loss during measurement.

Considering the highly volatile and reactive nature of $\mathrm{H}_{2} \mathrm{~S}$, analyte loss and issues with reproducibility are a concern with most previously published measurement methods, including the assay used in this work. The significant decrease in free $\mathrm{H}_{2} \mathrm{~S}$ at room temperature from Syrah control compared to precursors treatments (Table 3.3) is most likely a result of analyte loss from free $\mathrm{H}_{2} \mathrm{~S}$ already present in the Syrah and unrelated to the compounds themselves. It may be possible that addition of those precursors is causing a shift which promotes $\mathrm{H}_{2} \mathrm{~S}$ complexation, however analyte loss during measurement seems more likely. In other cases where the same measurement was conducted weeks later, similar results were obtained. For example, preliminary $80{ }^{\circ} \mathrm{C}$ measurements with Syrah 
(Table 3.1) are similar to final $80^{\circ} \mathrm{C}$ values with the same Syrah (Table 3.3), but this could also potentially indicate systematic error within the method. Although care was taken in sample preparation, further steps could be taken to ensure accurate results such as transfer of wine samples in inert atmosphere glove box and ensuring that the wine from which samples are taken is kept chilled at $4{ }^{\circ} \mathrm{C}$ at all times. After beakers were removed from the hot water bath, internal pressure change during cooling caused the lid to pop off some beakers, resulting in inaccurate values of $\mathrm{H}_{2} \mathrm{~S}$ in those samples. Further method optimization should also involve selection of a lid and vessel more suited to pressure changes.

\section{Conclusions}

A convenient method for assessing the risk a wine has for $\mathrm{H}_{2} \mathrm{~S}$ issues over low oxygen bottle storage was developed and used to investigate $\mathrm{H}_{2} \mathrm{~S}$ emergence from hypothesized precursor compounds. Optimization of the accelerated aging procedure involved incubation of wine samples at $80{ }^{\circ} \mathrm{C}$ instead of $50{ }^{\circ} \mathrm{C}$ to decrease the model aging period from 3 weeks to 1 hour. Minimal artifact formation from heat decomposition of cysteine, glutathione, and $\mathrm{H}_{2} \mathrm{~S}-4 \mathrm{MeC}$ adducts was found at elevated temperatures, however, apparent formation of MeSH from MTA and DMDS may have caused interferences with gas detection tubes at the elevated temperature or excess $\mathrm{H}_{2} \mathrm{~S}$ production by an unknown mechanism. Therefore, this assay may exaggerate $\mathrm{H}_{2} \mathrm{~S}$ production in wines with unusually high levels of MTA or DMDS, but this is not expected to be a widespread problem considering concentrations in most wines are well below concentrations used in this study. 
Significant increases in $\mathrm{H}_{2} \mathrm{~S}$ production after accelerated aging was found in some wines spiked with cysteine, $\mathrm{SO}_{2}$, MTA, DMDS, and $\mathrm{H}_{2} \mathrm{~S}-4 \mathrm{MeC}$ adducts. Of the three wines studied, emergence of $\mathrm{H}_{2} \mathrm{~S}$ from $\mathrm{H}_{2} \mathrm{~S}-4 \mathrm{MeC}$ adducts in both red wines were lower than control, while emergence in white wine was significantly greater than the control. Further studies are needed to characterize the differences in wine composition which promote or inhibit emergence from precursors and the role that these precursors may play as mediators of emergence from other pools. TCEP, a strong reducing agent, was also used as to release $\mathrm{H}_{2} \mathrm{~S}$ from unknown precursors or complexes in wine. Emergence of $\mathrm{H}_{2} \mathrm{~S}$ from this unknown pool was lower in a Syrah with sulfurous odors compared to a fault-free Cabernet Sauvignon.

Further validation of the accelerated aging procedure should be carried out to ensure that results obtained after aging at $80{ }^{\circ} \mathrm{C}$ correlate to normal aging and additional tests should be run on a broader range of wines to better assess the suitability and reproducibility of this procedure, especially considering the wide ranging results with some hypothesized precursors in different wines. The $\mathrm{H}_{2} \mathrm{~S}$ selective method used here did not allow for accurate measurement of MeSH, another key contributor to "reductive" character in wines stored under low oxygen conditions, and other work should investigate $\mathrm{MeSH}$ emergence from the hypothesized precursor compounds studied here as well.

\section{References}

Bekker M, Smith M, Smith P, Wilkes E. 2016a. Formation of Hydrogen Sulfide in Wine: Interactions between Copper and Sulfur Dioxide. Molecules 21:1214. doi: 10.3390/molecules21091214.

Bekker MZ, Day MP, Holt H, and others. 2016b. Effect of oxygen exposure during fermentation on volatile sulfur compounds in Shiraz wine and a comparison of strategies for remediation of reductive character. Aust J Grape Wine Res 22:24-35. doi: 10.1111/ajgw.12172.

Bekker MZ, Mierczynska-Vasilev A, Smith PA, Wilkes EN. 2016c. The effects of pH 
and copper on the formation of volatile sulfur compounds in Chardonnay and Shiraz wines post-bottling. Food Chem 207:148-156. doi:

10.1016/j.foodchem.2016.03.060.

Bobet RA, Noble AC, Boulton RB. 1990. Kinetics of the ethanethiol and diethyl disulfide interconversion in wine-like solutions. J Agric Food Chem 38:449-452. doi: 10.1021/jf00092a025.

Bracher PJ, Snyder PW, Bohall BR, Whitesides GM. 2011. The Relative Rates of ThiolThioester Exchange and Hydrolysis for Alkyl and Aryl Thioalkanoates in Water. Orig Life Evol Biosph 41:399-412. doi: 10.1007/s11084-011-9243-4.

Burns JA, Butler JC, Moran J, Whitesides GM. 1991. Selective reduction of disulfides by tris(2-carboxyethyl)phosphine. J Org Chem 56:2648-2650. doi: 10.1021/jo00008a014.

Chen Y, Jastrzembski JA, Sacks GL. 2016. Copper-Complexed Hydrogen Sulfide in Wine: Measurement by Gas Detection Tubes and Comparison of Release Approaches. Am J Enol Vitic. doi: 10.5344/ajev.2016.16024.

Clark AC, Grant-Preece P, Cleghorn N, Scollary GR. 2015. Copper(II) addition to white wines containing hydrogen sulfide: Residual copper concentration and activity. Aust J Grape Wine Res 21:30-39. doi: 10.1111/ajgw.12114.

Danilewicz JC. 2007. Interaction of sulfur dioxide, polyphenols, and oxygen in a winemodel system: Central role of iron and copper. Am J Enol Vitic 58:53-60.

Dimkou E, Ugliano M, Dieval JB, and others. 2011. Impact of Headspace Oxygen and Closure on Sulfur Dioxide, Color, and Hydrogen Sulfide Levels in a Riesling Wine. Am J Enol Vitic 62:261-269. doi: 10.5344/ajev.2011.11006.

Eschenbruch R. 1974. Sulfite and Sulfide formation during winemaking - A Review. Am J Enol Vitic 25:23-27.

Fang Y, Qian MC. 2005. Sensitive quantification of sulfur compounds in wine by headspace solid-phase microextraction technique. J Chromatogr A 1080:177-185. doi: 10.1016/j.chroma.2005.05.024.

Franco-Luesma E, Ferreira V. 2016a. Reductive off-odors in wines: Formation and release of $\mathrm{H} 2 \mathrm{~S}$ and methanethiol during the accelerated anoxic storage of wines. Food Chem 199:42-50. doi: 10.1016/j.foodchem.2015.11.111.

Franco-Luesma E, Ferreira V. 2014. Quantitative analysis of free and bonded forms of volatile sulfur compouds in wine. Basic methodologies and evidences showing the existence of reversible cation-complexed forms. J Chromatogr A 1359:8-15. doi: 10.1016/j.chroma.2014.07.011.

Franco-Luesma E, Ferreira V. 2016b. Formation and Release of H2S, Methanethiol, and Dimethylsulfide during the Anoxic Storage of Wines at Room Temperature. J Agric Food Chem 64:6317-6326. doi: 10.1021/acs.jafc.6b01638.

Godden P, Francis IL, Field J, and others. 2001. Wine bottle closures: physical characteristics and effect on composition and sensory properties of a Semillon wine. I. Performance up to 20 months post-bottling. Aust J Grape Wine Res 7:64-105. doi: 10.1111/j.1755-0238.2001.tb00196.x.

Goniak OJ, Noble AC. 1987. Sensory study of selected volatile sulfur compounds in white wine. Am J Enol Vitic 38:223-227.

Gruenwedel DW, Patnaik RK. 1971. Release of hydrogen sulfide and methyl mercaptan from sulfur-containing amino acids. J Agric Food Chem 19:775-779. 
Jackson R. 2014. Wine Science: Principles and Applications, 4th ed. Academic Press. Jastrzembski JA, Sacks GL. 2015. Precursors of Hydrogen Sulfide during Wine Storage the Role of Elemental Sulfur Pesticide Residues. In: 66th American Society of Enology and Viticulture National Conference. Portland, OR, .

Jiranek V, Langridge P, Henschke P. 1995. Regulation of hydrogen sulfide liberation in wine-producing Saccharomyces cerevisiae strains by assimilable nitrogen. Appl Environ Microbiol 61:461-467.

Jongberg S, Gislason NE, Lund MN, and others. 2011. Thiol-quinone adduct formation in myofibrillar proteins detected by LC-MS. J Agric Food Chem 59:6900-6905. doi: 10.1021/jf200965s.

Kreitman GY, Danilewicz JC, Jeffery DW, Elias RJ. 2016a. Reaction Mechanisms of Metals with Hydrogen Sulfide and Thiols in Model Wine. Part 1: Copper-Catalyzed Oxidation. J Agric Food Chem 64:4095-4104. doi: 10.1021/acs.jafc.6b00642.

Kreitman GY, Danilewicz JC, Jeffery DW, Elias RJ. 2016b. Reaction Mechanisms of Metals with Hydrogen Sulfide and Thiols in Model Wine. Part 2: Iron- and CopperCatalyzed Oxidation. J Agric Food Chem 64:4105-4113. doi: 10.1021/acs.jafc.6b00642.

Kwasniewski MT, Allison RB, Wilcox WF, Sacks GL. 2011. Convenient, inexpensive quantification of elemental sulfur by simultaneous in situ reduction and colorimetric detection. Anal Chim Acta 703:52-57. doi: 10.1016/j.aca.2011.07.010.

Lopes P, Silva MA, Pons A, and others. 2009. Impact of oxygen dissolved at bottling and transmitted through closures on the composition and sensory properties of a Sauvignon blanc wine during bottle storage. J Agric Food Chem 57:10261-10270. doi: $10.1021 / \mathrm{jf} 9023257$.

López R, Lapeña AC, Cacho J, Ferreira V. 2007. Quantitative determination of wine highly volatile sulfur compounds by using automated headspace solid-phase microextraction and gas chromatography-pulsed flame photometric detection. Critical study and optimization of a new procedure. J Chromatogr A 1143:8-15. doi: 10.1016/j.chroma.2006.12.053.

Loscos N, Ségurel M, Dagan L, and others. 2008. Identification of S-methylmethionine in Petit Manseng grapes as dimethyl sulphide precursor in wine. Anal Chim Acta 621:24-29. doi: 10.1016/j.aca.2007.11.033.

Nikolantonaki M, Waterhouse AL. 2012. A Method To Quantify Quinone Reaction Rates with Wine Relevant Nucleophiles. J Agric Food Chem 60:8484-8491. doi: $10.1021 / \mathrm{jf302017j.}$

O’Brien V, Francis IL, Osidacz P. 2009. Packaging choices affect consumer enjoyment of wines. Aust New Zeal Wine Ind J 24:48-54.

Park S-K. 2008. Development of a method to measure hydrogen sulfide in wine fermentation. J Microbiol Biotechnol 18:1550-1554.

Pripis-Nicolau L, de Revel G, Bertrand A, Maujean A. 2000. Formation of flavour components by the reaction of amino acid and carbonyl compounds in mild conditions. J Agric Food Chem 48:3761-3766.

Schutz M, Kunkee RE. 1977. Formation of Hydroge Sulfide from Elemental Sulfur During Fermentation by Wine Yeast. Am J Enol Vitic 28:137-144.

Segurel MA, Razungles AJ, Riou C, and others. 2005. Ability of possible DMS precursors to release DMS during wine aging and in the conditions of heat-alkaline 
treatment. J Agric Food Chem 53:2637-2645. doi: 10.1021/jf048273r.

Siebert T, Bramley B, Solomon M. 2009. Hydrogen sulfide: aroma detection threshold study in white and red wine. AWRI Tech Rev 183:14-16.

Siebert TE, Solomon MR, Pollnitz AP, Jeffery DW. 2010. Selective determination of volatile sulfur compounds in wine by gas chromatography with sulfur chemiluminescence detection. J Agric Food Chem 58:9454-9462. doi: 10.1021/jf102008r.

Singleton V. 1987. Oxygen with Phenols and Related Reactions in Musts, Wines, and Model Systems: Observations and Practical Implications. Am J Enol Vitic 38:69-77.

Smith ME, Bekker MZ, Smith PA, Wilkes EN. 2015. Sources of volatile sulfur compounds in wine. Aust J Grape Wine Res 21:705-712. doi: 10.1111/ajgw.12193.

Solomon M, Geue J, Osidacz P, Siebert T. 2010. Aroma detection threshold study of methanethiol in white and red wine. AWRI Tech Rev 186:8-10.

Thomas C, Boulton R, Silacci M, Gubler D. 1993. The effect of elemental sulfur, yeast strain, and fermentation medium on hydrogen sulfide production during fermentation. Am J Enol Vitic 44:211-216.

Ugliano M. 2013. Oxygen contribution to wine aroma evolution during bottle aging. $\mathbf{J}$ Agric Food Chem 61:6125-6136. doi: 10.1021/jf400810v.

Ugliano M, Dieval JB, Siebert TE, and others. 2012. Oxygen consumption and development of volatile sulfur compounds during bottle aging of two Shiraz wines. influence of pre- and postbottling controlled oxygen exposure. J Agric Food Chem 60:8561-8570. doi: 10.1021/jf3014348.

Ugliano M, Fedrizzi B, Siebert T, and others. 2009. Effect of nitrogen supplementation and saccharomyces species on hydrogen sulfide and other volatile sulfur compounds in Shiraz fermentation and wine. J Agric Food Chem 57:4948-4955. doi: 10.1021/jf8037693.

Ugliano M, Henschke PA. 2010. Comparison of three methods for accurate quantification of hydrogen sulfide during fermentation. Anal Chim Acta 660:87-91. doi: 10.1016/j.aca.2009.09.049.

Ugliano M, Kolouchova R, Henschke PA. 2011a. Occurrence of hydrogen sulfide in wine and in fermentation: Influence of yeast strain and supplementation of yeast available nitrogen. J Ind Microbiol Biotechnol 38:423-429. doi: 10.1007/s10295-010-0786-6.

Ugliano M, Kwiatkowski M, Vidal S, and others. 2011b. Evolution of 3mercaptohexanol, hydrogen sulfide, and methyl mercaptan during bottle storage of Sauvignon blanc wines. Effect of glutathione, copper, oxygen exposure, and closurederived oxygen. J Agric Food Chem 59:2564-2572. doi: 10.1021/jf1043585.

Vasserot Y, Steinmetz V, Jeandet P. 2003. Study of thiol consumption by yeast lees. Antonie Van Leeuwenhoek 83:201-207. doi: 10.1023/A:1023305130233.

Viviers MZ, Smith ME, Wilkes E, Smith P. 2013. Effects of five metals on the evolution of hydrogen sulfide, methanethiol, and dimethyl sulfide during anaerobic storage of chardonnay and shiraz wines. J Agric Food Chem 61:12385-12396. doi: 10.1021/jf403422x.

Waterhouse AL, Laurie VF. 2006. Oxidation of Wine Phenolics: A Critical Evaluation and Hypotheses. Am J Enol Vitic 57:306-313. 
Ye DQ, Zheng XT, Xu XQ, and others. 2016. Evolutions of volatile sulfur compounds of Cabernet Sauvignon wines during aging in different oak barrels. Food Chem 202:236-246. doi: 10.1016/j.foodchem.2016.01.139. 


\section{Figures and Tables}

Figure 3.1 Emergence of $\mathrm{H}_{2} \mathrm{~S}(\mu \mathrm{g} / \mathrm{L})$ in 2014 Syrah after accelerated aging treatment at $50,65,80$, and $100^{\circ} \mathrm{C}$ compared to aging at cellar temperature $\left(15.5^{\circ} \mathrm{C}\right)$ over 4 hours in $\mathrm{A}$ and over 2 weeks in B. Dashed line in B represents $\mathrm{H}_{2} \mathrm{~S}$ concentration at $100{ }^{\circ} \mathrm{C}$ for 4 hours, not actual values and is shown for comparative purposes. Error bars represent standard deviation for $n=2$ in $15.5,65,80$ and $100^{\circ} \mathrm{C}$ and $n=3$ in $50^{\circ} \mathrm{C}$.
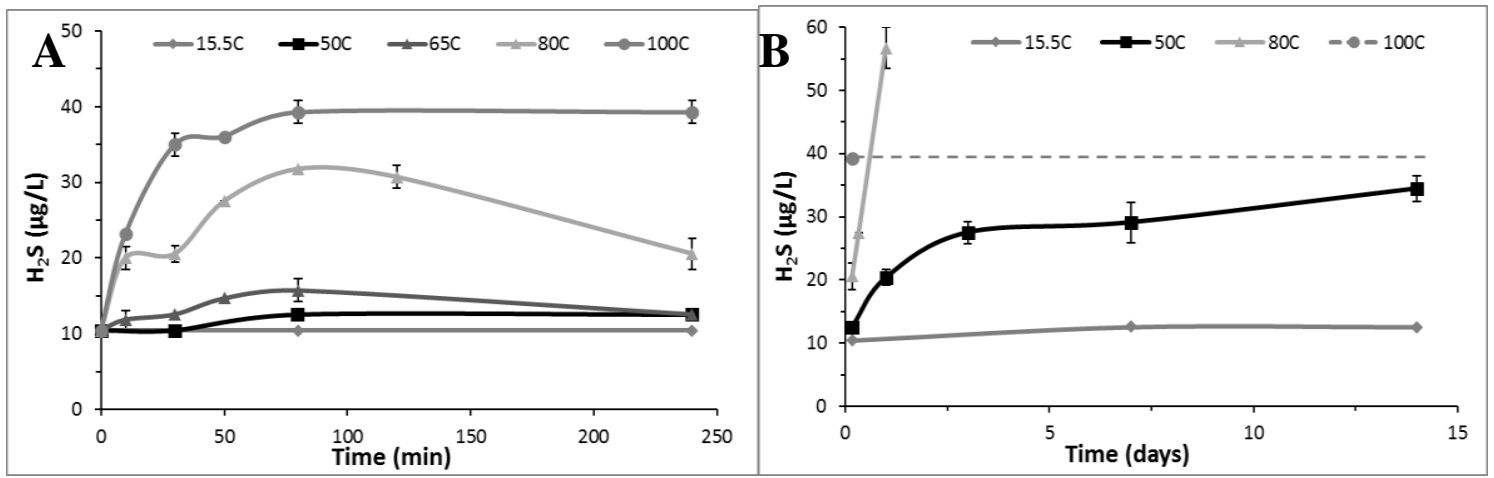

Figure 3.2 Emergence of $\mathrm{H}_{2} \mathrm{~S}(\mu \mathrm{g} / \mathrm{L})$ in 2015 Chambourcin after accelerated aging treatment at 50 and $100{ }^{\circ} \mathrm{C}$ over 4 hours. Error bars represent standard deviation for $\mathrm{n}=4$ in $100{ }^{\circ} \mathrm{C}$. Error bars are too small to be seen behind the data points in $50^{\circ} \mathrm{C}$, each point is the average value for $n=2$.

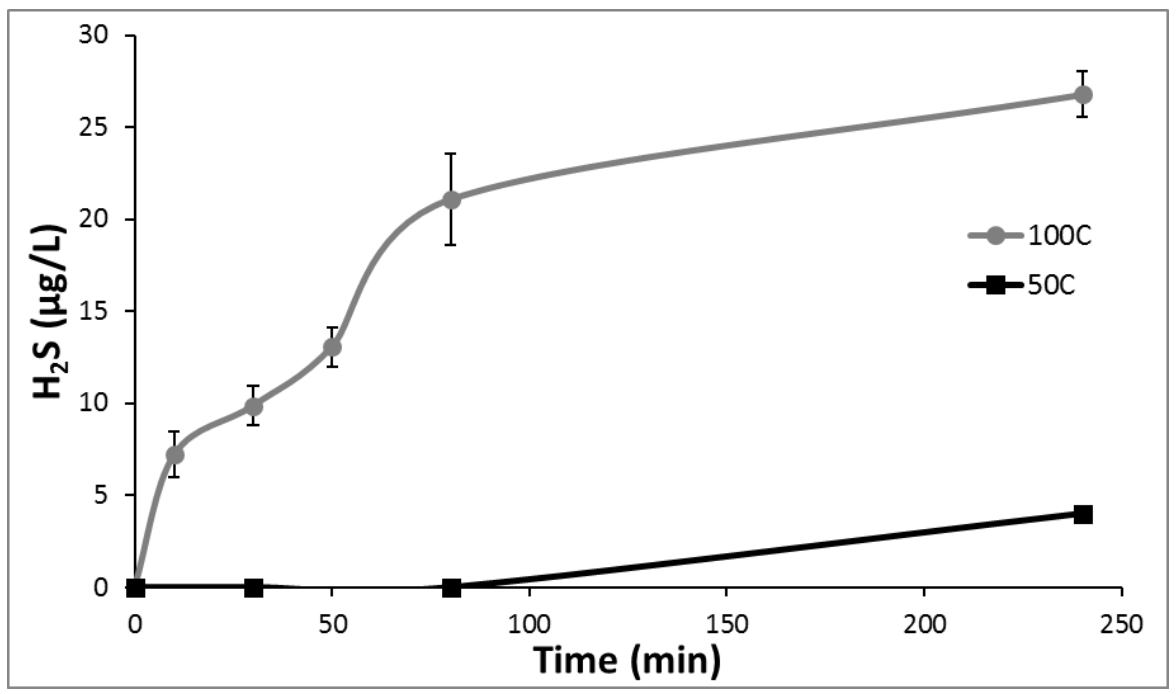


Table 3.1 Preliminary results for emergence of $\mathrm{H}_{2} \mathrm{~S}(\mu \mathrm{g} / \mathrm{L})$ after accelerated aging treatment at $80^{\circ} \mathrm{C}$ for 1 hour in three wines spiked with hypothesized precursors. Values are averages and standard deviations for $\mathrm{n}=3$ in Syrah Control, Syrah Cysteine, and Chambourcin Control; $n=2$ in all other measurements.

\begin{tabular}{|c|c|c|c|c|c|c|}
\hline \multirow[b]{2}{*}{ Hypothesized Precursor } & \multicolumn{2}{|c|}{2014 Syrah } & \multicolumn{2}{|c|}{2015 Chambourcin } & \multicolumn{2}{|c|}{2014 Sauvignon Blanc } \\
\hline & ave & \pm & ave & \pm & ave & \pm \\
\hline Control & 21.8 & 1.2 & 10.8 & 0.7 & 3.8 & 0.0 \\
\hline $100 \mathrm{mg} / \mathrm{L} \mathrm{glu}$ & 22.2 & 1.5 & $*$ & & 12.5 & 5.3 \\
\hline $10 \mathrm{mg} / \mathrm{L}$ cys & 36.8 & 8.6 & 20.6 & 0.9 & 3.8 & 5.3 \\
\hline $1 \mathrm{mg} / \mathrm{L} \mathrm{MTA}$ & 15.7 & 1.5 & 22.5 & 1.8 & 5.6 & 0.9 \\
\hline
\end{tabular}

*measurement not taken with glutathione in Chambourcin

Table 3.2 Emergence of $\mathrm{H}_{2} \mathrm{~S}(\mu \mathrm{g} / \mathrm{L})$ after accelerated aging at 50,80 , and $10{ }^{\circ} \mathrm{C}$ for 1 hour or after addition of reducing agent (TCEP) in model wine spiked with hypothesized precursors. Values are averages and standard deviations for $\mathrm{n}=2$ for all measurements excluding $\mathrm{H}_{2} \mathrm{~S}-4 \mathrm{MeC}$ treatment with TCEP, where $\mathrm{n}=1$.

\begin{tabular}{|c|c|c|c|c|c|c|c|c|}
\hline \multirow[b]{2}{*}{ Hypothesized Precursor } & \multicolumn{2}{|c|}{$50^{\circ} \mathrm{C}$} & \multicolumn{2}{|c|}{$80^{\circ} \mathrm{C}$} & \multicolumn{2}{|c|}{$100^{\circ} \mathrm{C}$} & \multicolumn{2}{|c|}{ TCEP } \\
\hline & ave & \pm & ave & \pm & ave & \pm & ave & \pm \\
\hline $10 \mathrm{mg} / \mathrm{L}$ glu & 0 & 0 & trace & & 0 & 0 & 8.4 & 2.6 \\
\hline $10 \mathrm{mg} / \mathrm{L}$ cys & 0 & 0 & trace & & trace & & 8.1 & 2.7 \\
\hline $70 \mu \mathrm{g} / \mathrm{L}$ MTA & trace & & 13.8 & 1.8 & 11.1 & 1.2 & 8.1 & 0.9 \\
\hline $\mathrm{H}_{2} \mathrm{~S}-4 \mathrm{MeC}$ adducts & 0 & 0 & 0 & 0 & 0 & 0 & $10 *$ & \\
\hline
\end{tabular}

Figure 3.3 Emergence of $\mathrm{H}_{2} \mathrm{~S}(\mu \mathrm{g} / \mathrm{L})$ at room temperature (free $\mathrm{H}_{2} \mathrm{~S}$ ), after accelerated aging treatment at $50^{\circ} \mathrm{C}$ for 1 week and $80^{\circ} \mathrm{C}$ for 1 hour, or after addition of reducing agent (TCEP) in 2014 Syrah spiked with hypothesized precursors. Error bars represent standard deviation for $\mathrm{n}=3$.

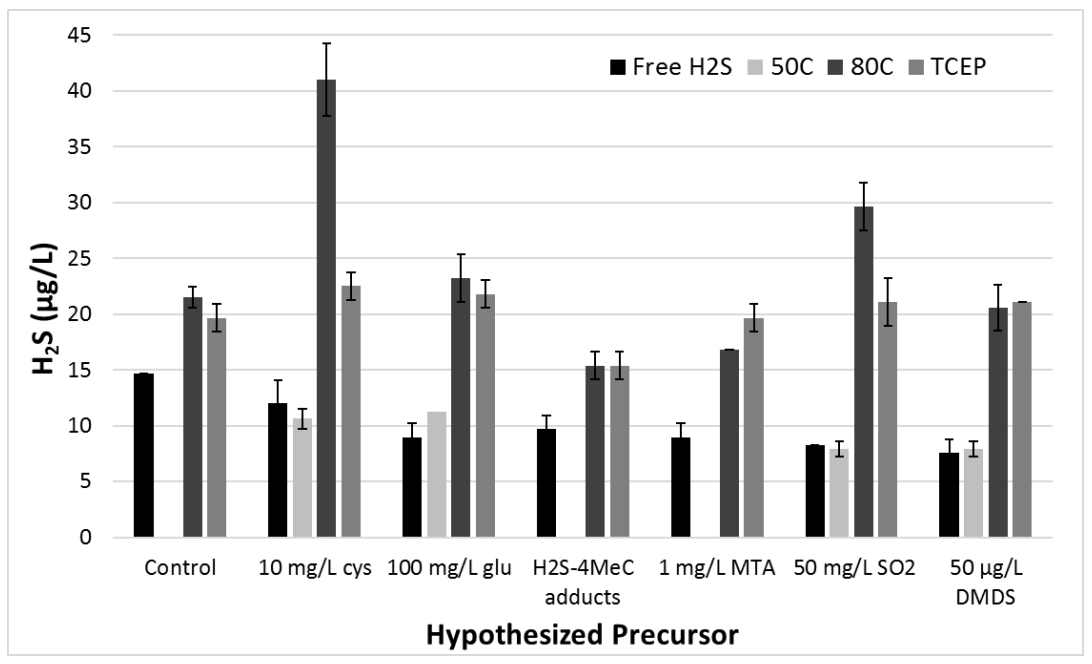


Table 3.3 Emergence of $\mathrm{H}_{2} \mathrm{~S}(\mu \mathrm{g} / \mathrm{L})$ at room temperature (free $\left.\mathrm{H}_{2} \mathrm{~S}\right)$, after accelerated aging treatment at $80^{\circ} \mathrm{C}$ for 1 hour, or after addition of reducing agent (TCEP) in 2014 Syrah spiked with hypothesized precursors $(n=3)$.

\begin{tabular}{|c|c|c|c|c|c|c|}
\hline \multirow[b]{2}{*}{ Hypothesized Precursor } & \multicolumn{3}{|c|}{ Free $\mathrm{H}_{2} \mathrm{~S}$} & \multicolumn{2}{|c|}{$80{ }^{\circ} \mathrm{C}$} & TCEP \\
\hline & ave & & \pm & ave & \pm & ave \\
\hline Control & 14.7 & $\mathbf{a}$ & 0.0 & $21.8 \mathrm{~cd}$ & 1.2 & 19.7 a 1.2 \\
\hline $10 \mathrm{mg} / \mathrm{L}$ cys & 12.5 & $\mathbf{a b}$ & 2.2 & $41.0 \mathbf{a}$ & 3.3 & 22.5 a 1.2 \\
\hline $100 \mathrm{mg} / \mathrm{L}$ glu & 9.0 & c & 1.2 & $23.2 \mathrm{c}$ & 2.2 & 21.8 a 1.2 \\
\hline $\mathrm{H}_{2} \mathrm{~S}-4 \mathrm{MeC}$ adducts & 9.7 & bc & 1.2 & $15.4 \mathrm{e}$ & 1.2 & 15.4 b 1.2 \\
\hline $1 \mathrm{mg} / \mathrm{L}$ MTA & 9.0 & c & 1.2 & 16.8 de & 0.0 & 19.7 a 1.2 \\
\hline $50 \mathrm{mg} / \mathrm{L} \mathrm{SO}_{2}$ & 8.3 & c & 0.0 & $29.6 \mathbf{b}$ & 2.2 & 21.1 a 2.1 \\
\hline $50 \mu \mathrm{g} / \mathrm{L}$ DMDS & 7.6 & c & 1.3 & $21.1 \mathrm{~cd}$ & 2.1 & 21.1 a 0.0 \\
\hline
\end{tabular}

Table 3.4 Emergence of $\mathrm{H}_{2} \mathrm{~S}(\mu \mathrm{g} / \mathrm{L})$ after accelerated aging treatment at $50{ }^{\circ} \mathrm{C}$ for 1 week in Pinot Grigio and at $50{ }^{\circ} \mathrm{C}$ for 1 week, $80{ }^{\circ} \mathrm{C}$ for 1 hour, and after addition of reducing agent (TCEP) in Cabernet Sauvignon spiked with hypothesized precursors. Values are averages and standard deviations for $n=3$ in all treatments except where noted.

\begin{tabular}{|c|c|c|c|c|c|}
\hline \multirow[b]{3}{*}{ Hypothesized Precursor } & \multirow{2}{*}{$\frac{\text { Pinot Grigio }}{50^{\circ} \mathrm{C}}$} & \multicolumn{4}{|c|}{ Cabernet Sauvignon } \\
\hline & & $50{ }^{\circ} \mathbf{C}$ & $80^{\circ} \mathrm{C}$ & \multicolumn{2}{|l|}{ TCEP } \\
\hline & ave & ave & ave & ave & \pm \\
\hline Control & 12.5 c 0.0 & $\begin{array}{l}4.2 \text { c } 0.7 \\
\end{array}$ & $\overline{34.6 \quad \text { b } 10.0}$ & $110.4 \mathbf{a b}$ & 2.6 \\
\hline $10 \mathrm{mg} / \mathrm{L}$ cys & 19.7 b 1.2 & 9.2 b 0.7 & 29.6 bc 6.4 & 96.7 bc & 3.6 \\
\hline $100 \mathrm{mg} / \mathrm{L}$ glu & 14.0 c 1.3 & $\begin{array}{lll}5.4 & \text { c } & 0.7\end{array}$ & 22.1 bc 3.8 & 101.3 abc & 6.5 \\
\hline $\mathrm{H}_{2} \mathrm{~S}-4 \mathrm{MeC}$ adducts & 25.9 a 1.9 & $1.3 *$ d 0.0 & 14.2 c 4.0 & $* *$ & \\
\hline $1 \mathrm{mg} / \mathrm{L}$ MTA & 6.8 d 1.3 & $10.4 \mathbf{a b} 0.7$ & 29.6 bc 3.6 & $114.2 \mathbf{a}$ & 3.6 \\
\hline $50 \mathrm{mg} / \mathrm{L} \mathrm{SO}_{2}$ & 11.8 c 1.2 & 12.5 a 1.3 & $* *$ & $93.3 \mathbf{c}$ & 7.6 \\
\hline $50 \mu \mathrm{g} / \mathrm{L}$ DMDS & 17.5 b 1.3 & $\begin{array}{lll}5.4 & \text { c } & 0.7 \\
\end{array}$ & 64.2 a 4.7 & $* *$ & \\
\hline
\end{tabular}

